\title{
Recent advances in the electrooxidation of biomass-based organic molecules for energy, chemicals and hydrogen production
}

\author{
Yaovi Holade, ${ }^{a *}$ Nazym Tuleushova, ${ }^{a}$ Sophie Tingry, ${ }^{a}$ Karine Servat, ${ }^{\mathrm{b}}$ Teko W. Napporn, ${ }^{\mathrm{b}}$ Hazar \\ Guesmi, ${ }^{\mathrm{c}}$ David Cornu, ${ }^{\mathrm{a}}$ and K. Boniface Kokoh ${ }^{\mathrm{b} *}$
}

\begin{abstract}
Electrosynthesis, a historically powerful tool for the production of a number of industrial-scale inorganic or organic materials, has experienced a renaissance over the last ten years with research efforts seeking a dual production platform for molecules and energy carriers. It is termed a "Power-to-X" approach. Specifically, hydrogen $\left(\mathrm{H}_{2}\right)$ is a key compound in emerging energy conversion and storage systems, acting as an energy carrier to provide electrical energy with a significantly reduced environmental footprint through $\mathrm{H}_{2} / \mathrm{O}_{2}$ fuel cells. The clean energy production strategy from energy carrier is inversely termed an "X-to-Power" approach. However, $\mathrm{H}_{2}$ source remains up to now the main key challenge. An increasing interest surrounds the development of advanced low energy consumption electrolysis cells enabling reliable, sustainable and dual production of both $\mathrm{H}_{2}$ and valuable chemicals from the selective oxidation of surplus biomass-derivates. It can thus be summed up that the tremendous idea of generating electricity or producing fuels such as $\mathrm{H}_{2}$, while synthesizing chemicals is an attractive pathway for organic synthesis and electricity production. However, precisely how this could be achieved in a cheap and sustainable way remains a puzzle for scientists. However, the organics selective electrooxidation reactions are central topics and bridge fuel cells and electrolysis cells research. A number of (bio)catalytic interfaces have been developed to overcome their sluggish electrochemical kinetics. Within this Perspective, we propose a detailed review on the recent advances over the last ten years in co-generative fuel cells and electrolysis cells that operate with biomass-based organic molecules (ethanol, ethylene glycol, glycerol, (oligo)saccharides, cellulose, hemicellulose) while highlighting experimental and theoretical research that unifies those fields to yield devices with improved performance. The identified main electrocatalytic reaction descriptors allow for new materials to be proposed, which could enable maximized activity, selectivity and durability of anode materials. This perspective particularly enlightens the missing fundamental knowledge on parameters dictating electrocatalysis of organic compounds in aqueous media. Overall, we discuss the implications for the wider scientific community of electrochemistry, electrocatalysis, materials science and organic chemistry, and finally provide several logical pathways and guidelines to stimulate progress, inspiring the development of organic-fuelled cogeneration electrochemical devices.
\end{abstract}

\section{Introduction}

In the mid-1990s, global electrical energy conversion systems have undergone a significant metamorphosis due to either a decline in fossil energy resources or environmental issues. ${ }^{1,2}$ Advances in technology have opened opportunities to reduce pollution due to greenhouse gases or fine particles resulting from internal combustion engines by designing relatively sustainable systems. Part of the proposed systems that are solar, wind and hydro based devices is intermittent and dependent on climatic conditions. Moreover, they cannot fairly satisfy the need for off-grid energy. A remaining option is electrochemical energy conversion and storage ${ }^{3}$ referred to as batteries. ${ }^{4,5}$ Fuel cells that have the primarily role of converting chemical energy stored as chemical bonds in molecules into electricity is expected to play a central role in delivering clean electrical energy in the next decades. Specifically, $\mathrm{H}_{2}$-based fuel cells are considered to be the most promising sustainable solution to reduce our dependence on conventional fossil fuel energy sources. $\mathrm{H}_{2} / \mathrm{O}_{2}$ fuel cells that can be broadly defined as a $\mathrm{H}_{2}$ combustion reaction $\left(2 \mathrm{H}_{2}+\mathrm{O}_{2} \rightarrow 2 \mathrm{H}_{2} \mathrm{O}+\right.$ heat) have been extensively investigated as a major alternative source of electrical energy production. ${ }^{6-8}$ The overall operating reaction indicates that the only formed product is $\mathrm{H}_{2} \mathrm{O}$. It thus enables the production of electricity with a significantly reduced environmental footprint during operation. So, in addition to the traditional end-use of $\mathrm{H}_{2}$ such as Haber-Bosch process of ammonia synthesis, Fischer-Tropsch process for hydrocarbons synthesis and metal refining among others, it has been now accepted as a fait accompli that this simple molecule is a cornerstone in the energy transition era, acting as an energy carrier in $\mathrm{H}_{2} / \mathrm{O}_{2}$ fuel cells. However, a sustainable production of $\mathrm{H}_{2}$ remains up to now the main key challenge.

In the early 2000s, some organic molecules were extensively scrutinized as alternative fuels to $\mathrm{H}_{2}$ fuel cells, owing to their attractive easy-to-produce, easy-to-handle and easy-to-use characteristics. ${ }^{9}$ Relatively small organic molecules such as ethanol and glycerol have been particularly studied in half-cell and single-cell electrochemical setups as potential fuels because of their low toxicity/volatility, and transport/storage facilities. ${ }^{10-29}$ It is worth mentioning that the most common oligosaccharides (glucose, fructose, cellobiose, lactose) have been extensively investigated to serve as potential fuels for a type of fuel cells, so-called biofuel cells, to power micro-power electronic or implantable devices. ${ }^{30-33}$ When using a carbonbased fuel in fuel cells, the best scenario for environment issue should not be the complete oxidation of the fuel to $\mathrm{CO}_{2}$, but rather a tight control of selectivity towards production of valuable chemical(s). Glycerol and oligosaccharides may be extremely interesting since their selective oxidation leads to valuable products owing to their hydroxyl groups. $12,24,25,34-36$ Hence, the envisaged idea of generating electricity while synthesizing platform chemicals (cogeneration strategy), can subtly become a reality. A crucial parameter for such systems is their performance in terms of the electrical power delivery. The maximum power density ( $P_{\max }$ ) for low temperature fuel cells employing either a proton exchange membrane (PEM) for acidic 
environments or an anion exchange membrane (AEM) for alkaline media is about $0.5-2 \mathrm{~W} \mathrm{~cm}^{-2}$ for the state-of-the-art $\mathrm{H}_{2} / \mathrm{O}_{2}$ fuel cell, whereas those based on organic molecules can barely deliver $0.2 \mathrm{~W} \mathrm{~cm}^{-2} .{ }^{12,37-43}$ This means that instead of using organic molecules directly in fuel cells, they act as an indirect route for a cheap $\mathrm{H}_{2}$ production.

Currently, $\mathrm{H}_{2}$ production is mainly (96\%) based on the thermal decomposition of fossil fuels, leading to $\mathrm{CO}_{2}$ and $\mathrm{CO}$ emissions and excessive energy consumption. ${ }^{44,45}$ This strategy seemingly violates the original intention of reducing global warming by the employment of $\mathrm{H}_{2}$ fuel cells. ${ }^{45}$ Therefore, a clean, renewable and efficient strategy for $\mathrm{H}_{2}$ production is highly sought after. Responsible for the remaining $4 \%$ of $\mathrm{H}_{2}$ production, water electrolysis faces major scientific and economic constraints due to the use of precious and/or rare metals ( $\mathrm{Pt}, \mathrm{Ru}, \mathrm{Ir}$ ) and high energy consumption (5 $\mathrm{kWh} /\left(\mathrm{Nm}^{3} \mathrm{H}_{2}\right)$ at $\left.10 \mathrm{kA} \mathrm{m}^{-2}\right){ }^{12,46}$ Indeed, the deployment of lowtemperature water electrolysis as $\mathrm{CO}_{2}$-free Power-to- $\mathrm{X}(\mathrm{X}=$ fuel, chemical) scenarios to make clean $\mathrm{H}_{2}$ has been impeded by the aforementioned issues. Specifically, the large overpotential of the oxygen evolution reaction (OER) at the anode is an issue. Furthermore, making electrolysis a reliable alternative relies on the development of robust, inexpensive and high-performance catalysts for the positive electrode. In addition to its production route, the future of $\mathrm{H}_{2}$ depends on advances in the areas of infrastructure, distribution, on-board fuel tank and on-board end-use. ${ }^{47}$ To address the electrochemical $\mathrm{H}_{2}$ production issues and as an alternative to water splitting, a change in paradigm has been envisaged with the production of $\mathrm{H}_{2}$ from organic molecules.

Electrolysis cells, commonly known as "electrolysers" are electricity driven electrochemical devices that utilize electrode materials and electrical current as the sole inputs to perform chemical oxidation or reduction reactions and have led to breakthroughs in organic electrosynthesis (minimizing hazardous reagents, avoiding large quantities of stoichiometric oxidizers and reductive reagents), mainly in unexplored classes of natural products for which organic synthesis has no practical solution. ${ }^{48,49}$ Interestingly for electrical energy consumption issues, oxidation reactions can be coupled with the hydrogen evolution reaction at the cathode. For example, by investigating cellulose's monomer and dimer selective electrolysis, ${ }^{50,51}$ it opens the way to a possible development of electrolysers based on electrochemical interfaces that selectively oxidize cellulose (most abundant biopolymer, $35-50 \%$ of biomass) to produce organic molecules and $\mathrm{H}_{2}$. Indeed, given the low oxidation potential of those organics, their use lowers the input energy compared to water electrolysis ( $\geq 2$-times). ${ }^{46,52-57}$ So, organic electrosynthesis is on the verge of a renaissance ${ }^{58-61}$ that can be redirected to operate in aqueous media for a concomitant $\mathrm{H}_{2}$ production. The practical realization of this smooth scenario is of paramount importance and faces three types of challenges, namely: (i) the development of electrode materials with improved activity, selectivity and durability; (ii) improved fundamental understanding of the main electrocatalytic and interfacial processes, and (iii) the scale up of such systems for practical end-use. Specialized reviews of organic molecule electrooxidation for application in organic electrosynthesis in non-aqueous media or in fuel cells can be found in the literature. ${ }^{34,58,62-69}$ However, this rapidly advancing field is still needed as well as a combined consideration of both experimental and computational approaches. This Perspective puts those opportunities and challenges into a broad context, discusses recent research (over the last ten years) and technological advances, and finally provides several logical and speculative pathways and guidelines that could inspire the development of ground-breaking organic-fuelled cogeneration devices. Specifically, we aim to examine the recent advances in the fabrication of nanostructured electrocatalysts for the oxidation of organic molecules in aqueous media as well as elucidating the specific steps that dictate the performance by using theoretical and computational approaches, in an attempt to build descriptors for activity, selectivity and stability. The identification of the main reaction descriptors allows future research directions to be proposed that could enable optimized performance. The combined experimental and theoretical approaches to interrogate the intricate efficiency trends is of particular interest to the communities of electrochemists, material scientists and organic chemists to move forward together and lay the foundation of a sustainable (in)organic electrosynthesis.

\section{Power-to-X ( $X=$ fuel, chemical) and $X$-to-power electrochemical systems}

\subsection{Working principle of fuel cells for electrochemical energy}

A fuel cell - in the broadest sense - is an electrochemical device comprised of two electrodes separated by a spacer, which converts the chemical energy directly into electrical energy (with heat release). This means that this kind of electrical energy converter can theoretically achieve an energy efficiency of $100 \%$. About $40-50 \%$ in electricity and more than $90 \%$ in combined heat and electrical power production are reached in practice compared to an internal combustion engine that is limited by Carnot's theorem, a theoretical maximum value of $40-45 \%$ and a practical efficiency of $15-25 \% .{ }^{44}$ The total efficiency $(\varepsilon)$ of a fuel cell has three contributions, which are thermodynamic $\left(\varepsilon_{\mathrm{th}}\right)$, faradaic $\left(\varepsilon_{\mathrm{F}}\right)$ and voltage $\left(\varepsilon_{\mathrm{U}}\right)$, Eq. (1).

$$
\begin{gathered}
\varepsilon=\varepsilon_{t h} \times \varepsilon_{F} \times \varepsilon_{U}=\left(\left|\frac{\Delta G^{\circ}}{\Delta H^{\circ}}\right| \times \frac{1}{U_{e q}} \times \frac{z_{\text {exp }}}{z_{t h}}\right) U \\
U=E(\text { cathode })-E(\text { anode })
\end{gathered}
$$

where $\Delta G^{\circ}$ is the Gibbs energy, $\Delta H^{\circ}$ is the enthalpy, $U_{\text {eq }}$ is the theoretical cell voltage, $U$ is the real cell voltage, $z_{\text {th }}$ is the theoretical exchanged electrons, $z_{\exp }$ is the experimental exchanged electrons, $E$ (cathode) is the potential of the cathode (positive electrode) and $E$ (anode) is the potential of the anode (negative electrode). 


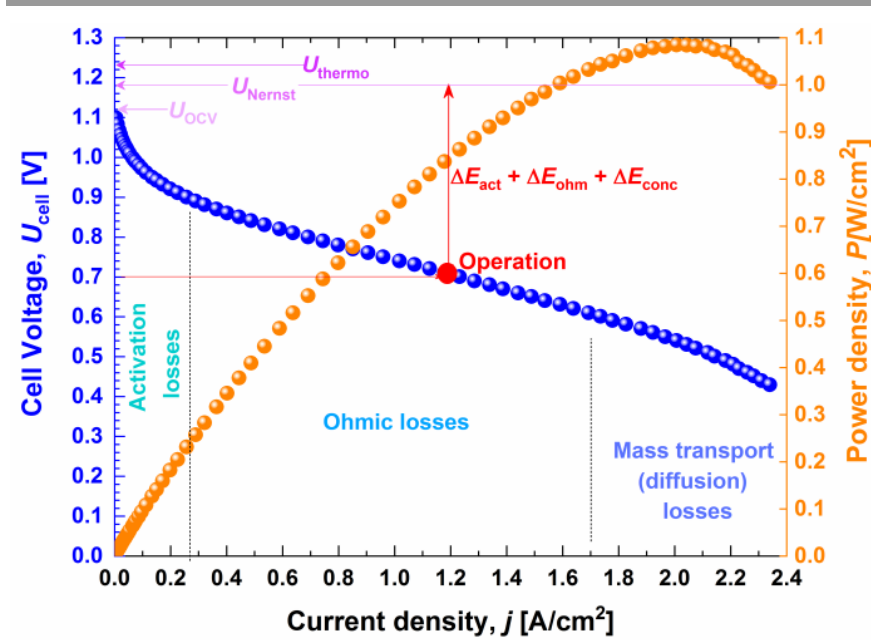

Fig. 1. Typical electrical polarization of low-temperature single $\mathrm{H}_{2} / \mathrm{O}_{2}$ fuel cell.

A typical electrical polarization (cell voltage $U_{\text {cell, }}$ and power density $P=U_{\text {cell }} \times j$ ) of low-temperature single $\mathrm{H}_{2} / \mathrm{O}_{2}$ fuel cells is shown in Fig. 1. The curves highlight different features: (i) the maximum cell voltage (OCV) is lower than the theoretical value predicted by thermodynamic and Nernst data, (ii) at the operation point (usually $2 / 3$ of $P_{\max }$ ), at much of the high current density can be extracted from the fuel cell, the cell voltage is significantly lower. During the normal operation of a fuel cell, if there is no drastic change of the reaction selectivity, both thermodynamic and faradaic contributions will not change. Thus, only the experimentally measured cell voltage $U$ affects the efficiency. A cathode performs the oxygen reduction reaction (ORR), which is thermodynamically expected to start at ca. $1.2 \mathrm{~V}$ vs reversible hydrogen electrode (RHE). Given the sluggishness of ORR, the best activity is achieved in the potential range of 1.0-0.7 V vs RHE (the discussion about ORR is beyond the scope of this review and is documented elsewhere ${ }^{12}$ ). According to Eq. (2), it becomes obvious that the main selection criteria of anode electrocatalysts for fuel cell (operating voltage optimization) is an electrooxidation with the lowest overpotential, i.e., at the lowest electrode potential (E), ideally $E<0.5$ V vs RHE.

\subsection{Working principle of dual electrosynthesis in aqueous media}

For a long time, the electron has been theorized as a "green reactant" to perform numerous chemical transformations, from the recovery of metals to the assembly of sub-unit of molecules. To do so, we need an electrical conducting material (electrode) to serve as a delivery of electrons (when a substance needs to be reduced) or as a sink (when a substance has to release electrons). In other words, two electrodes are needed, one acting as the "working" and another one as the "counter". Consequently, in aqueous media, the reaction of interest at either the working electrode or the counter electrode could be coupled smartly with one of the two solvent's "wall reactions" at the counter electrode (see Section 3.1.1). More precisely, an electrooxidation at the working electrode can be coupled with the hydrogen evolution reaction (HER) at the counter electrode, or the electroreduction at the working electrode can be combined with oxygen evolving reaction (OER) at the counter electrode. This dual electrosynthesis is termed "paired electrosynthesis". ${ }^{62,65-67,70}$ In such a situation, the ratio of the working and counter electrode areas should be carefully considered to avoid any parasitic/non-productive reactions such as the dissolution or degradation of the electrodes. ${ }^{71}$ Fundamentally, the polarization of an electrode (its potential being forced away from its value at open circuit) induces an electrical current flow due to electrochemical reactions at both working and counter electrode surfaces. The magnitude of the current, proportional to the amount of the chemical substance in moles (Faraday's first law), is controlled by reaction kinetics and/or the diffusion of reactants and products, towards and away from the electrode surface.

Going through the encyclopaedia of electrochemical reactions, almost all reactions including relatively simple redox reactions and metal depositions depict a dependence on the nature of the electrode surface. Under an electrical current flow, processes occurring at the surface of a given electrode are those depending on the nature of the electrode and those that are not. The aforementioned electrochemical processes are routinely classified into two categories. ${ }^{72-76}$ First, the outersphere redox processes, whereby there is no physical interaction between the redox species and electrode surface. It is influenced by the solvent and/or electrolyte properties (double layer effects) and the electron transfer occurs between two species with no bonding between them through electron tunnelling from one to the other across a solvation layer. It is benchmarked by a formal redox potential $\left(E^{\circ \prime}\right)$, standard rate constant $\left(k^{\circ}\right)$, and charge-transfer coefficient $(\alpha)$ as defined in the Butler-Volmer formalism of electrode kinetics. Second, the inner-sphere or catalytic redox processes wherein the bonding or adsorption of reactants, intermediates, and/or products to the electrode surface has a major effect on the reaction kinetics. The electron transfer occurs in an activated complex where a ligand is shared between the donor and acceptor molecules (and where the bridging ligand may or may not be transferred during the reaction). It is gauged by an overpotential (n), Tafel slope (semi-quantitative indicator of charge-transfer kinetics and/or mechanisms for simple processes), and/or exchange current density $(j o$, the current density at the equilibrium potential, which is a quantitative indicator of charge transfer kinetics) as defined in the well-known Tafel equation.

It should be rationally summed up that the majority of the reactions in electrochemistry are found between these two boundaries. In the first case, the electrode acts as a donor or an acceptor of electrons. The consequence is that the reaction kinetics is expected to be independent of the electrode material, but the required electrode potential is likely to depend on the nature of the electrode material. In other words, different materials will lead to the same yield. At the industrial scale, we just need to augment the geometric surface area in order to change the conversion rate. This situation is extremely rare, if not impossible to achieve in electrochemistry. In the second one, the electrode surface acts as a catalyst (an electrocatalyst). In this case, the type and rate of the reaction depend critically on specific interactions between the electrode 
surface and chemical species that are present in the electrolyte. Precisely, electrosynthesis driven by this type of interactions (electrocatalysis) is burgeoning. Instead of relying exclusively on the "geometric surface area" in the first case, one can, for the same geometric surface area, change the yield, conversion, mechanism, electrode potential (thus indirectly the consumed electrical energy). Sections 2.4 and 4 will critically examine different tools used by researchers to provide increased efficiencies, particularly the nano-structuring and the heterogeneous composition of catalytic electrodes.

\subsection{Working principle of electrolysis cells for $\mathrm{H}_{2}$ production in alkaline $\mathrm{pH}$}

The primary idea behind the concept of harvesting $\mathrm{H}_{2}$ from water is that it does not involve any carbon sources. Operation under alkaline environments is expected to provide the best advantages (non-noble catalysts, cost-effective, long-term stability) compared to acid media. ${ }^{77}$ In an alkaline medium, the balanced equation of HER is shown in Eq. (3), which highlights the critical step of $\mathrm{H}_{2} \mathrm{O}$ dissociation. From Eqs. (4)-(5), it can be concluded that the only way to reduce the consumed electrical energy $(W)$ is to couple the cathodic process (HER) with an efficient anodic reaction. If water is used as the sole reactant (in addition to $\mathrm{H}^{+}$or $\mathrm{HO}^{-}$as ionic conductors), the anode process that is OER leads to an overall system that requires at least $U=$ $1.5 \mathrm{~V}$, as shown in Fig. 2 (in theory $1.23 \mathrm{~V}$ (based on $\Delta G$ ) and $1.48 \mathrm{~V}$ (based on $\Delta H)$ ).

$$
\begin{aligned}
& 2 \mathrm{H}_{2} \mathrm{O}+2 \mathrm{e}^{-} \rightarrow \mathrm{H}_{2}+2 \mathrm{OH}^{-}, E^{\circ}\left(\mathrm{H}_{2} \mathrm{O} / \mathrm{H}_{2}\right)=-0.84 \mathrm{~V} \text { vs SHE } \\
& \qquad \mathrm{W}=\mathrm{Q} \times \mathrm{U}=2 \mathrm{nFU}=\frac{2 \mathrm{FV}}{\mathrm{V}_{\mathrm{m}}} \mathrm{U}=\frac{2 \mathrm{FPV}}{\mathrm{RT}} \mathrm{U}
\end{aligned}
$$

$$
\mathrm{W}\left(\mathrm{kWh} / \mathrm{Nm}^{3}\right)=2.39 \times \mathrm{U} \text { or } \mathrm{W}(\mathrm{kWh} / \mathrm{kg})=26.59 \times \mathrm{U}
$$

where SHE is the standard reference electrode, $W$ is the consumed electrical energy, $Q$ is the required electrical charge, $U$ is the required cell voltage, $n$ is the produced moles of $H_{2}, F$ (96485 C mol-1) is the Faraday constant, $V$ is the produced volume of $\mathrm{H}_{2}, V_{\mathrm{m}}$ is the molar volume in normal conditions ( $T=$ $273.15 \mathrm{~K}, P=101325 \mathrm{~Pa}), \mathrm{R}\left(8.314 \mathrm{~J} \mathrm{~K}^{-1} \mathrm{~mol}^{-1}\right)$ is the universal gas constant. For $\mathrm{H}_{2}$, a normal cubic meter $\left(\mathrm{Nm}^{3}\right)=0.09 \mathrm{~kg}$.

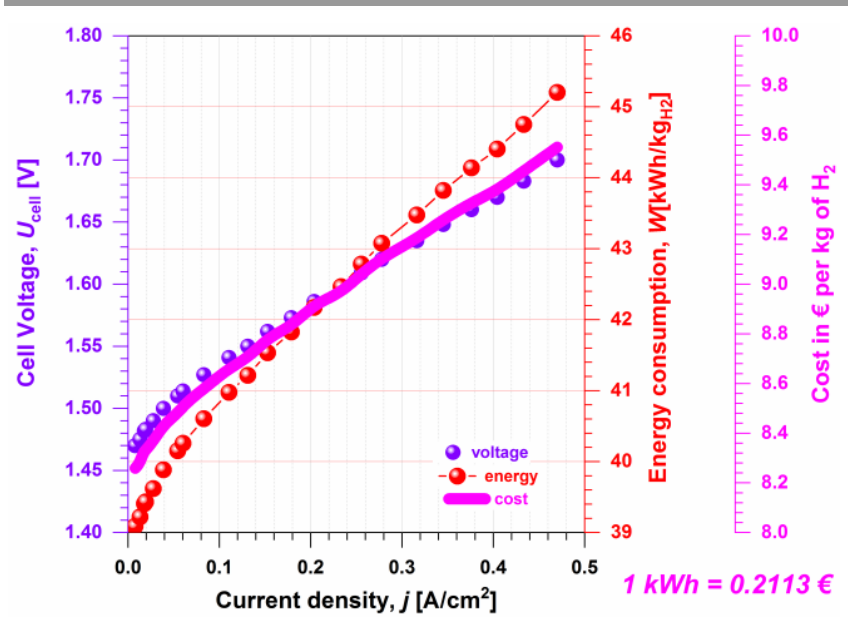

Fig. 2. Typical performance of low-temperature single water electrolysis cell.

As mentioned above, the total efficiency $(\varepsilon)$ of electrolysis cell has three contributions: thermodynamic $\left(\varepsilon_{\text {th }}\right)$, faradaic $\left(\eta_{F}\right)$ and voltage ( $\left.\varepsilon_{u}\right)$, Eq. (6). According to Eq. (7), as $E$ (cathode) is fixed for a given HER's electrocatalyst, it becomes obvious that the main selection criteria of anode electrocatalysts for the purposes of electrolysis is an electrooxidation with the lowest overpotential, i.e., at the lowest electrode potential. In aqueous media, this can be achieved for a number of organic compounds such as those reviewed in the present paper. Keeping in mind that the electrolysis cell will operate in the current density range of $0.2-1.0 \mathrm{~A} \mathrm{~cm}^{-2}$, the cost associated with $\mathrm{H}_{2}$ production that is about $8-10 € / \mathrm{kg}\left(\mathrm{H}_{2}\right)$ (considering the mean electricity cost in Europe, $0.2113 € / \mathrm{kWh}^{78}$ ) can be also greatly reduced with the co-production of value-added chemical(s) at the anode. To do so, the driving force behind the tight control of the " $\mathrm{C}-\mathrm{C}$ " bond cleavage should be carefully understood and optimized.

$$
\begin{gathered}
\varepsilon=\varepsilon_{t h} \times \varepsilon_{F} \times \varepsilon_{U}=\left(\left|\frac{\Delta G^{\circ}}{\Delta H^{\circ}}\right| \times U_{e q} \times \frac{z_{\exp }}{z_{t h}}\right) \frac{1}{U} \\
U=E(\text { anode })-E(\text { cathode })
\end{gathered}
$$

where $\Delta G^{\circ}$ is the Gibbs energy, $\Delta H^{\circ}$ is the enthalpy, $U_{\text {eq }}$ is the theoretical cell voltage, $U$ is the real cell voltage, $z_{\text {th }}$ is the theoretical exchanged electrons, $z_{\exp }$ is the experimental exchanged electrons, $E$ (cathode) is the potential of the cathode (negative electrode) and $E$ (anode) is the potential of the anode (positive electrode).

\subsection{Performance-by-design principles for selectivity in the electrooxidation of organics in aqueous media}

In aqueous media, the first design principle for high selectivity is the proper choice of electrode material that catalyses only the oxidation of the organic molecule(s) without any interference by OER. The material should specifically be designed to function at an anode electrode potential that is not more positive than the onset potential of OER, that is $E_{\mathrm{OER}}=1.23 \mathrm{~V}_{\mathrm{RHE}}=(1.23-$ $0.06 \times \mathrm{pH}) \mathrm{V}_{S H E}$ (note that at $25^{\circ} \mathrm{C}$, the slope $\mathrm{RT} / \mathrm{F}=0.06$ ). It should be noted that most OER materials suffer from sluggishness that induces overpotential of at least $200 \mathrm{mV}$. 
Furthermore, we should keep in mind that the theoretical onset potential can be below $E_{\mathrm{HER}}=0 \mathrm{~V}_{\mathrm{RHE}}=-0.06 \times \mathrm{pH} \mathrm{V}_{\mathrm{SHE}}\left(\right.$ at $25^{\circ} \mathrm{C}$ ). For example, the 2-electron oxidation of glucose to gluconate is thermodynamically expected to start at an open circuit potential (OCP) of $-1.12 \mathrm{~V}_{\mathrm{SHE}}=-0.294 \mathrm{~V}_{\mathrm{RHE}}$ for $\mathrm{T}=25^{\circ} \mathrm{C}$ and $\mathrm{pH}=$ $14 . .^{50}$ Consequently, it might be important to add a second designing principle in order to restrict a concomitant HER. Furthermore, the implementation of electrocatalysis in aqueous media for the selective oxidation of organics to valuable molecules could be confronted by twin processes that involve multi-electron and multi-proton transfer steps, and induce the formation of many reaction intermediates (thus energy barriers), which lead to larger overpotentials, and many reaction products. So the third designing principle should be a tight control of $\mathrm{C}-\mathrm{C}$ bond cleavage. A common case is the precise engineering of advanced electrodes by a tight control over activity (meaning conversion) and selectivity, which is a crucial bottleneck in the electrocatalysis of organics. In some cases, it might be useful to alloy metals, one having higher energy than optimal value (i.e., binding energy of the performance descriptor) and another one having lower energy. Then, it is expected that the turnover and the indicators of the catalytic efficiency (described by Eqs. (8)-(11)) will increase. To sum up, a perfect electrode material for the selective electrooxidation of organic molecules in aqueous media should be able to: (i) dissociate $\mathrm{C}-\mathrm{H}$ (or $\mathrm{C}-\mathrm{Cl}, \mathrm{C}-\mathrm{N}$, etc.) bonds with minimal driving force (i.e., with the smallest overpotential); (ii) provide Ocontaining (or appropriate heteroatoms) species and facilitate their reaction with the intermediates, (iii) minimize $\mathrm{C}-\mathrm{C}$ bond cleavage in order to avoid obtaining a cascade of products. To achieve this, both criteria of several neighbouring but unoccupied active sites and/or the displacement of the initially adsorbed $\mathrm{H}$ atoms is required.

$$
\begin{gathered}
\text { zexp }=\frac{\text { Qexp (in C) }}{F} \times \frac{1}{\text { reactant converted (in mol) }} \\
\text { conversion }(\%)=\frac{\text { reactant converted (in mol) }}{\text { initial reactant (in mol) }} \times 100 \\
\text { selectivity }(\%)=\frac{\text { product (in mol) }}{\text { all products (in mol) }} \times 100 \\
\text { selectivity }(\%)=\frac{\text { product (in mol) }}{\text { reactant converted (in mol) }} \times \frac{1}{\mathrm{z}} \times 100
\end{gathered}
$$

where $z_{\exp }$ is the experimental exchanged number of electrons, $\mathrm{F}\left(=96485 \mathrm{C} \mathrm{mol}^{-1}\right), Q_{\exp }$ is the experimentally recorded electrical charge and $z$ is the stoichiometric number for the product of interest.

\subsection{Cogeneration electrochemical devices}

2.5.1. Basis of organic molecule-based fuel cells for the dual production of electricity and chemicals. When an organic molecule is used as the fuel at the anodic compartment instead of $\mathrm{H}_{2}$ (for which the net reaction product is $\mathrm{H}_{2} \mathrm{O}$ ), the main objective should not be its complete oxidation (routinely called mineralization). Of course, a maximum faradaic yield can be achieved, but the arising question is about the future of the final oxidation product, which is $\mathrm{CO}_{2}\left(\mathrm{CO}_{3}{ }^{2-}\right.$ in an alkaline environment). Indeed, the benefits of employing a fuel cell for "sustainable electricity" production would be a paradox if a high amount of "waste" is correspondingly released. Hence, fuel cells that utilise organics should be designed to avoid the total oxidation so that the reaction product would be another organic molecule that has an added value. Fig. 3 shows the case study of glycerol, which could be concurrently converted into electricity and chemicals if a rational and smart anode's electrocatalysts development approach is found. Therefore, it becomes obvious that the main requirement for anode electrocatalysts of organics-fuelled fuel cells switches into an electrooxidation with the lowest overpotential (ideally $E<0.5 \mathrm{~V}$ vs $\mathrm{RHE}$ ) and the best $\mathrm{C}-\mathrm{C}$ bond control. Conclusively, the selectivity at the anode should lead to value-added products that compensate the loss in electricity production or contribute to overall cost reduction.

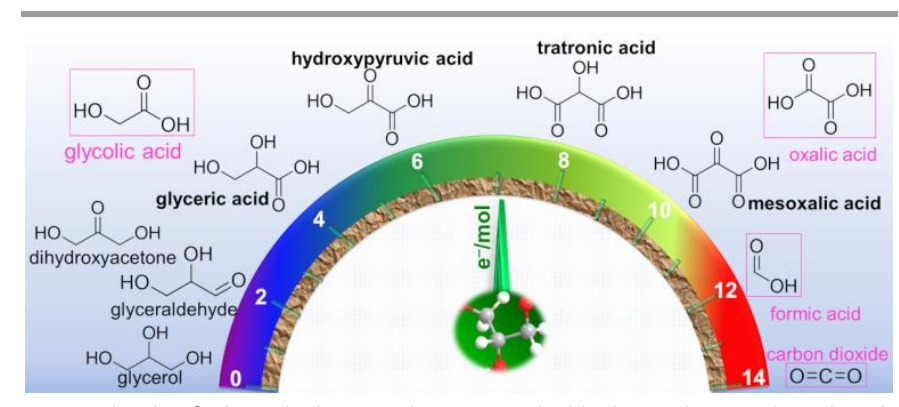

Fig. 3 Sketch of glycerol electrooxidation to valuable by-products. Adapted with permission from Ref. ${ }^{12}$, Copyright 2017, Wiley-VCH Verlag GmbH \&Co. KGaA, Weinheim.

2.5.2. Basis for low energy consumption organic molecule-fuelled electrolysis cells for the simultaneous production of $\mathrm{H}_{2}$ and chemicals. There is no electricity demand for a fuel cell to operate because it is a galvanic cell that has a stock of chemical energy. In the case of an electrolysis cell, an electrical energy should be supplied. The most important idea to keep in mind when designing electrode materials to operate in an electrolysis cell as anode or cathode is to minimize the overall energy input that is proportional to the cell voltage between the anode and cathode. The majority of the organic compounds (at least those studied herein) have a lower oxidation potential in comparison to the $\mathrm{O}_{2} / \mathrm{H}_{2} \mathrm{O}$ couple $\left(\mathrm{O}_{2} / \mathrm{OH}^{-}\right.$in alkaline media). Hence, one elegant way is to electro-oxidize selectively an organic molecule at the positive electrode of the electrolyser instead of $\mathrm{H}_{2} \mathrm{O}$, as highlighted in Fig. 4. In these regards, a high purity $\mathrm{H}_{2}$ (since there is no other gas in the reactor as it could happen for total organics oxidation at the anode) is produced at the cathode and a value-added chemical is produced at the anode. This type of strategy is so-called "co-generation or co-production" in a paired electrolysis cell. $62,65-67,70$ 


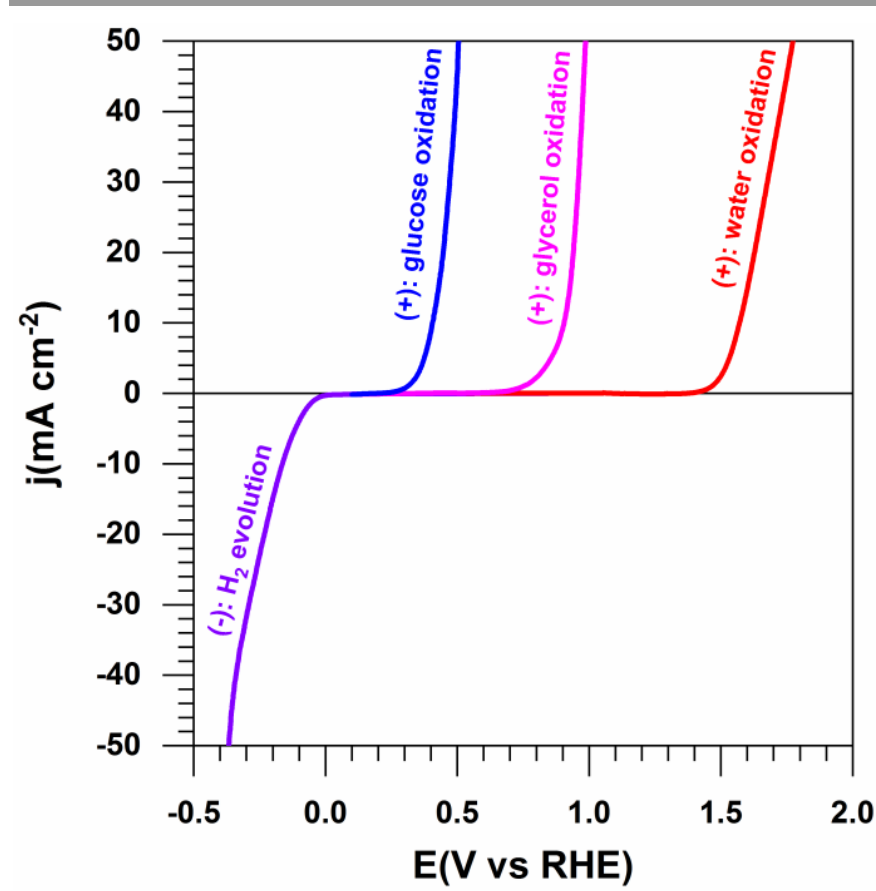

Fig. 4 Typical half-cell electrolysis polarization curves illustrating the working principle of solid alkaline membrane electrolysis cell (SAMEC), at nanomaterials. Negative electrode (cathode): Water reduction at Pt (HER, $\left.1 \mathrm{M} \mathrm{KOH}, 25^{\circ} \mathrm{C}, 5 \mathrm{mV} \mathrm{s}^{-1}\right)$. Positive electrode (anode): water oxidation at Pt (OER, $\left.1 \mathrm{M} \mathrm{KOH}, 25^{\circ} \mathrm{C}, 5 \mathrm{mV} \mathrm{s}^{-1}\right)$, glycerol oxidation at $\mathrm{Au}$ (1 $\mathrm{M} \mathrm{KOH}+0.5 \mathrm{M}$ glycerol, $25^{\circ} \mathrm{C}, 5 \mathrm{mV} \mathrm{s}^{-1}$ ) and glucose oxidation at $\mathrm{Au}(1 \mathrm{M} \mathrm{KOH}+0.5$ M glucose, $25^{\circ} \mathrm{C}, 5 \mathrm{mV} \mathrm{s}^{-1}$ ).

\section{Analytical approach for testing and validating electrochemical performance of electrodes}

Due to the lack of familiarity with electrochemistry, many chemists have been intimidated by the unfamiliar territory of electrosynthesis and by the perception that the equipment needed is complicated and expensive, which has caused researchers to turn to the use of reagents and familiar methods for which they have prior experience, even when an electrochemical method might hold a distinct advantage over that more comfortable approach. ${ }^{60}$ This section aims at stimulating the best practices for performing and reporting the electrocatalytic performance for the electrooxidation of organics and inviting other chemists to join the landscapes offered by electrochemistry. Specifically, the section aims at providing an updated and complete portfolio for setting up electrochemical experiments. The section includes the choice of: the appropriate electrolyte, the type of the cell, and the methods of electrochemical characterization, namely cyclic voltammetry (CV), linear sweep voltammetry (LSV), chronoamperometry, chronopotentiometry, and electrochemical impedance spectroscopy (EIS). We also provide details surrounding product analysis by in/ex situ coupling methods (spectroelectrochemistry, chromatography, spectrometry, etc.).

\subsection{General work-up tips for electrosynthesis in aqueous media}

3.1.1. Choice of the appropriate electrolytic solution. The term "aqueous media" implies that water is the solvent. It should be of high purity (routinely called ultrapure water of ca. $18 \mathrm{M} \Omega \mathrm{cm}$ at $20^{\circ} \mathrm{C}$ ). The ionic conductivity of that water being negligible (ca. $5.5 \times 10^{-6} \mathrm{~S} \mathrm{~m}^{-1}$ ), the addition of selected species to act as an electrolyte (also known as electrolytic solution or supporting electrolyte) is required to insure ionic conductivity (this will suppress migration effects of electroactive species under an electrical field), except the situation where the compound that will be electrolysed is actually a salt or one is using a flow cell with a very small electrode gap (micro-scale or lower). Its main function is to assist with ionic conductivity, which means that the compound is soluble in the solvent and dissociates into ions. In aqueous media, the potential window is limited by hydrogen evolution and oxygen evolution due to the overpotentials, so that the electrolyte should not undergo any oxidation, reduction or other types of degradation in this window. The electrolyte should facilitate extraction, separation and purification of the reaction products. Its concentration should be at least $0.1 \mathrm{M}^{79}$. Of course, a lower value may be sufficient in some cases. The presence of electrolyte is expected to minimize the uncompensated resistance; the precise determination of this resistance is an important task (Section 3.2.1.). It is very important to point out that this resistance also depends on the type of substrate and the cell geometry. For the last one, those parameters are the working electrode area and distance between two electrodes which are used to measure an electrical voltage. Besides, there are some types of flow electrolysis cells in which the use of an electrolyte can be minimized if not eliminated. $66,74,80-85$ To complete this subject, whether to use an electrolyte or not and at what concentration should be decided on a case-by-case basis during control experiments. In aqueous media, the most widely used electrolytes can be inorganic salts of neutral $\mathrm{pH}(\mathrm{NaCl}, \mathrm{KCl}$, $\mathrm{KNO}_{3}, \mathrm{~K}_{2} \mathrm{SO}_{4}$, etc.), compounds with a stable $\mathrm{pH}$ of certain value (buffers: phosphate, carbonate, citrate, etc.), and compounds with variable $\mathrm{pH}$ (acid or base: $\mathrm{HClO}_{4}, \mathrm{NaOH}, \mathrm{KOH}, \mathrm{HCO}_{3}{ }^{-}$, etc.). Beware using halide anions $\left(\mathrm{X}^{-}, \mathrm{X}=\mathrm{Cl}, \mathrm{Br}, \mathrm{I}\right)$ that can be oxidized to either $\mathrm{X}_{2}$ or halonium ion $\left(\mathrm{X}^{+}\right)$. In addition to the electrolyte's stability within the potential window, its compatibility with the reactants and products must be taken into account too (not involved in parasite reactions that can modify the kinetics/efficiency). ${ }^{86,87}$

When the electrooxidation of an organic molecule involves a "proton-coupled electron-transfer step", the pH has a crucial impact on the activity. Seminal (electro)catalytic studies have shown that the performance of the reaction is maximal at $\mathrm{pH}$ close to the pKa (dissociation constant) of the organic molecule being studied. ${ }^{88-96}$ For this reason, in aqueous media, $\mathrm{CO}_{2}$ is studied for a $\mathrm{pH}$ around 8 (pKa of $\mathrm{CO}_{2(\mathrm{aq})}=6.3$ and 10.3), formic acid ( $\mathrm{pKa}=3.77$ ) about $\mathrm{pH} 4$ and alcohols above $\mathrm{pH} 12$ (very weak acids: $\mathrm{pKa}=12.23,14.15,14.77,15.9$, for glucose, glycerol, ethylene glycol, and ethanol, respectively). It is argued that the alkoxide (anion of dissociated alcohol) is the real active 
species in alkaline media. ${ }^{88,89,91-94}$ Hence, the pKa is a key property to describe the reactivity, since it reflects the concentration of the active species (alkoxide ions). Work by de Souza et al. ${ }^{96}$ studied the reactivity of three-carbon-atom chain alcohols on a bulk Au electrode and observed that an increase of pKa results in the decrease of the current densities.

3.1.2. Choice of the appropriate electrochemical cell setup: configuration and electrodes. There are two types of electrochemical cells, an undivided or a beaker-type cell (1 compartment), and a divided or H-type cell (2 compartments) wherein both the counter electrode and working electrode compartments are isolated by separators, ${ }^{97,98}$ e.g. a membrane, diaphragm, etc. Indeed, in the course of an electrochemical reaction, when the oxidation occurs at the working electrode, a parallel reduction process happens at the counter electrode, while the reverse is also true. So, as the intermediate/product that is produced at the working electrode can diffuse or migrate to the counter electrode, it is strongly advised to use an H-type cell. This helps to avoid any potential transformation of the product at the counter electrode or interference with the process occurring there. Both configurations should be carefully examined when deciding to employ a three- or two-electrode setup. For a two-electrode configuration, electrodes are referred to as positive and negative electrodes. In this case, the driving force during the electrosynthesis can consist of applying either a cell voltage $\Delta E(\mathrm{~V})$ between those electrodes or a current. That current is routinely normalized as a current density $j\left(\mathrm{~A} \mathrm{~cm}^{-2}\right)$ with respect to the limiting electrode. Industrial-scale electrolysers mostly operate in a two-electrode configuration by applying a fixed current (the duration of the process is evaluated by the second law of Faraday). In some cases, it is more convenient to use a three-electrode setup where the introduced third electrode is the reference electrode. The potential of the reference electrode should be stable in order to enable a tight control of the potential of working electrode so that electrosynthesis can be performed correctly. This is very important in electrocatalysis where the surface state of the working electrode depends on the applied potential. Indeed, in a three-electrode configuration, the working electrode is where the investigated reaction takes place. Its feature is to allow good activity, selectivity, and durability. Notably, in aqueous media, chemical species composed of the solvent and/or electrolyte are adsorbed at the working electrode $\left(\mathrm{H}_{(\mathrm{ads})}, \mathrm{OH}_{(\mathrm{ads})}\right)$ and take part in the reaction. Except the case of non-aqueous media, where the carbon electrodes are used for a large spectrum of reactions, the choice of the working electrode in aqueous media should be treated on a case-by-case basis. This is outlined in Section 4. For this threeelectrode arrangement, the counter electrode ensures the circulation of the electrical current by reducing (if oxidation occurs at the working electrode and vice-versa) the solvent/electrolyte at its surface. The area ratio between the counter electrode and that of the working should be optimized to ensure that the occurring electrochemical reaction at the counter electrode's surface is not the overall limiting process. A ratio of at least 3 with respect to the working electrode is recommended in electrocatalysis. However, depending of the cell setup and the electrochemical process occurring at the counter electrode (much faster kinetics than the process at the working electrode), the counter electrode can have lower area. In fact, the electrooxidation of certain organic molecules in an aqueous medium could be done using just a Pt wire. Indeed, the kinetics of the evolution reaction of $\mathrm{H}_{2}$ on $\mathrm{Pt}$ in these conditions is known to be very fast and not limiting. Even though Pt-based materials have been employed as the counter electrode material for many years, one should be aware of possible Pt dissolution and re-deposition at the working electrode. As an active catalyst for the majority of substrates, it will interfere with the process at the working electrode.99-101 Jerkiewicz et al. ${ }^{71}$ have shown that, under electrochemical conditions, the area ratio between the working electrode and the counter electrode has a noteworthy role on the dissolution of metallic species that are on the working electrode. When the active species have to be immobilized onto the working electrode surface (NPs, enzymes, etc.), the same precautions apply. When the upper potential limit is not exceeding 1.2-1.5 V vs RHE, high purity glassy carbon is an excellent choice as a counter electrode or supporting material of catalytic species (NPs, enzymes, etc.) being deposited onto the surface of the working electrode.

For the choice of the reference electrode, the most popular ones in aqueous solutions are: silver-silver chloride $(\mathrm{Ag}|\mathrm{AgCl}| \mathrm{KCl}, \quad \mathrm{SSCE})$, saturated calomel electrode $\left(\mathrm{Hg}\left|\mathrm{Hg}_{2} \mathrm{Cl}_{2}\right| \mathrm{KCl}_{\text {sat }}, \mathrm{SCE}\right)$, mercury-mercurous sulphate electrode $\left(\mathrm{Hg}\left|\mathrm{Hg}_{2} \mathrm{SO}_{4}\right| \mathrm{K}_{2} \mathrm{SO}_{4}, \mathrm{MSE}\right)$, mercury-mercury oxide electrode $(\mathrm{Hg}|\mathrm{HgO}| \mathrm{Na}(\mathrm{K}) \mathrm{OH}, \mathrm{MOE})$ and the reversible hydrogen electrode $\left(\mathrm{Pt}\left|\mathrm{H}_{2}\right| \mathrm{H}^{+}, \mathrm{RHE}\right)$. All electrode potentials can be readily converted versus $\mathrm{RHE}$ and vice-versa through the Nernst formula, Eq. (12). It should be stated that RHE (a pH independent $\mathrm{RE}$, suited for coupled electron-proton transfer reactions, is the metric electrode for electrochemists in aqueous media. So when possible, all data should be reported with RHE. The most appropriate method to precisely determine the conversion term expressed in Eq. (13) between RHE and another reference electrode is to use the calibration curve in high-purity $\mathrm{H}_{2}$-saturated electrolyte. Typically, a steady-state $\mathrm{CV}$ is recorded in $\mathrm{H}_{2}$-saturated electrolyte at a scan rate not higher than $1 \mathrm{mV} \mathrm{s}^{-1}$ by employing a high purity Pt (plate, wire, etc.) as the working electrode, another Pt or glassy carbon as the counter electrode and the targeted reference as the reference electrode. Hence, in such CVs collected at a quasi-steady state scan rate, the average of the two potentials at which the current crossed zero is taken to be the thermodynamic potential for the hydrogen electrode reactions (HER and HOR). Furthermore, the nature of materials used for the fabrication of the glassware should be carefully probed.102 The traditional approach for minimizing the contamination of the reference electrode by 
organic molecules has been assumed to make use of a "salt bridge" (main role of allowing only the ionic conductivity), for example, double-junction RE or Haber-Luggin capillary tip, 101,103 which is important for the chloride-based reference electrodes. For experiments in acid or neutral pHs, SCE, SSCE and MSE are recommended, but their utilization for long-term experiments should be avoided in alkaline pHs, where MOE is the best option. For chloride ions issues, MSE is the best option in lieu of SCE or SSCE. Indeed, not only trace concentrations of ions (such as chloride) might adsorb on the working electrode and dramatically change its electrochemistry, but also can alter the nature and performance of the electrochemical reaction being studied. Lastly, whilst RHE has the benefit of being filled with the electrolyte in all range of $\mathrm{pHs}$, it should not be used in a single compartment cell without a salt bridge because of a possible pollution by organic molecules and gaseous products that can enter in the reference electrode, alter its potential value over time and compromise the quality of the electrochemical response.

$$
\begin{array}{r}
E(V \text { vs } R H E)=E(V \text { vs } R E)+\frac{2.3 R T}{F} p H+E^{\circ}(V \text { vs } S H E) \\
\Delta E(V)=\frac{2.3 R T}{F} p H+E^{\circ}(V \text { vs } S H E)
\end{array}
$$

where $E^{\circ}$ is the standard potential corresponding to the redox couple associated with the reference electrode (RE). For example, $E^{\circ}(V$ vs SHE $)=0.208,0.242$ and 0.640 for SSCE, SCE and MSE, respectively.

\subsection{Methods of electrochemical characterization and products analysis}

3.2.1. Half-cell and cell reactions characterization. Three methods can be used to run electrosynthesis: constant current electrolysis (or chronopotentiometry, applied parameter $=j(\mathrm{~A}$ $\mathrm{cm}^{-2}$ )), constant potential electrolysis (or chronoamperometry, applied parameter $=E_{\mathrm{appl}}(\mathrm{V}$ vs $\left.\mathrm{RE})=E_{\mathrm{WE}}-E_{\mathrm{RE}}\right)$, and constant cell voltage electrolysis (applied parameter $=U_{\text {applied }}(\mathrm{V})=E_{\mathrm{WE}}-E_{\mathrm{CE}}$ ). When a three-electrode arrangement is required because the potential of the working electrode needs to be monitored, the method of constant current electrolysis and constant potential electrolysis are used. Otherwise, the constant current electrolysis and constant voltage electrolysis are used for twoelectrode setups. In some cases, it might be useful to substitute a constant potential electrolysis method (a single step potential) by the programmed potential electrolysis, which is made of at least two potential steps in order to manage the catalyst deactivation. ${ }^{13,98,104}$ In fact, the constant potential electrolysis method (single step) is suitable for reactions either predominated by outer-sphere processes or performed with robust catalytic electrodes that do not suffer from the surface poisoning phenomenon. So in order to retain activity, the main step, i.e., the reaction plateau (lasts tens of seconds), is followed by a shorter pulse (of a duration ranging from milliseconds to a second) at a more positive potential to electrooxidize the strongly adsorbed species that were previously formed. Sometimes, a third plateau that lasts a few seconds may be necessary at more negative potentials in order to adsorb the organic molecules being studied or to deposit electrocatalytic species (ad-atoms by under potential deposition, $\mathrm{H}_{\text {(as) }}$ or $\mathrm{OH}_{(\mathrm{ads})}$ ) at the surface used to regulate the catalytic performance. It should be emphasized that the pulsed transition between different plateaux is typically executed by a simple jump of potential can be substituted by a LSV (at a scan rate of at least $100 \mathrm{mV} \mathrm{s}^{-1}$ ). ${ }^{98}$ Note that programmed potential electrolysis methods must be always accompanied by the single step technique of constant potential electrolysis to ensure that product distribution corresponds exactly to faradaic processes of the main plateau.

The fulfilment of an electrolysis experiment by one of these methods assumes that the molecule is reactive under the considered reaction conditions, which is not necessarily obvious. So, preliminary blank and control measurements by $\mathrm{CV}^{105,106}$ or LSV in a conventional three-electrode cell are mandatory in order to refine the final composition of the reaction medium. CV (electrode's potential cycling periodically between two limits at a constant scan rate of typically 1-100 mV $\mathrm{s}^{-1}$ ) or LSV (electrode's potential cycling from one value to another one at a constant scan rate of $1-100 \mathrm{mV} \mathrm{s}^{-1}$ ) should be initially recorded in the electrolyte and secondly in the presence of the substrate to determine whether the reactant can be electrooxidized or not. During this experiment, the position of the oxidation peaks should be precisely determined after the ohmic drop correction. ${ }^{101,103,106,107}$ Indeed, a potential drop between the reference and working electrodes modelled by " $\mathrm{iR}$ " is the result of the ohmic resistance or the uncompensated resistance $\left(R_{\Omega}\right.$, or $R_{U}$ ) that depends on the conductivity of the electrolyte as well as the geometry and arrangement of the reference and working electrodes in the cell. That uncompensated resistance is sometimes called "solution resistance $\left(R_{s}\right)$ ", which should not be the case for the simple reason that it includes contributions from the electrode connections and electrolyte. Note that the use of extension cables in addition to that of the potentiostat is strongly discouraged since it adds a layer of electrical wiring/contact resistances. However, when it is unavoidable, the length should be kept as minimal as possible. After correction by Eq. (14), the plots are usually called "iR-free voltammograms".

$$
E_{\text {real }}(V \text { vs } R E)=E_{\text {appl }}(V \text { vs } R E)-I \times R_{\Omega}
$$

where $E_{\mathrm{appl}}$ is the applied value, $E_{\text {real }}$ is the received value, $I$ is the electrical current and $R_{\Omega}$ is the ohmic resistance. 

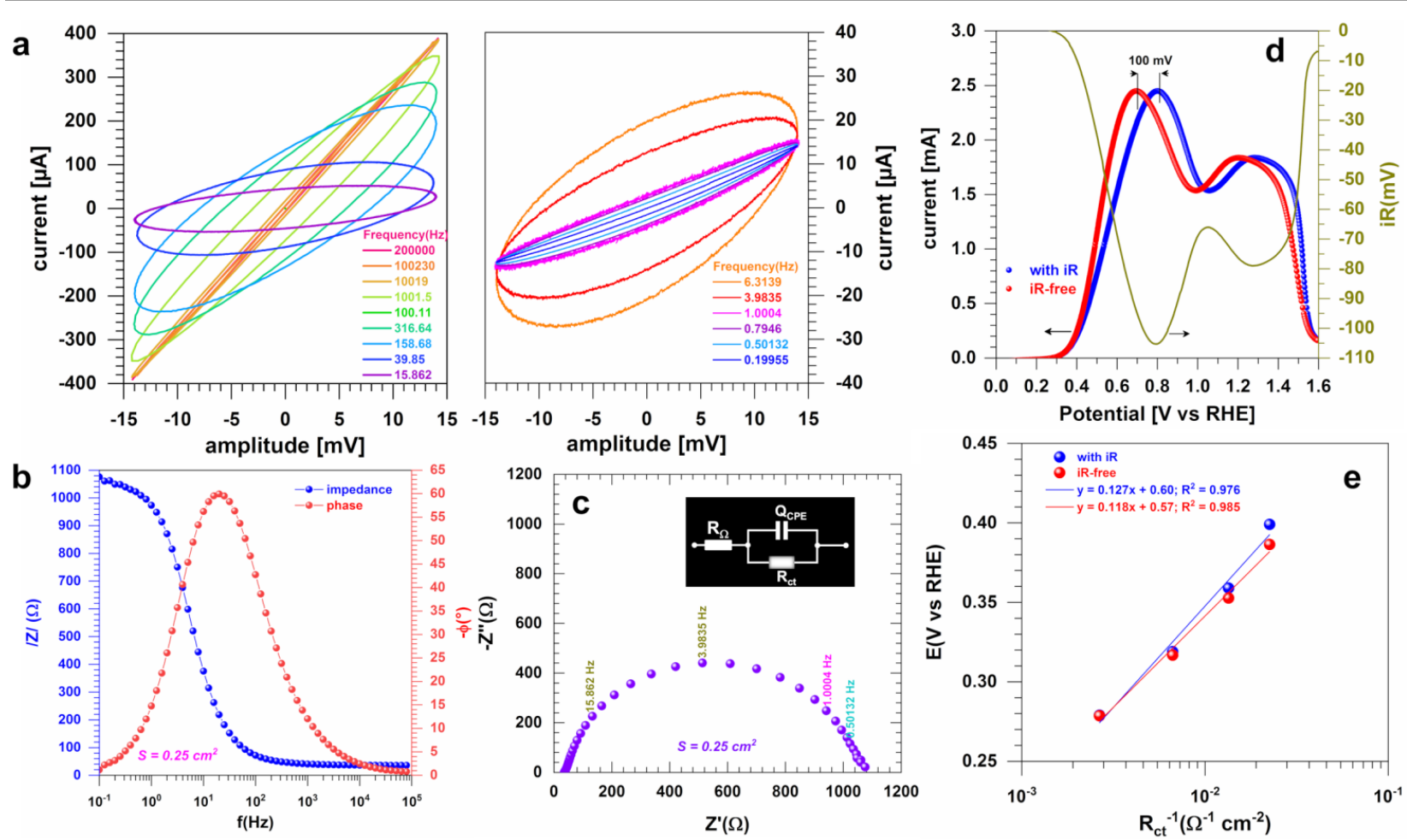

Fig. 5. Typical characterization of a half-cell reaction by EIS at OCP $\left(0.1 \mathrm{M} \mathrm{KOH}+0.1 \mathrm{M}\right.$ glucose, $\left.25^{\circ} \mathrm{C}\right)$. (a) Lissajous plots. (b) Bode diagrams. (c) Complex-plane Nyquist impedance plots. (d) Left y-axis: voltammograms (without and with iR drop) recorded at $50 \mathrm{mV} \mathrm{s}^{-1}$; right $\mathrm{y}$-axis: iR drop potential. (e) Tafel plots by $\mathrm{R}_{\mathrm{ct}}$.

The emerged and widely employed method to get $R_{\Omega}$ is the electrochemical impedance spectroscopy (EIS) ${ }^{108,109}$ that can be performed in potentiostatic or galvanostatic mode. Basically, EIS is performed by scanning a range of frequencies from $\mathrm{kHz}$ to $\mathrm{mHz}$ at amplitudes of few $\mathrm{mV}$ for potentiostatic or few $\mu \mathrm{A}-\mathrm{mA}$ for galvanostatic and insuring the linearity and stability of the system. Fig. 5a shows Lissajous plots of the alternative potential on $x$-axis and alternative current on the $y$-axis, which highlights the cut-off between two regimes. Even if the value of $R_{\Omega}$ is not impacted, this drastically changes the trends from other quantitative data and their interpretation. Visually, when the linearity condition is respected, the plot exhibits a central symmetry with respect to the origin of the plot, Fig. 5a, left side. For a non-linear response, the central symmetry of the plot is not respected, as illustrated in Fig. 5a, right side. In the Bode plot (Fig. 5b), $R \Omega$ corresponds to the value of the impedance at the high frequency region. In a Nyquist plot (Fig. 5c); the intersection of the impedance data with the $x$-axis at the high frequency leads to the determination of $R_{\Omega}$. There are other ways for the accessing the iR drop, namely the distance variation and the current interrupt methods. ${ }^{74,84,103,107}$ The ohmic potential drop can then be compensated by means of a numerical post-measurement, an automatic positive feedback or a negative resistance; those methods are well explained in Ref. ${ }^{107}$ Further modelling of EIS by representative equivalent electrical circuit is input in Fig. 5 c, i.e., $R_{\Omega}+Q_{\mathrm{CPE}} / / R_{\mathrm{ct}}$ wherein $R_{\mathrm{ct}}$ is the charge transfer resistance and $Q_{\mathrm{CPE}}$ is the constant phase element. ${ }^{108,109}$ In fact, modelling an electrochemical phenomenon with an ideal capacitor $(C)$ implicitly assumes that the surface of the electrode under investigation is homogeneous, which is rarely achievable, if not impossible. So, this lack of homogeneity is modelled with a $Q_{\text {CPE. }}$ In some case, it can be useful to add a Warburg element $(W)$ in serial with $R_{\mathrm{ct}}$ whereas the Warburg impedance models the mass transport, i.e., diffusion. The metric of $R_{\mathrm{ct}}$ (inversely proportional to rate constant $k^{\circ}$, thus to the exchange current density $j_{0}$ ) is the ability of the electron-transfer and the difficulty of an electrode reaction for driving larger current density with a less driving force (i.e., overpotential). ${ }^{74}$ For a given electrode, the lower $R_{\mathrm{ct}}$ is, the higher is the kinetic rate. Fig. $5 d$ depicts the contribution of the $R_{\Omega}$ on the profile of a collected CV. Depending on the value of $R_{\Omega}$ and the magnitude of the current, the potential drop can be from few $\mathrm{mV}$ to hundreds of $\mathrm{mV}$, which might not be negligible. This would strongly affect not only the value of the electrode potential to be applied during an electrosynthesis by the constant potential electrolysis method, but also the mechanism descriptors such as the Tafel slope $b\left(\mathrm{mV} \mathrm{dec}^{-1}\right){ }^{79}$

The determination of $R_{\mathrm{ct}}$ at different electrode potentials and the plotting of $E$ vs $\log \left(R_{\mathrm{ct}}{ }^{-1}\right)$ can be used as an alternative method $^{110-112}$ to the classical $E$ vs $\log (j)$ when accessing the value of the Tafel slope. The use of $1 / R_{\mathrm{ct}}$ is simply due to the fact that $R_{\mathrm{ct}}$ is inversely proportional to the rate constant (thus to the current/current density too), which is a function of the applied potential for a heterogeneous electron-transfer reaction. ${ }^{74} \mathrm{Fig}$. 5 e shows an example where $b=127$ and $118 \mathrm{mV} \mathrm{dec}^{-1}$ before and after iR-drop correction, respectively. Furthermore, the description of the $\mathrm{CV}$ of an organic molecule can be finalized by collecting CVs for different scan rates $v=1-200 \mathrm{mV} \mathrm{s}^{-1}$ and by 
plotting $\log \left(j_{\text {peak }}\right)$ vs $\log (v)$ where: (i) slope $=1$ means that the reaction is limited by adsorption (reactants), (ii) slope $=0.5$ means that the reaction is limited by diffusion (reactants and products), (iii) slope $=0.5-1$ means that the reaction is limited by both adsorption and diffusion, and (iv) slope $<0.5$ is translated to as a complex process (adsorption, diffusion, electron transfer). In tandem with classic CV/LSV for substrate and electrolyte concentration effects (orders of reaction, etc.), experiments should be performed at different temperatures for the assessment of the electrochemical activation energy, an important kinetic parameter indicating the activation energy barrier to overcome before the reaction occurs. ${ }^{51}$ Finally, as a routine, solutions should be outgassed by bubbling an inert gas such as $\operatorname{Ar}$ or $\mathrm{N}_{2}$ prior to electrochemical measurements (the use of $\mathrm{N}_{2}$ should be justified for low potentials, $E<-0.7 \mathrm{~V}$ vs RHE, since the catalysts could be active for the electrocatalytic $\mathrm{N}_{2}$ reduction reaction, thus modifying the efficiency). ${ }^{113,114}$

3.2.2. Multivariate intermediates and products analysis: in-situ versus ex-situ. Traditional "pure electrochemical methods" (CV, LSV, etc.), whereby electrode activity and dynamics can be visualized in the form of graph, do not provide any specific information on the products and/or intermediates. Whereas ex situ methods allow assessing the final product(s), the use of in situ measurements helps to rationalize an electrochemical process in order to determine the reaction mechanism. The coupling of electrochemical measurements with spectroscopic, spectrometric and chromatographic methods enables improved understanding of the electrochemical processes at the electrode-electrolyte interface and more importantly, the governing mechanism. Spectroelectrochemistry, i.e., the coupling, for example, of Fourier transform infrared spectroscopy (FTIRS) to electrochemistry experiments is an advanced online technique that enables one to qualitatively assess the nature of the reaction products/intermediates and determine the best electrode potential to be applied for bulk electrolysis during a constant potential electrolysis program. Indeed, high-performance liquid chromatography (HPLC, HPLIC), mass spectrometry (MS) and nuclear magnetic resonance (NMR) give only the final and stable reaction products in solution. Spectroelectrochemistry, however, provides relevant and temporal data of high resolution that can be correlated directly with the underlying reaction pathways during an organic molecule electrooxidation. ${ }^{115-119}$ Depending on the configuration, it can enable the identification of adsorbed species on the electrode surface owing to their interaction with the radiation. A three-electrode spectroelectrochemical cell typically has a $\mathrm{CaF}_{2}$ infrared (IR) transparent window allowing the beam to pass through a thin layer of electrolyte and to be reflected at an incidence angle. The working electrode consists of a catalytic ink deposited onto a highly reflecting support pressed against the $\mathrm{CaF}_{2}$ window to obtain a thin layer of electrolytic solution in order to avoid excessive IR beam absorption. Those temporally resolved spectra can be recorded in two different ways. Scanning the electrode potential through CV or LSV known as "single potential alteration infrared spectra (SPAIRS)" is the first method. It consists of recording the electrode reflectivity at different potentials in steps of $10-100 \mathrm{mV}$ at a quasi-steady state scan rate of $0.5-2 \mathrm{mV} \mathrm{s}^{-1}$. Fixing the potential/current and recording spectra at different dwelling times of few seconds to minutes is the second method. Although the data from spectroelectrochemistry are temporally resolved, the approach however often provides qualitative results in addition to the frequent overlaps and uncertainties in the assignment of the bands. Another method might be differential or online electrochemical mass spectrometry (DEMS, OLEMS), which allows for the identification of volatile species. ${ }^{120,121}$ Given that the products are not always volatile and intermediates of short lifetime cannot be detected and quantified by DEMS, HPLC (elution by acidic force) and HPLIC (elution by conductivity strength) seem to be the appropriate techniques for investigating the organic molecules oxidation products (aldehydes, ketones, and carboxylic acids) both at a qualitative and quantitative levels, performed offline ${ }^{13,51,120-123}$ and even online. ${ }^{124}$ After bulk electrolysis, in addition to standard separation/purification methods, samples from the reaction media could be passed through an ionic resin to remove electrolytic salts; in the case of alkaline solutions, carboxylates are converted to their protonated forms. The recovered aqueous solution containing the organic species is frozen and Iyophilized to remove water by sublimation. Few attempts have been reported for the isolation of the reaction products; ${ }^{36}$ this well-known practical problem can be very strenuous in aqueous media. ${ }^{50}$ Furthermore, the ex situ analysis by LC-MS in negative or positive ionization mode enables the determination of the molecular weight of the products. Standard 1D and 2D NMR techniques of ${ }^{1} \mathrm{H},{ }^{13} \mathrm{C},{ }^{1} \mathrm{H}-{ }^{1} \mathrm{H},{ }^{1} \mathrm{H}-{ }^{13} \mathrm{C}$, and DEPT-135 (to differentiate $\mathrm{CH}_{3}$ and $\mathrm{CH}$ signals to that of $\mathrm{CH}_{2}$ ) as well as other heteroatoms' NMR enable to improve assignments towards an unambiguous identification.

\section{Advancements in $\mathrm{C2}$ and $\mathrm{C} 3$ alcohols electrocatalysis for organic electrosynthesis}

\subsection{Nanostructured electrocatalysts for active and selective C2 and $\mathrm{C} 3$ alcohols oxidation}

The range of materials that have been explored for the oxidation of C2-C3 alcohols is relatively broad, ranging from "platinum group" or "noble" metals to transition metals and those within the buzzword of "metal-free". When the main idea behind the development of nanostructured catalysts for the oxidation of organic molecules is the efficiency with the lowest overpotential and the best selectivity towards value-added product(s), any practical electrode materials should contain at least one element from $\mathrm{Pt}, \mathrm{Pd}, \mathrm{Ru}, \mathrm{Rh}$, and $\mathrm{Au}$. Of course, a catalyst without those elements can be used, but an efficient catalytic activity can be reached only at relatively high electrode 
potentials, about 1.3-1.9 V vs RHE, ${ }^{90,125-128}$ where the carbon support corrosion and C-C bond cleavage are highly probable. In the following discussions, we intentionally focus on the realistic systems of noble metals in the form of monometallic, alloy, core-shell, or porous at nanoscale.

The use of bulk polycrystalline and single-crystal surfaces for electrocatalytic processes serve only as guidelines to assess the performance descriptors. For a practical deployment, costeffective materials based on nanostructured interfaces should be found. Furthermore, the design principles to tailor such advanced electrocatalysts should allow the presence of terraces, defects, nanoparticles (NPs) polydispersity, shapes, morphologies and compositions. The improvement in activity of pure monometallic $\mathrm{M}_{1}\left(\mathrm{M}_{1}=\mathrm{Pt}, \mathrm{Pd}, \mathrm{Ru}, \mathrm{Rh}, \mathrm{Au}\right)$ catalysts due to the presence of a second metal $\mathrm{M}_{2}$ (from transition metals to those of the previous list) is thought to be a combination of a bifunctional mechanism and ligand effects. ${ }^{18,20,26,129-141}$ According to the bifunctional effect, a partially oxidized transition metal $M_{2}$ provides oxygenated species $\left(M_{2}-(O H)_{x}\right)$ which allow the optimal oxidation. In heterogeneous electrocatalysis, this is known as the Langmuir-Hinshelwood mechanism. On the other side, the ligand effect considerations imply that the second metal $M_{2}$ leads to changes in the electronic structure of the main metal $M_{1}$, which entail the weakening of the $\mathrm{M}_{1}$-intermediate (product) bond. Hence, any strategy to obtain a high-performance material should advisedly be based on these two approaches. Among the different methods for the preparation of nanoelectrocatalysts, the use of colloidal routes is the most conventional approach. These methods are characterized by the chemical reduction of the metallic precursor in the presence of a capping agent or surfactant, electrodeposition, radiolysis, decomposition of bulk metals into NPs (laser ablation) and atomic layer deposition (ALD) routes. ${ }^{13-16,18-20,119,122,127,136,142-171}$ Different carbon substrates based on Vulcan, Ketjenblack, nanotubes, graphene are currently used in catalysis. The goal is to achieve a good dispersion of NPs, minimal amount of the metal content and good support-active site interactions. Those substrates are electrically conductive, chemically stable and have high BET surface area (few hundreds of square meter per gram). Vulcan types are $X C 72$ and $72 R^{172,173}$, and the metal content goes from 20 to 60 wt.\%. It should be noted that in gas-phase heterogeneous catalysis (activation results from temperature or pressure change), the metal loading on the support is typically 0.1-1 wt.\%. However, because of the reduced masstransport rates of the reactant molecules in the liquid phase (electrocatalysis) versus the gas phase, the metal content in an electrocatalyst must be at least $10 \mathrm{wt} . \% .{ }^{79}$ Furthermore, if Vulcan will be used as support, it is highly desired to perform a thermal pre-treatment to remove potential contaminants coming from the industrial manufacturing process such as sulphur. It also augments the electrochemically active surface area (ECSA) and catalytic activity of metallic NPs such as Pt. ${ }^{174}$

Figs. 6a-d show the transmission electron microscopy (TEM) images of Pt-Pd-Ru/C synthesized by the microwave-assisted heating method, ${ }^{16,175}$ which involves a mixture of metal precursors, propylene glycol (solvent and reductant), Vulcan XC
72 , sodium acetate (stabilizing agent), sodium hydroxide (to reach a $\mathrm{pH}$ of 10) and hydrazine (co-reducing agent). From Fig. $6 \mathrm{e}$, it can be observed that the presence of Ru notably boosts the electroactivity of $\mathrm{Pd}$ and $\mathrm{Pt}$; the mass current density at the peak follows the order $\mathrm{Pt}_{86} \mathrm{Ru}_{14} / \mathrm{C}>\mathrm{Pd}_{71} \mathrm{Ru}_{29} / \mathrm{C}>\mathrm{Pd} / \mathrm{C}>\mathrm{Pt} / \mathrm{C}$. It can also be seen that $\mathrm{Pt}_{86} \mathrm{Ru}_{14} / \mathrm{C}$ has at least $100 \mathrm{mV}$ negative shift of the onset potential (0.5 V vs RHE compared to 0.6-0.7 V vs RHE for other electrodes). Since the NPs have the same size distribution of 2-5 nm, the significant improvement of the electrocatalytic activity for bimetallic systems can be explained by a dual combination of bifunctional and ligand effects. The difference in terms of the onset potential when Ru is associated with Pt or Pd should result from an initial step that obviously does not occur at Ru actives sites. This activation undoubtedly has a correlation with the adsorption of glycerol and more likely $\mathrm{OH}^{-}$since $\mathrm{Pt}-\mathrm{OH}$ species can be formed at a lower potential than $\mathrm{Pd}-\mathrm{OH}$, which has been routinely used to explain the excellent oxidation of $\mathrm{CO}$ in alkaline media at $\mathrm{E} \leq 0.5 \mathrm{~V}$ vs RHE. ${ }^{119}$ The materials reported by Palma et al. ${ }^{16}$ have been found to exhibit good stability in $1 \mathrm{M} \mathrm{NaOH}+0.5 \mathrm{M}$ glycerol as determined by controlled potential electrolysis at $E=0.7 \mathrm{~V}$ vs RHE. Electrolysis in a H-type Pyrex cell using an anion-exchange membrane (Fumasep, FAA, Fumatech) and HPLC analysis reveal that the major oxidation product is glycerate (4-electron selectivity) at Pd-based electrodes and 1,3-dihydroxyacetone (DHA) at Ptbased electrodes. The results imply that the adsorption of glycerol occurs through either one of the primary alcohol function at the extremity of the molecule or the secondary alcohol function, depending of the nature and the composition of the electrode. Those trends in selectivity are in agreement with seminal observations at bulk and nano-electrodes in alkaline media.116,118,121,176 Koper's group combined online HPLC, OLEM and spectroelectrochemistry to show that on the $\mathrm{Pt}(111)$ electrode, glyceraldehyde, glyceric acid, and DHA are the products of glycerol oxidation, while on the $\mathrm{Pt}(100)$ electrode, glyceraldehyde was detected as the main product of the reaction in acidic media. ${ }^{176}$ Glyceraldehyde is not a stable compound in alkaline media, undergoing a conversion into glycerate. Furthermore, $\mathrm{Bi}$ has been found to be a co-catalyst that induces a 2-electron pathway by the secondary alcohol group of glycerol into DHA. ${ }^{118}$

There was no direct physicochemical evidence that the catalysts reported by Palma et al. ${ }^{16}$ are alloy, core-shell or "simple bimetallic (made of individual particles)" systems. Figs. $6 \mathrm{f}-\mathrm{I}$ show examples of alloy phases that have been screened for C1-C3 electrooxidation (methanol, ethanol, ethylene glycol, and glycerol) in alkaline media. Fig. $6 f$ displays the high-angle annular dark field aberration-corrected scanning transmission electron microscopy (HAADF-STEM) coupled energy dispersive $\mathrm{X}$-ray spectroscopy (EDS) elemental mapping images of CNTs supported PdAg NPs, prepared by an aqueous-phase reduction method. ${ }^{177,178}$ Those of the unsupported PdPt nanowire networks ${ }^{136}$ are reported in Figs. 6e-l. It was found from X-ray photoelectron spectroscopy (XPS) that the alloying of Ag to Pd prevents the oxidation of $\mathrm{Pd}$ atoms leading to metallic $\mathrm{Pd}(0)$, while the majority of the Pd surface in the monometallic Pd/CNT is in the oxidized state $\mathrm{Pd}(+\mathrm{II}) .{ }^{177} \mathrm{As}$ shown in Fig. $6 \mathrm{~m}$, the 
synthesis of PdPt nanowire networks by mixing $\mathrm{H}_{2} \mathrm{PtCl}_{6}$, $\mathrm{Na}_{2} \mathrm{PdCl}_{4}, \mathrm{KBr}$, polyvinylpyrrolidone (PVP) and $\mathrm{NaBH}_{4}$ leads to alloys, whereby the binding energies of $\mathrm{Pt}$ and $\mathrm{Pd}$ shift significantly. The $P t 4 f_{7 / 2}$ peak of $P d P t$ is about 1.1-1.3 eV lower than that of pure $\mathrm{Pt}$, whereas that of $\mathrm{Pd} 3 \mathrm{~d}_{5 / 2}$ negatively shifts by about $1.1 \mathrm{eV}$ compared with monometallic Pd. ${ }^{136,179}$ XPS patterns of alloyed $\mathrm{PdNi}, \mathrm{PdAu}$, and $\mathrm{PdAuNi}$ nanosponges ${ }^{18}$ also highlighted a shift of Pd energy level. These electronic modifications can be corroborated to the increase in electrocatalytic performance, as shown in Fig. $6 \mathrm{n}$ for glycerol electrooxidation in $1 \mathrm{M} \mathrm{KOH}$. The electroanalytical investigation is still remaining at those exotic materials of nanosponges or nanowires to determine whether the change in electronic states may affect the selectivity trend or not.
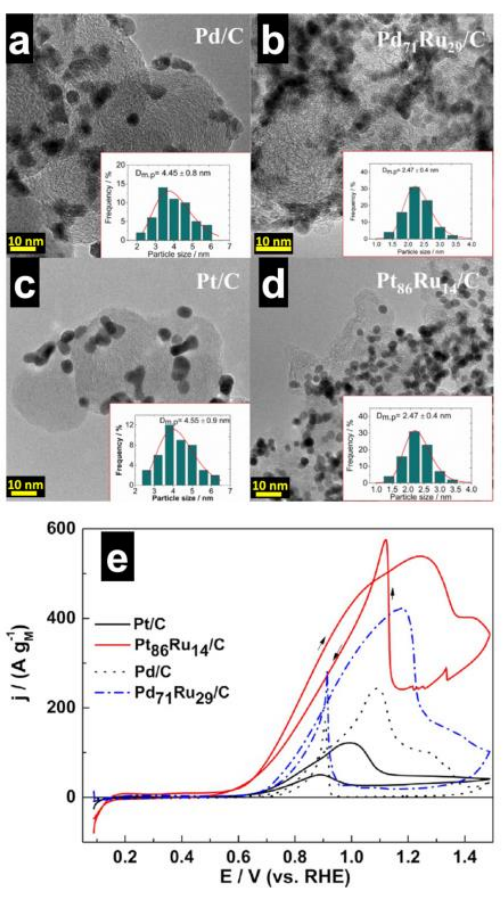
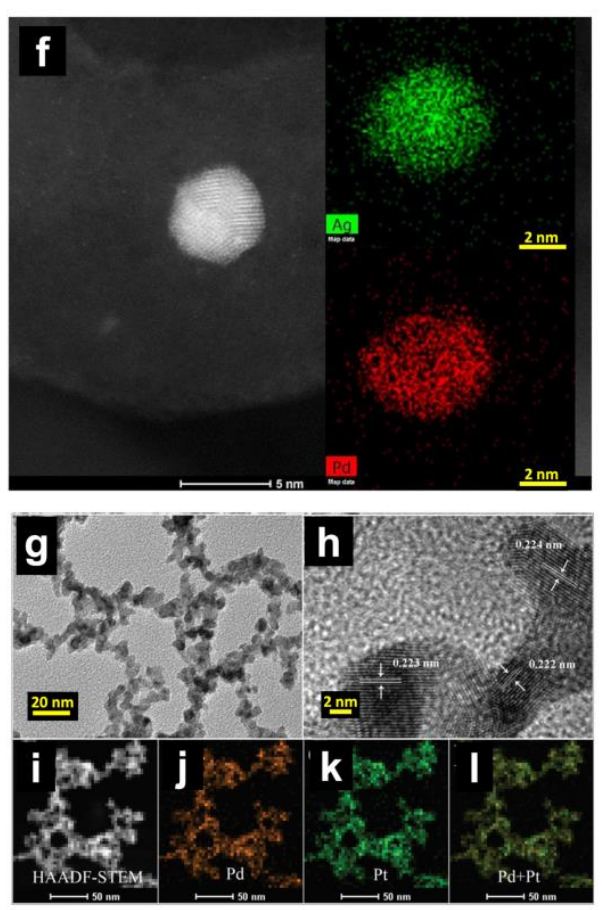
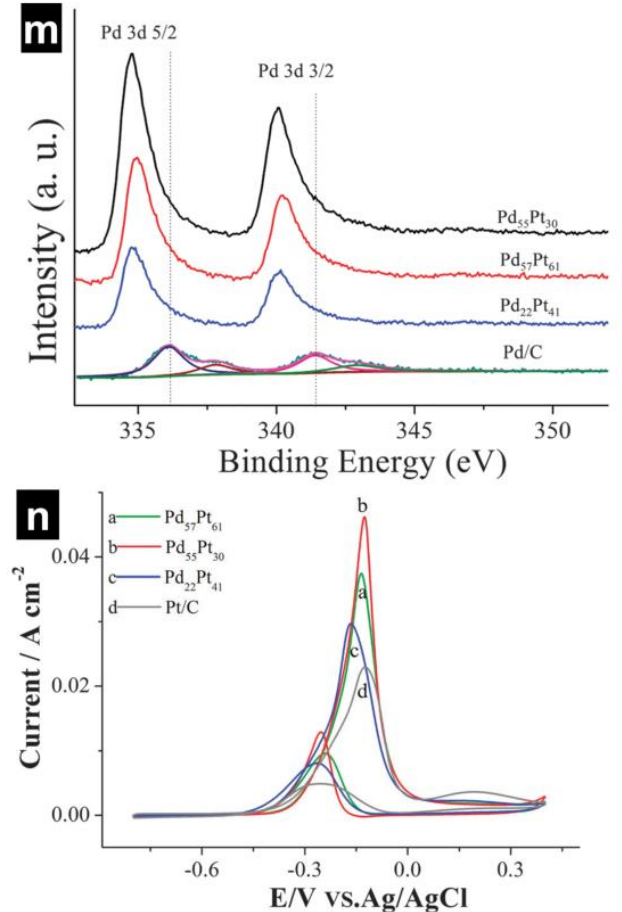

Fig. 6. (a-d) TEM images of Pd-based and Pt-based nanoparticles dispersed on Vulcan XC-72 carbon at 40 wt.\% metal loading (in insets histograms of the particles size distribution) and the corresponding CVs at $10 \mathrm{mV} \mathrm{s}^{-1}$ in $1 \mathrm{M} \mathrm{NaOH}$ in the presence of $1 \mathrm{M}$ glycerol (e). (f) HAADF-STEM-EDS mapping images of a single PdAg of PdAg/CNT catalyst. (g-n) PdPt nanowire networks (NNWs) characterization and performance: (g) TEM, (h) HRTEM, (i) HAADF-STEM, (j-l) elemental mapping, (m) XPS of Pd $3 d$ and ( $\mathrm{n}$ ) CVs at $50 \mathrm{mV} \mathrm{s} \mathrm{s}^{-1}$ in $1 \mathrm{M} \mathrm{KOH}$ + $0.1 \mathrm{M}$ glycerol. (a-e) Reprinted and adapted with permission from Ref. ${ }^{16}$; Copyright 2017, Wiley-VCH Verlag GmbH\&Co. KGaA, Weinheim. (f) Reprinted and adapted with permission from Ref. ${ }^{177}$; Copyright 2017, Elsevier B.V. (g-n) Reprinted and adapted with permission from Ref. ${ }^{136}$; Copyright 2015 , The Royal Society of Chemistry.

Another important point to consider during the nanostructuration of electrocatalysts is the "utilization efficiency", which depends not only on the NPs size, but also on the used synthesis method. Indeed, the presence of organic molecules in the synthesis reactor can constitute a problem in electrochemical applications because it might block some catalytic active sites. Indeed, the presence of organic compounds residues initially introduced as "surfactant or capping agents" and strongly tethered to the surface of the NPs frequently leads to the poisoning of the active sites in terms of either "activity" or "selectivity". To come up with that, the best compromise in cleaning methods to remove those organics without perturbing the NPs shape is based on chemical/thermal treatments or a relatively fast electrochemical potential cycling at a scan rate of $100-500 \mathrm{mV} \mathrm{s}{ }^{-1} .^{180-183}$ Ideally, surfactant-free methods for the synthesis of nano-electrocatalysts is the best option, such as those reported in Refs. ${ }^{13,14,51,166,184,185}$ Indeed, it was reported that the $\mathrm{PdAg} / \mathrm{C}$ and $\mathrm{PdNi} / \mathrm{C}$ nanomaterials synthesized by the bromide anion exchange method mainly catalyse glycerol electrooxidation to glycerate and glycolate, as evaluated by ionic chromatography, spectroelectrochemistry and LC-MS. ${ }^{13,186,187}$ This surfactant-free method employs only $\mathrm{KBr}$ as an ionic capping agent to regulate the NPs.

Monometallic and alloy nanomaterials are the conceptually simplest approach to fabricate an electrocatalyst. A second class of materials that can be used as electrode materials is core-shell $M_{1} @ M_{2}$ and porous NPs or core-shell (Fig. 7a). Among the metals of interest for organics electrooxidation, $\mathrm{Au}$ provides the best performance in terms of stability. So using $M_{1}$ $=\mathrm{Au}$ as the core element to design and synthesize active coreshell electrocatalysts has been found to be an elegant strategy that combines a high density of low-coordinated second metal $\mathrm{M}_{2}$ atoms at the NPs surface with the Au core to modulate the electronic structure of the $M_{2}$ shell. ${ }^{55,162,163}$ Indeed, the shell thickness can be used as an effective tool to tightly regulate the synergistic effect between the two metals, thus the catalytic properties. Depending on $M_{2}$, an upshift of the $d$-band centre may occur, induced mainly by the expansion of the lattice, which may accelerate the removal of the poisoning intermediates during the alcohol oxidation and the suppressing of the shell oxidation. ${ }^{55,162}$ Miller et al. ${ }^{55}$ probed the performance of carbon-supported Au@Pd core-shell NPs (Figs. 
7b-e) towards C2-C3 alcohols electrooxidation: ethanol (EtOH), ethylene glycol (EG), glycerol (G), 1,2-propanediol (1,2-P), 1,3propanediol (1,3-P), and 1,4-butanediol (1,4-B). The STEM-EDX maps show that the size of the Au@Pd core-shell NPs is ca. 10$12 \mathrm{~nm}$ with a Pd shell thickness of $\sim 2 \mathrm{~nm}$. Fig. $7 \mathrm{f}$ shows that the electrooxidation of $\mathrm{EtOH}$ occurs much earlier than other alcohols with an onset potential of $0.35 \mathrm{~V}$ vs RHE, about $200 \mathrm{mV}$ lower than $\mathrm{G}$ and $\mathrm{EG}$. This result is expected since the chemical structure of EtOH is far less complex than those of EG and $G$ that has two $-\mathrm{OH}$ functions. Electrolysis in a flow reactor equipped with an AEM (Tokuyama A201) demonstrated that EtOH is selectively oxidized to acetate without $\mathrm{C}-\mathrm{C}$ bond cleavage (4electron selectivity), G oxidation leads to $\mathrm{C}-\mathrm{C}$ bond scission resulting in a mixture of products (tartronate, oxalate, glycolate, formate), while EG and 1,2-P yield to glycolate and lactate, respectively. ${ }^{55}$

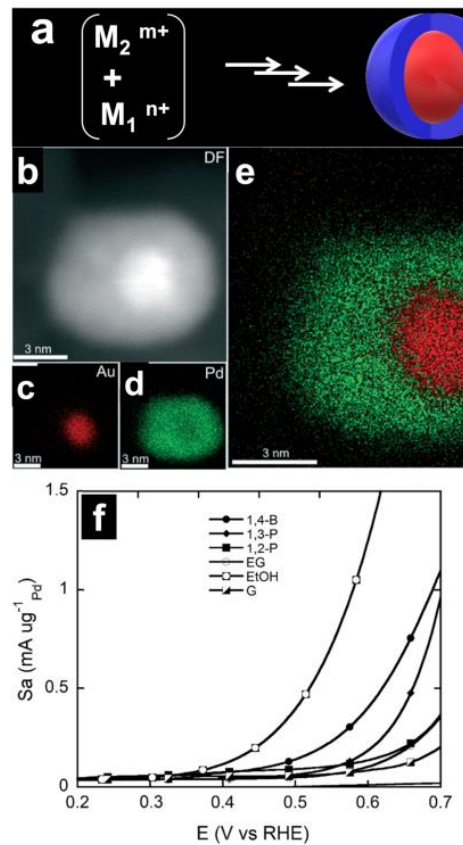

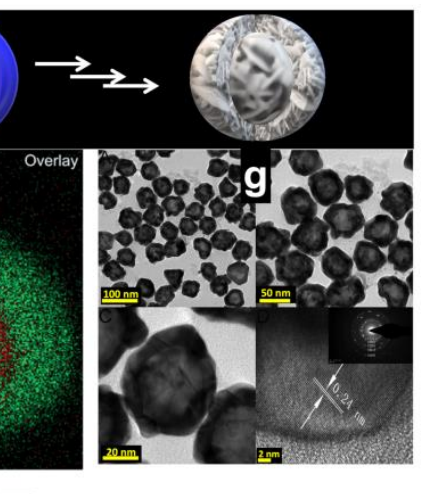
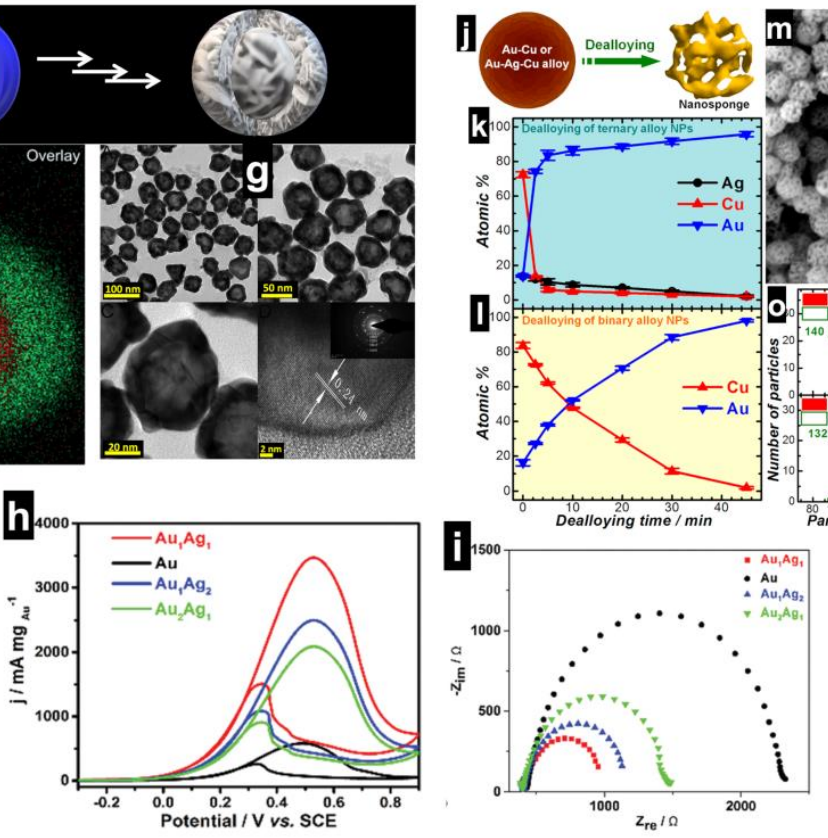

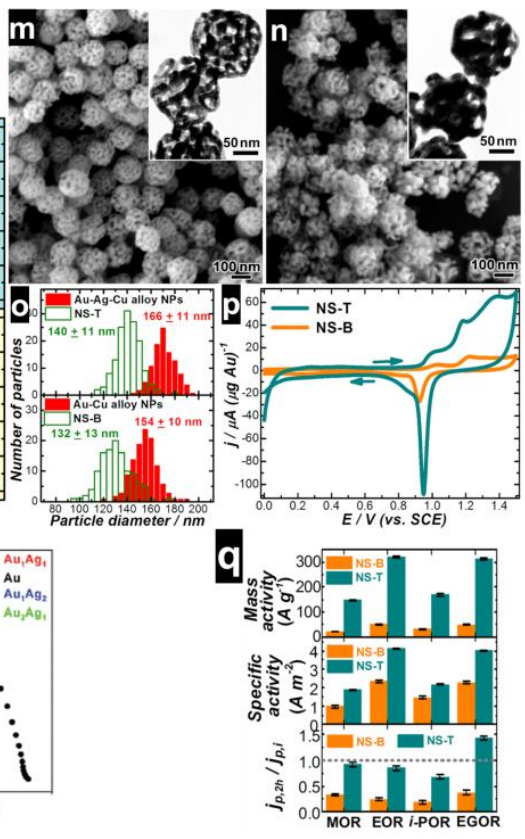

Fig. 7. (a) Nanoalloys and nanoporous alloys fabrication routes. (b-f) Carbon supported Au-Pd core-shell NPs: (b) Dark-field TEM; (c) STEM-EDX map showing of Au; (d) STEM-EDX map of Pd; (e) STEM-EDX map shown as an overlay of both Au and Pd signals; (f) CVs at $10 \mathrm{mV} \mathrm{s}^{-1}$ and recorded in $2 \mathrm{M} \mathrm{KOH}$ and in the presence of $2 \mathrm{M}$ alcohol. (g-i) Hollow AuxAg/Au core/shell nanospheres and their performance: (g) TEM, HRTEM and SAED images; (h) CVs at $50 \mathrm{mV} \mathrm{s}^{-1}$ in $1 \mathrm{M} \mathrm{KOH}+1 \mathrm{M}$ glycerol and the corresponding Nyquist plots at $0.3 \mathrm{~V}$ vs SCE (i). ( $\mathrm{j}$-q) Strategies towards dealloyed gold nanosponges (NS) and their performance: (j) Schematic illustration of the percolation dealloying of alloy NPs; Temporal evolution of particle compositions during the percolation dealloying of ( $\mathrm{k}$ ) $\mathrm{Au}_{0.14} \mathrm{Ag}_{0.14} \mathrm{Cu}_{0.72}$ trimetallic alloy NPs (NS-T) and (I) $\mathrm{Au}_{0.16} \mathrm{Cu}_{0.84}$ bimetallic alloy NPs (NS-B) in $3 \mathrm{M} \mathrm{HNO}$ (error bars represent the standard deviations of three samples); SEM images and TEM images (insets) of $(\mathrm{m})$ NS-T and (n) NS-B; (o) Size distributions of NS-T, NS-B, and alloy NPs; ( $p$ ) CVs at 5 $\mathrm{mV} \mathrm{s}^{-1}$ of NS-T and NS-B in $0.5 \mathrm{M} \mathrm{H}_{2} \mathrm{SO}_{4}$; (q) Peak current density and stability from CVs recorded at $5 \mathrm{mV} \mathrm{s}^{-1}$ in $0.5 \mathrm{M}$ KOH containing different alcohols ( $1 \mathrm{M}$ methanol, $1 \mathrm{M}$ ethanol, $1 \mathrm{M}$ isopropanol, $0.25 \mathrm{M}$ ethylene glycol), stability referred to as CA performed at $0.20 \mathrm{~V}$ vs SCE for $2 \mathrm{~h}$ (error bars represent the standard deviations of five samples). (b-f) Reprinted and adapted with permission from Ref. ${ }^{55}$; Copyright 2016, The Royal Society of Chemistry. (g-i) Reprinted and adapted with permission from Ref. ${ }^{15}$; Copyright 2017 , The Royal Society of Chemistry. (j-q) Reprinted and adapted with permission from Ref. ${ }^{188}$; Copyright 2016, American Chemical Society.

Table 1 summarizes the performance of those anode materials. The above discussion showed that alloys and coreshell nanostructures enable substantial improvements to the electrocatalytic responses for the oxidation reaction of organic molecules. In electrocatalysis, however, it is possible to combine these two advantages and develop nanoporous and nanoalloyed structures comprising either binary or ternary systems via a combination of seed mediated growth and galvanic replacement methods. ${ }^{15,163,188-197}$ In the case of Aubased electrocatalysts, Ag NPs routinely act as the template during the galvanic displacement since the standard redox potential of $\mathrm{Ag}^{+} / \mathrm{Ag}$ is greatly lower than that of $\mathrm{AuCl}_{4}{ }^{-} / \mathrm{Au}, 0.80$ $\mathrm{V}$ vs. SHE compared to $1.00 \mathrm{~V}$ vs. SHE. Hence, the galvanic replacement reaction can contribute to the formation of hollow nanostructures. $\mathrm{Xu}$ et al. $^{15}$ synthesized hollow $\mathrm{Au}_{x} \mathrm{Ag} / \mathrm{Au}$ core/shell nanospheres (Fig. $7 \mathrm{~g}$ ) by injecting $\mathrm{HAuCl}_{4}$ aqueous solution into an aqueous mixture of trimethyl ammonium chloride (CTAC, capping agent, surfactant) and ascorbic acid (AA, mild reducing agent); before introducing pre-prepared $\mathrm{Ag}$ seeds. In this procedure, the tight control of the competition between the galvanic displacement (between $\mathrm{AuCl}_{4}{ }^{-}$and $\mathrm{Ag}$ ) and co-reduction $\left(\mathrm{AuCl}_{4}{ }^{-}\right.$and $\mathrm{Ag}^{+}$ions by $\mathrm{AA}$ followed by their co-deposition on the pristine $\mathrm{Ag}$ ) phenomena at different rates allows regulation of the different types of hierarchical nanostructures of "Au-Ag" core and "Au" shell. ${ }^{15,196,198-203}$ The combination of the etching, growth and nanostructuration provides a smart route to carving out new designs in metal nanofabrication in order to target high electrocatalytic performance such as those displayed in Fig. $7 \mathrm{~h}$. The hollow nanospheres have a shell thickness of about $10 \mathrm{~nm}$. In details, the mass activity trend is $\mathrm{Au}_{1} \mathrm{Ag}_{1}\left(3486 \mathrm{~mA} \mathrm{mg} \mathrm{Au}^{-1}\right)>\mathrm{Au}_{1} \mathrm{Ag}_{2}$ (2556 mA mg $\left.{ }^{-1}{ }^{-1}\right)>A_{2} A_{1}$ (2158 mA mg ${ }^{-1}$ ) > Au (602 mA $\mathrm{mg}_{\mathrm{Au}^{-1}}{ }^{-1}$, considering the bulk chemical compositions. Note that monometallic $\mathrm{Ag}$ is inactive in the considered electrode 
potential window. Deeper electrochemical analysis by EIS shows, from the Nyquist plots at $0.3 \mathrm{~V}$ vs SCE (Fig. 7i), that the charge-transfer resistance, $R_{\mathrm{ct}}$, of the core-shell electrocatalysts is significantly lower than that of the monometallic $\mathrm{Au}\left(R_{\mathrm{ct}}\right.$ is the diameter of the depressed semi-circle). It can be observed from Fig. 7i that for all materials, the plots start roughly at the same position, which was expected since the ohmic resistance, $R \Omega$, does not change tremendously (both $\mathrm{Ag}$ and $\mathrm{Au}$ are excellent electrical conductors at the working electrode, so they do not impact the total ohmic resistance). However, no electrolysis was performed with those porous materials to determine if the change in the morphology and composition could be impacting the selectivity trend or not. Figs. 7j-q show the results obtained by $\mathrm{Li}$ et al. ${ }^{188}$ who used the percolation dealloying of multimetallic alloys ${ }^{204-208}$ to intentionally dismiss a less-noble metal together with the nano-restructuration of the more noble one to give up to sponge-like nanoporous architectures with a unique set of structural characteristics of high interest for heterogeneous catalysis. The monitoring of the process to investigate the dealloyed nanosponge (NS) obtained after dealloying in $3 \mathrm{M} \mathrm{HNO}_{3}$ of $\mathrm{Au}_{14} \mathrm{Ag}_{14} \mathrm{Cu}_{72}$ ternary alloy (NS-T) and $\mathrm{Au}_{16} \mathrm{Cu}_{84}$ binary alloy NPs (NS-B), demonstrates that at $45 \mathrm{~min}$, the leaching of $\mathrm{Ag}$ and $\mathrm{Cu}$ is quite finished (residual $\mathrm{Cu}$ and $\mathrm{Ag}$ both below 2 at.\%). Surprisingly, the electrocatalytic tests in 0.5 $\mathrm{M} \mathrm{KOH}$ electrolytic solution in the presence of different $\mathrm{C} 1-\mathrm{C} 3$ alcohols ( $\mathrm{MeOH}, \mathrm{EtOH}$, iPr, EG) shows that the best efficiency is reached for those nanosponges materials. It is striking to see from the CV profiles of NS-B and NS-T electrodes within Fig. 7p that during the cathodic sweep, the peak current associated with the surface oxide reduction (formed during the anodic sweep) at 0.9-1.0 V vs SCE is unusually strong (the same amount of NS $(4.0 \mu \mathrm{g})$ was immobilized onto a glassy carbon electrode of $3 \mathrm{~mm}$ diameter). The associated ECSA is ca. 4 times higher for NS-T $\left(80 \mathrm{~m}^{2} \mathrm{~g}^{-1}\right)$ compared to NS-B $\left(22 \mathrm{~m}^{2} \mathrm{~g}^{-1}\right)$. The same trend has been observed for the electrocatalytic responses in the presence of substrates (Fig. 7q), which would mean that Ag is playing a key role. It is argued that residual $\mathrm{Ag}$ could stabilize the surface active sites during not only the dealloying, but also the electrocatalytic reactions. ${ }^{188}$ The authors observed from XPS measurements that while the binding energy of the Au $4 f$ peak remains essentially unchanged in regards to those of bulk $\mathrm{Au}$, both the $\mathrm{Cu} 2 \mathrm{p}$ and $\mathrm{Ag} 3 \mathrm{~d}$ peaks significantly down-shift by 0.4 and $0.5 \mathrm{eV}$, respectively compared to their bulk materials. This set of results underpins the conclusion that residual $\mathrm{Ag}$ and $\mathrm{Cu}$ remained alloyed with Au participate in its electrocatalytic activity increase in addition to the 3D networks that maximize the exposed number of low coordinated atoms. ${ }^{188,209}$

During the last two years, numerous studies showed that other types of electrocatalysts from the above systems to interface-confined hierarchically structured 2D catalysts composed of $\mathrm{Pt}, \mathrm{Pd}, \mathrm{Ag}$, and $\mathrm{Au}$ can enable reaching selectively a 2-electron product from glycerol electrooxidation (in H-type cells), either glyceraldehyde usually trapped because of stability issues (for example by 2,4-dinitrophenyl-hydrazine (2,4-DNPH) solution ${ }^{10}$ ) or dihydroxyacetone. ${ }^{197,210-213}$ This is interesting given the high price of those chemicals compared to the starting material, i.e., glycerol. However, the guiding principle or the driving force behind the selectivity in electrocatalysis or organics in aqueous media is something that is particularly surprising, intriguing and unsolved in literature. This is mainly due to the possibility allowed by electrocatalysis, at a given pressure and temperature (the main regulators in heterogeneous catalysis), to "manipulate" the electrochemical interface by changing the amplitude of the applied electrode potential in a three-electrode adjustment. This has the direct consequence of changing the surface state, and precisely the nature and type of chemical species at the electrode-electrolyte interface, i.e., the adsorption behaviour thereof. Zhou and Zhen observed in 2018 that at a Pd/C-based electrode in a solution of $0.5 \mathrm{M}$ glycerol $+0.5 \mathrm{M} \mathrm{KOH}$, the selectivity towards glyceraldehyde increases while that of the oxalic acid decreases significantly with increasing the applied potential from -0.4 to $0.2 \mathrm{~V}$ vs SCE (about 0.6 to $1.2 \mathrm{~V}$ vs RHE); the selectivity of glyceric acid is kept unchanged. ${ }^{211}$ At nanocubes (Pd NCs) dominated by (100) crystallographic facets, the highest glyceraldehyde selectivity (with the presence of tartronic acid (TA)) was recorded among Pd/C, Pt/C, Pd NCs and Pt@Pd NPs; and interestingly, the applied potential shows limited effects in the selectivity of glyceraldehyde and oxalic acid. At Pt@Pd NPs, glyceric acid is detected with the highest selectivity. Taken together, all those results would indicate that, at Pd-based catalysts, glycerol is first converted into glyceraldehyde via a two-electron transfer process, which is much facilitated at nanocubes because of the dominant $\operatorname{Pd}(100)$ facets that have the best driving force in terms of adsorption energy and binding configuration towards the reactant and intermediates.

Earlier in 2016, Garcia et al. ${ }^{176}$ combined experimental and computational studies of electrochemical glycerol oxidation in acidic media on $\mathrm{Pt}(111)$ and $\mathrm{Pt}(100)$ bulk electrodes and realized that at $\mathrm{Pt}(100)$ surface, the dehydrogenated glycerol intermediate binds to the surface through one double $\mathrm{Pt}=\mathrm{C}$ bond, yielding glyceraldehyde as the sole reaction product. However, at a $\mathrm{Pt}(111)$ surface, the dehydrogenated glycerol intermediate binds to the surface via two single $\mathrm{Pt}-\mathrm{C}$ bonds, yielding an enediol-like intermediate, which serves as a precursor to both glyceraldehyde and dihydroxyacetone. ${ }^{176}$ Since both Pt and Pd have a face-centred cubic $(f c c)$ structure, it can thus be summed up that (100) promotes the single binding of dehydrogenated glycerol, while a bridge binding is necessary at (111) surface. Hence, the synthesis methods should be designed in order to yield catalysts that satisfy criteria of several neighbouring and unoccupied active sites as well as allowing enough distance between those active sites if we want to give priority to the bridge binding. Furthermore, it can be readily evaluated for (100), (110) and (111) surfaces of a $f c c$ structure that the occupancy rate - defines to as the surface atoms density - is $78.5,55.5$ and $90.7 \%$, respectively (see calculations in Footnotes $\neq$ ). This would mean that, at dense surfaces, glycerol adsorption occurs via two sequential carbon atoms. This conclusion might hold for other types of polyol organics provided that the spatial conformation makes it possible, such as ethylene glycol but not necessary true for long chain organics, for example carbohydrates wherein the steric effects would prevail. 
The electrocatalytic selectivity can be handled by designing multicomponent catalysts (the most effective being bimetallic ones) where the control over the distance between active sites can be sufficient to manage the electrode performance or the foreign (second or third) atoms could block some adsorption pathway(s). Koper's group coupled online HPLC and in situ FTIRS to interrogate the electrooxidation pathways of glycerol at $\mathrm{Pt} / \mathrm{C}$ and $\mathrm{Bi}$-modified $\mathrm{Pt} / \mathrm{C}$ electrodes in acidic media. They came up with the conclusion that $\mathrm{Bi}$ not only blocks the pathway for primary alcohol function oxidation, but also provides specific $\mathrm{Pt}$ Bi surface sites for secondary alcohol oxidation, converting glycerol into dihydroxyacetone with a selectivity of $100 \%$, while glyceraldehyde would be obtained in the absence of $\mathrm{Bi}^{118}$ One of the reasons would be a specific coordination of glycerol and other polyols to $\mathrm{Bi}$ or $\mathrm{Bi}-\mathrm{M}\left(\mathrm{M}=\mathrm{Pt}, \mathrm{Pd}\right.$, etc.). ${ }^{118,214-217}$

Table 1. Comparative performance of nanostructured electrocatalysts for the C2 and C3 alcohols oxidation.

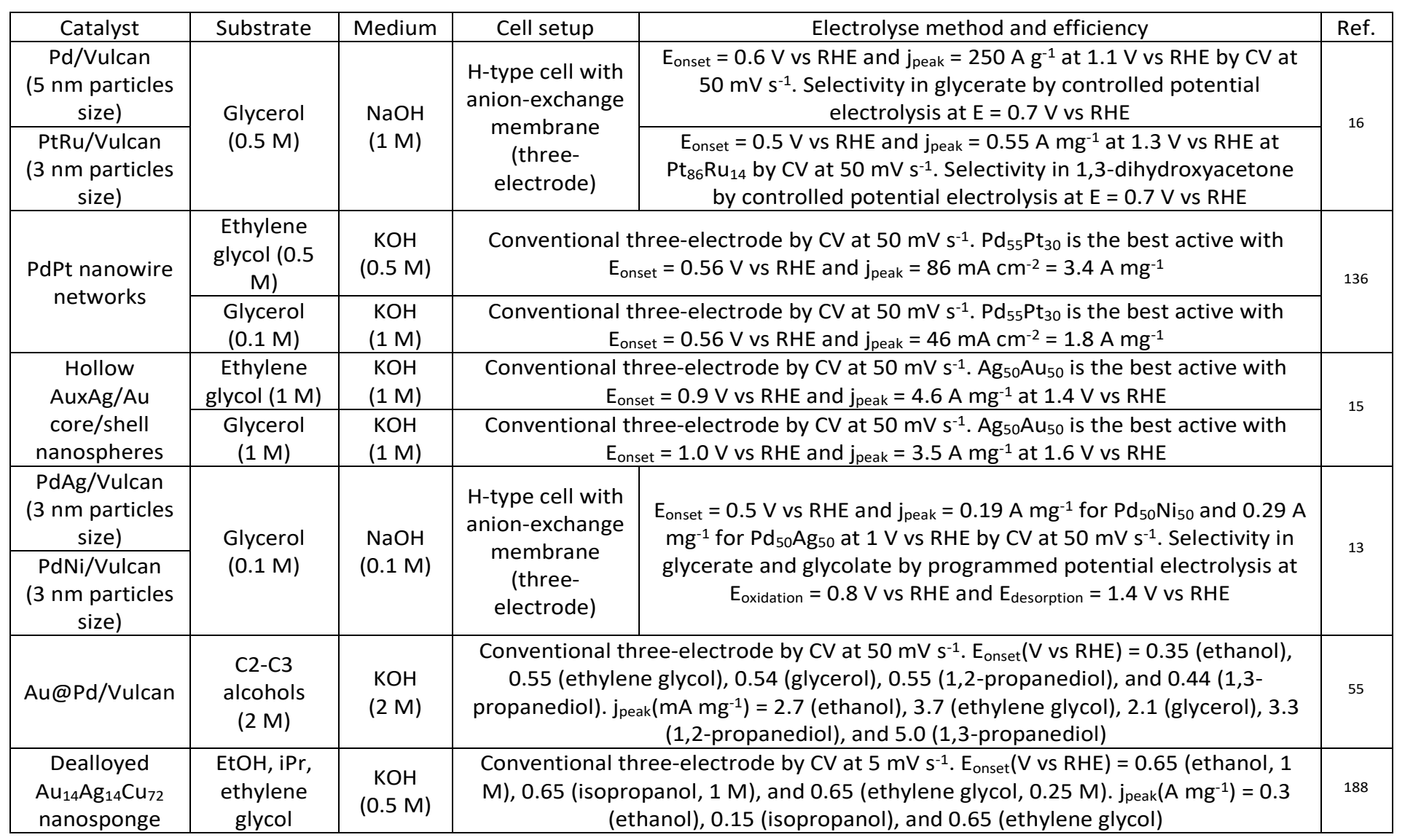

\subsection{Theoretical and computational insights in $\mathrm{C} 2$ and $\mathrm{C} 3$ alcohols oxidation}

Electrocatalysis is consistently facing the challenge of achieving results that move beyond the classic proof-of-concept towards industrial deployment. In fact, as in any field, the translation is crucial to maintain relevance and support the field. For that, experimentalists and theoreticians are moving forwards together to ensure that the knowledge gained from a model system of "an ideal catalyst" is used to tailor and fabricate "a practical catalyst" while new challenges arisen by the experience of prototype materials are sent back to model. ${ }^{77,218}$

Different theoretical approaches such as density functional theory (DFT) have been developed to examine the oxidation of C2-C3 alcohols, namely ethanol, ${ }^{219-222}$ ethylene glycol ${ }^{223}$ and glycerol.35,176,224-231 For the electrocatalysis community, the most extracted information is more valuable when a direct correction is made between DFT data wherein the Fermi level potential is commonly expressed in "eV" and those of the electrode/electrical potential traditionally articulated as " $\mathrm{V}$ vs $\mathrm{SHE}$ " or in the best case as " $\mathrm{V}$ vs RHE" (RHE being the universal electrochemical reference that does not depend on the $\mathrm{pH}$ of the electrolytes). The relationships of the potential $E$ between the "vacuum scale" and "electrochemical scale" are given below by Eqs. (15-16). ${ }^{232-239}$

$$
\begin{array}{r}
E(e V)+E(V \text { vs SHE })=-0.44 \\
E(e V)+E(V \text { vs } R H E)=-0.44+\frac{2.3 R T}{F} p H
\end{array}
$$

Miao et al. 221,240,241 used DFT calculations to access the C-C and $\mathrm{C}-\mathrm{H}$ scissions at the catalytic surfaces of transition metals $\mathrm{Ni}, \mathrm{Cu}, \mathrm{Ru}, \mathrm{Rh}, \mathrm{Pd}, \mathrm{Ag}, \mathrm{Ir}, \mathrm{Pt}$, and $\mathrm{Au}$. The main goal is to computationally elucidate the catalytic selectivity towards $\mathrm{CH}_{3} \mathrm{COOH}$ production or $\mathrm{CO} / \mathrm{CO}_{2}$ formation. The analysis of the reaction energy barriers (eV scale) suggests that $\mathrm{Ni}, \mathrm{Ru}, \mathrm{Rh}, \mathrm{Ir}$, and $\mathrm{Pt}$ can be considered as the $\mathrm{C}-\mathrm{C}$ bond cleavage catalysts (key 
step: $\mathrm{CHCO}^{*}+{ }^{*} \rightarrow \mathrm{CH}^{*}+\mathrm{CO}^{*}, *$ denotes the active site) while $\mathrm{Cu}$, $\mathrm{Ag}, \mathrm{Au}$, and $\mathrm{Pd}$ are the $\mathrm{C}-\mathrm{O}$ bond coupling catalysts (key step: $\left.\mathrm{CH}_{3} \mathrm{CO}^{*}+\mathrm{OH}^{*} \rightarrow \mathrm{CH}_{3} \mathrm{COOH}^{*}+{ }^{*}\right)$. Among the $\mathrm{C}-\mathrm{C}$ bond cleavage catalysts, $\mathrm{Ni}$ and Ir parade as the most efficient catalysts. The case of $\mathrm{Ni}$ needs additional studies since it is used for splitting predominantly the C-C bonds in glycerol. ${ }^{125,126}$ Wang et al. ${ }^{219}$ used DFT to investigate the adsorption behaviour and oxidation mechanisms of EtOH on Pd surfaces, including the closedpacked $\mathrm{Pd}(111)$, the stepped $\mathrm{Pd}(110)$, and the open $\mathrm{Pd}(100)$. The calculations indicate that the energy levels are $-2.43,-2.40$, and -2.06 eV for EtOH-Pd(100), EtOH-Pd(110), and EtOH$\mathrm{Pd}(111)$, respectively. The minimum distance between the atoms in the EtOH molecule and the Pd surface is 2.26, 2.27 and $2.38 \AA$, respectively. In other words, the interaction between $\mathrm{EtOH}$ and $\mathrm{Pd}(100)$ is much stronger than those of $\mathrm{Pd}(111)$, meaning that the first step, dehydrogenation of $\mathrm{EtOH}$, is much favourable at $\mathrm{Pd}(100)$. For ethylene glycol, it was found by DFT calculations that its decomposition on terraced and stepped $\mathrm{Pt}$ surfaces of $\mathrm{Pt}(111)$ and $\mathrm{Pt}(211)$ is much favourable through the $\mathrm{C}-\mathrm{C}$ bond scission compared to the $\mathrm{C}-\mathrm{H}$ one. ${ }^{223}$ However, one should be aware of the conclusions resulting from a pure DFT study that do not take into account the effects of the double catalytic layer, subject to changes depending on the operational electrocatalytic conditions.

Garcia et al. ${ }^{176}$ described a combined experimental and DFT study of the structure sensitivity of glycerol electrooxidation in acidic media, employing bulk surfaces of $\mathrm{Pt}(111)$ and $\mathrm{Pt}(100)$ as model catalysts given the high probability to obtain experimentally those surfaces from NPs synthesis methods. In fact, under thermodynamic equilibrium conditions, the shape of the crystals is described by the Wulff theorem; and for an element with a crystal symmetry $f c c$, the polyhedron corresponding to the most stable thermodynamic form for a NPs is a truncated octahedron, which is particularly true for supported NPs. ${ }^{242,243}$ For $\mathrm{Au}, \mathrm{Pt}$ and Pd (the most active in organics electrooxidation), this means that NPs synthesized for practical applications are mostly composed of (100) and (111) faces. The DFT calculation results demonstrate that the first dehydrogenation step of glycerol on $\mathrm{Pt}(111)$ preferentially abstracts the hydrogen atoms that are connected to the carbon, which was in agreement with earlier findings of Liu and Greeley. ${ }^{176,226}$ Indeed, in a combined DFT, thermochemical and kinetic study of the energy decomposition pathways of glycerol via $\mathrm{C}-\mathrm{H}, \mathrm{O}-\mathrm{H}$, and $\mathrm{C}-\mathrm{C}$ bonds scission on $\mathrm{Pt}(111)$, the authors found that glycerol dehydrogenation products at intermediate levels of dehydrogenation ("C-H bond scission") are the most thermochemically stable. ${ }^{226}$ Their results also suggest that C-C bonds are only broken after glycerol is "significantly dehydrogenated", meaning that mesoxalate (or mesoxalic acid, see Fig. 3) could be a potential final reaction product at Pt(111) surface at moderate electrode potentials. In the course of the sequential oxidation, the second step is the dehydrogenation that involves the breaking of a $\mathrm{C}-\mathrm{H}$ bond since the entire intermediates that adsorb through $\mathrm{O}-\mathrm{H}$ bond breaking are found to be at least $0.5 \mathrm{eV}$ less favourable than those adsorbing through carbon. ${ }^{176}$ It can thus be generally argued that, the electrocatalytic oxidation of polyols such as alcohols and carbohydrates occurs through a successive $\mathrm{C}-\mathrm{H}$ bonds scission; rarely, if not never by those of "O-H" or "C-O". The main difference between $\mathrm{Pt}(111)$ and $\mathrm{Pt}(100)$ is that, at $\mathrm{Pt}(111)$ surface, the resulting 2-electron and 2-protons dehydrogenation intermediate binds to the surface through two single Pt-C bonds yielding to an enediol-like intermediate, which serves as a precursor to both glyceraldehyde and dihydroxyacetone products. On $\mathrm{Pt}(100)$ surface however, it binds to the surface through one double $\mathrm{Pt}=\mathrm{C}$ bond, yielding to glyceraldehyde as the only product.

Figs. 8a-b shows mechanistic sketches from combined DFT and experimental study reported by Valter et al. ${ }^{231}$ It should be stressed, however, that the experimental part is just about CV of a polycrystalline Au electrode in $0.1 \mathrm{M} \mathrm{HClO}_{4}$ and $0.1 \mathrm{M} \mathrm{H}_{2} \mathrm{SO}_{4}$ (with and without glycerol). No quantitative online or ex situ analysis was carried out to support the postulated chemical structures of intermediate and products. According to the authors, adsorbed glycerol is the starting point with the dehydrogenation of the secondary carbon (1ab, requiring 0.39 $\checkmark$ vs RHE, Fig. $8 \mathrm{~b}$ ), and the secondary hydroxyl group, forming dihydroxyacetone ( $2 a,-0.31 \mathrm{~V}$ vs RHE). After that, the removal of hydrogen from the primary carbons leads to a six-membered ring ( $3 a, 0.42 \mathrm{~V}$ vs RHE) and a five-membered ring $(4 a, 0.40 \mathrm{~V}$ vs $\mathrm{RHE}$ ) with the $\mathrm{Au}$ surface. These first steps that propose a "metal-O" adsorbed species are radically opposed to those previously discussed, from Koper (methods of DFT, CV, HPLC, OLEMS and spectroelectrochemistry) ${ }^{176}$ and Greeley (method of DFT), ${ }^{226}$ which rather highlight "metal-C" adsorbed intermediates. It should also be noted, however, that the proposals are very superficial since they do not integrate contributions from $\mathrm{OH}$ adsorption, which would lead to carboxylate or carbonate products. Although there is no experimental study to date on $\mathrm{Au}(111)$ surface combining electrolysis, HPLC and DFT, it is highly unlikely that the only product resulting from glycerol electrooxidation is $\mathrm{CO}$. The only meaningful way to unambiguously determine whether the adsorbed intermediate from the first step of $\mathrm{C}-\mathrm{H}$ bond scission binds via "metal-C" or "metal-O" is to develop highly sensitive electrochemistry-coupled probes such as FTIRS and Raman spectroscopies, which allow interrogating the bond. 

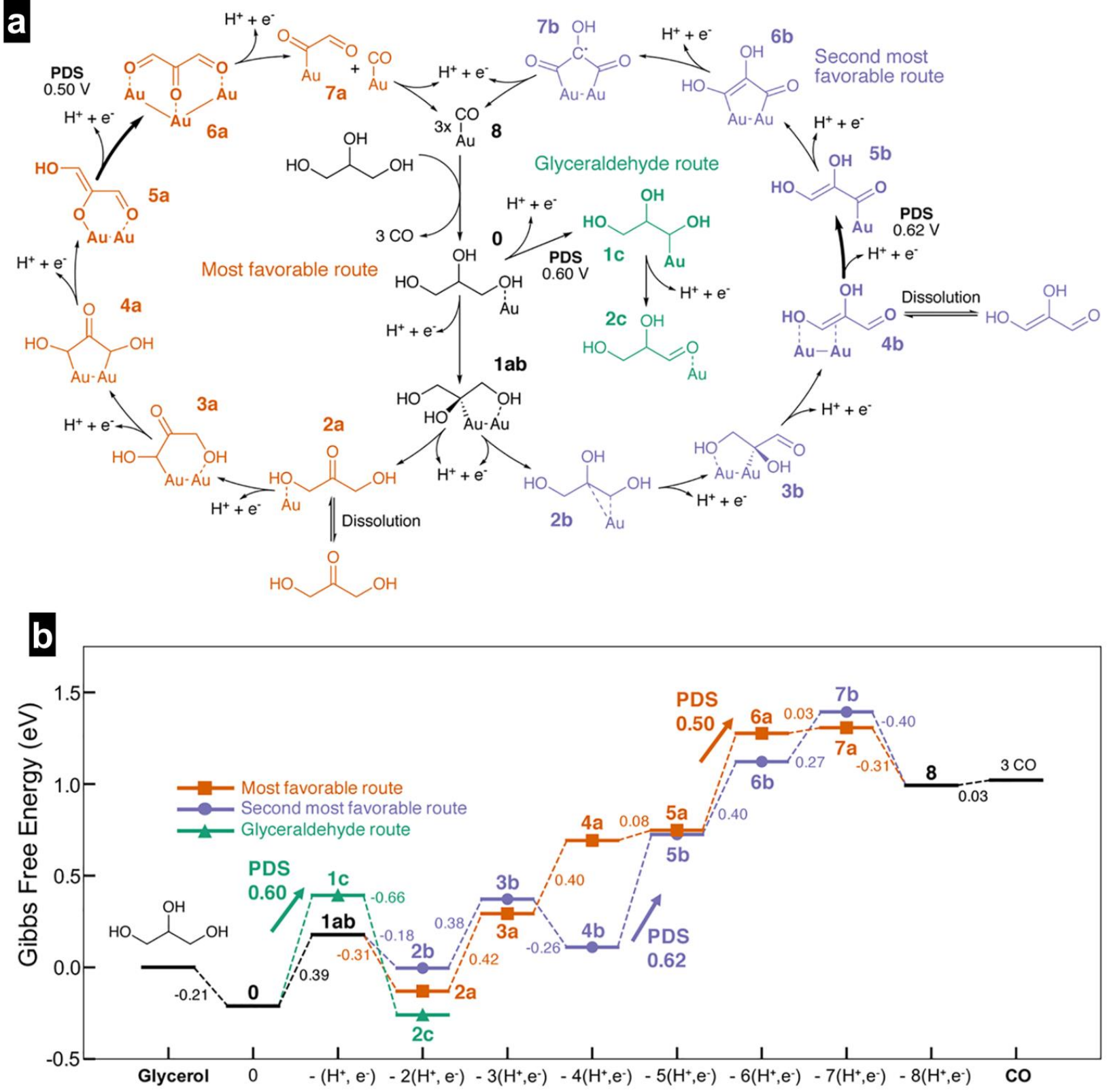

Fig. 8. Catalytic routes of glycerol dehydrogenation on $\mathrm{Au}(111)$, presented as (a) catalytic cycles and (b) energy landscape. The two most favourable complete dehydrogenation routes to $\mathrm{CO}$ are marked in red with squares and blue with circles, respectively, while a path ending in adsorbed glyceraldehyde is shown in green with triangles. Potential determining step (PDS in V vs RHE) is marked for each route. Reprinted and adapted with permission from Ref. ${ }^{231}$; Copyright 2018, American Chemical Society.

\subsection{C2 and C3 alcohols fuelled fuel cells for simultaneous production of electricity and chemicals}

The direct alcohol fuel cells (DAFCs) testing and validation have been dominated for a long time by methanol and the research is mainly conducted in acidic media. ${ }^{9,82,244-248}$ The term "direct" means that there is no reforming step of the fuel before the reaction at the anode. For example, $\mathrm{NaBH}_{4}$ can be used to firstly release $\mathrm{H}_{2}$ that will further be oxidized. For other $\mathrm{C2}-\mathrm{C} 3$ polyols, ethanol is the most investigated in both acidic and alkaline conditions (for full and detailed overview, readers can refer to
Ref. $\left.{ }^{249}\right) \cdot{ }^{250-255}$ Fuel cell testing under acidic environments is routinely performed with $\mathrm{Nafion}^{\circledR} 117$ or 115 as the proton exchange membrane (PEM) which has benefited from intense R\&D over the last 50 years. For polymer electrolyte DAFCs utilizing a hydroxyl anion exchange membrane (AEM), ${ }^{256-258}$ the threshold in terms of ionic conductivity and chemical/thermal stability and all over, the long-term durability is low compared to PEM devices. The last three years have witnessed significant advances that should be continued. ${ }^{37-40,258}$ 


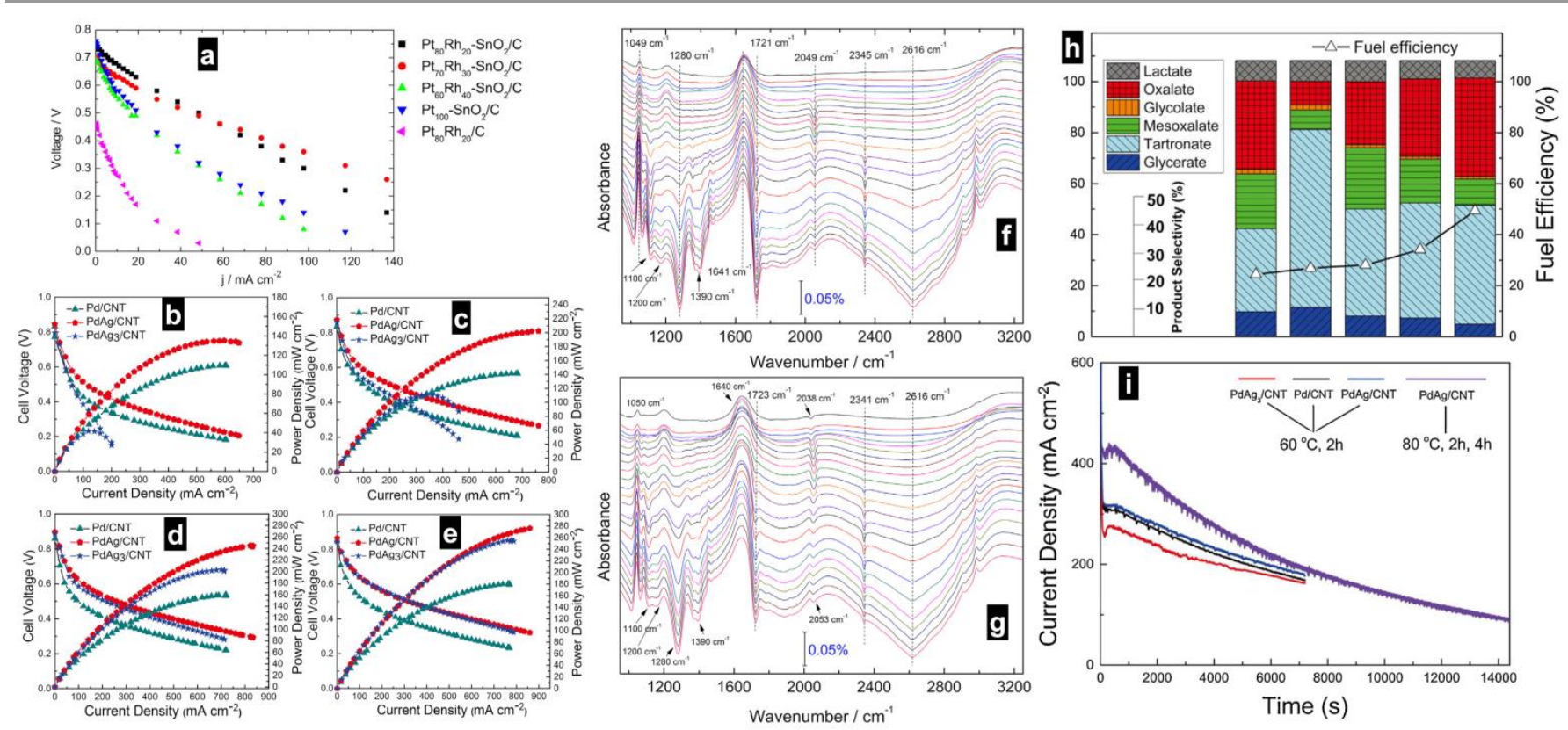

Fig. 9. (a) Direct ethanol fuel cell performance $\left(5.29 \mathrm{~cm}^{2}, 80^{\circ} \mathrm{C}\right.$, Nafion ${ }^{\oplus} 117 \mathrm{PEM}$ ) at Pt/C-ETECK cathode (humidified $\mathrm{O}_{2}, \mathrm{P}_{\mathrm{O} 2}=2.0$ bar, flow $=60 \mathrm{~mL}$ min ${ }^{-1}$ ) and different anodes $\left([\mathrm{EtOH}]=2.0 \mathrm{M}, \mathrm{P}_{\mathrm{EtOH}}=1.0 \mathrm{bar}, 60 \mathrm{~mL} \mathrm{~min}{ }^{-1}\right)$. (b-e) Electrical performance of direct alcohol fuel cell $\left(5 \mathrm{~cm}^{2}, 80^{\circ} \mathrm{C}\right.$, Tokuyama A901 AEM) with Fe-based cathode catalyst (Acta 4020 at $3.0 \mathrm{mg}_{\text {catalyst }} \mathrm{cm}^{-2}, 200 \mathrm{sccm} \mathrm{O}$, ambient pressure) with different anode catalysts $\left(0.5 \mathrm{mg}_{\mathrm{Pd}} \mathrm{cm}^{-2}, 6.0 \mathrm{M} \mathrm{KOH}+3.0 \mathrm{M}\right.$ fuel, $4.0 \mathrm{ml} \mathrm{min}{ }^{-1}$ ): (b) methanol, (c) ethanol, (d) ethylene glycol and (e) glycerol. (f, g) SPAIRS spectra of the (f) $\mathrm{Pt}_{-} \mathrm{SnO}_{2} / \mathrm{C}$ and (g) $\mathrm{Pt}_{80} \mathrm{Rh}_{20} \mathrm{SnO}_{2} / \mathrm{C}$ electrocatalysts at potentials varying from 0.05 to $1.2 \mathrm{~V}$ vs $\mathrm{RHE}$ ( $1 \mathrm{mV} \mathrm{s} \mathrm{s}^{-1}$, spectra recorded every $50 \mathrm{mV}$ ) in $0.5 \mathrm{M} \mathrm{H}_{2} \mathrm{SO}_{4}$ containing $1.0 \mathrm{M} \mathrm{EtOH}$ : reference spectrum taken at $0.05 \mathrm{~V}$ vs RHE. (h-i) Stability operation of direct glycerol $\mathrm{FC}$ at a cell voltage of $0.2 \mathrm{~V}$ for $2 \mathrm{~h}\left(60^{\circ} \mathrm{C}\right)$ and $4 \mathrm{~h}\left(80^{\circ} \mathrm{C}\right)$ at different anode catalysts $\left(0.5 \mathrm{mgd}_{\mathrm{Pd}} \mathrm{cm}^{-2}, 6.0 \mathrm{M} \mathrm{KOH}+1.0 \mathrm{M}\right.$ glycerol, $\left.23.5 \mathrm{~mL}, 1.0 \mathrm{~mL} \mathrm{~min}^{-1}\right)$ and Fe-based cathode catalyst $\left(\right.$ Acta $4020,3 \mathrm{mg} \mathrm{cm}{ }^{-2}$, high purity $\mathrm{O}_{2}$, $100 \mathrm{~mL} \mathrm{~min}{ }^{-1}$, ambient pressure), Tokuyama A901 AEM: (h) Selective in C-C bond cleavage and fuel efficiency; (i) the corresponding amperometric / vs $t$ traces. (a, f, g) Reprinted and adapted with permission from Ref. ${ }^{10}$; Copyright 2016, Elsevier B.V. (d-e, h, i) Reprinted and adapted with permission from Ref. ${ }^{178}$; Copyright 2016, Elsevier B.V

Fig. 9a shows the direct ethanol fuel cell performance $(80$ ${ }^{\circ} \mathrm{C}$, Nafion ${ }^{\circledR} 117$ PEM) at Pt/C cathode (humidified $\mathrm{O}_{2}$ at 2 bar and $60 \mathrm{~mL} \mathrm{~min}{ }^{-1}$ ) and different anode materials (2 M EtOH supplied at 1 bar and $60 \mathrm{~mL} \mathrm{~min}-1$ ), while Figs. 9f-g display the SPAIRS spectra recorded every $50 \mathrm{mV}$ at $1 \mathrm{mV} \mathrm{s}^{-1}$ for Pt-SnO $2 / \mathrm{C}$ and $\mathrm{Pt}_{80} \mathrm{Rh}_{20} \mathrm{SnO}_{2} / \mathrm{C}$ electrodes ( 0.05 to $1.2 \mathrm{~V}$ vs $\mathrm{RHE}$ ). ${ }^{10}$ The electrical performance is much higher for trimetallic systems; for instance $\mathrm{Pt}_{70} \mathrm{Rh}_{30} \mathrm{SnO}_{2} / \mathrm{C}$ electrocatalyst with $P_{\max }=37 \mathrm{~mW}$ $\mathrm{cm}^{-2}$ reached at $117 \mathrm{~mA} \mathrm{~cm}^{-2}$ ( $0.32 \mathrm{~V}$ cell voltage). According to the authors, the high electrical performance of the ternary anode catalysts resulted from the synergistic effects due to the double incorporation of rhodium and tin oxide into the platinum electrode, which promotes the oxidative removal of adsorbed intermediates and increases the power density. In Fig. 9f-g, specific bands of acetaldehyde $\left(928\right.$ and $1367 \mathrm{~cm}^{-1}$ assigned to $\mathrm{C}-\mathrm{C}-\mathrm{O}$ asymmetric stretching and $\mathrm{CH}_{3}$ symmetric deformation) and acetic acid (1280 and $1390 \mathrm{~cm}^{-1}$ attributed to $\mathrm{C}-\mathrm{O}$ stretching and $-\mathrm{OH}$ deformation; broad band centred at $2616 \mathrm{~cm}^{-1}$ from $v(\mathrm{C}-\mathrm{H})$ asymmetric stretching of the $-\mathrm{CH}_{3}$ group) indicate their formation as intermediates or products. Additionally, the bands between 2030 and $2055 \mathrm{~cm}^{-1}$ corresponding to the linearly adsorbed $\mathrm{CO}$ at $\mathrm{Pt}$ sites and those at $2345 \mathrm{~cm}^{-1}$ for $\mathrm{O}=\mathrm{C}=\mathrm{O}$ asymmetric stretching highlight the formation of products from $\mathrm{C}-\mathrm{C}$ bond cleavage, i.e. $\mathrm{CO}$ and $\mathrm{CO}_{2}$ at higher potential values. These in situ investigations indicate that acetaldehyde, acetic acid, $\mathrm{CO}$ and $\mathrm{CO}_{2}$ are possible EtOH electrooxidation intermediates or final products. Quantitatively, the reported $4 \mathrm{~h}$ long-term electrolysis (acetaldehyde is trapped in 0.2 wt.\% 2,4-DNPH solution prepared with $2 \mathrm{M} \mathrm{HCl}$ and $\mathrm{CO}_{2}$ is entrapped in $0.1 \mathrm{M} \mathrm{NaOH}$ ) at $0.6 \mathrm{~V}$ vs RHE in a conventional $\mathrm{H}$-type cell followed by product determination by HPLC shows that the selectivity towards 4electron process (acetic acid) is $85-98 \%$; the remaining being shared between $\mathrm{CO}_{2}(1-15 \%)$ and acetaldehyde (0.04\%). ${ }^{10}$ For the same conversion, the best selectivity in acetic acid is achieved at $\mathrm{Pt}_{60} \mathrm{Rh}_{40}-\mathrm{SnO}_{2} / \mathrm{C}$, about $98.5 \%$ whilst the best performing catalyst $\left(\mathrm{Pt}_{70} \mathrm{Rh}_{30}-\mathrm{SnO}_{2} / \mathrm{C}\right)$ in terms of power density enables $84.7 \%$ selectivity. ${ }^{10}$ These data show that for the cogeneration in fuel cells, i.e., the simultaneous production of electricity and chemicals, a compromise needs to be made between the "faradaic yield" and the "selectivity".

Compared to those fuel cells that operate with acidic electrolytes, the AEM-based technology is not mature and has to deal with the inherent presence of $\mathrm{CO}_{2}$ in air, which is supplied at the cathode. In some cases, the origin of " $\mathrm{CO}_{2}$ " just results from the complete oxidation of the organic fuel. $\mathrm{CO}_{2}$ presence induces not only the consumption of $\mathrm{OH}^{-}$, but also the formation of carbonate species that precipitate $\left(\mathrm{CO}_{2(\mathrm{~d})}+\right.$ $\left.2 \mathrm{OH}^{-}{ }_{(\mathrm{aq})} \rightarrow \mathrm{CO}_{3}{ }^{2-}{ }_{(\mathrm{aq})}+\mathrm{H}_{2} \mathrm{O}_{(\mathrm{l})}\right)$ and shrinks the overall operating cycle. For those scientific and technological reasons, DAFC-AEM technologies should utilize high purity $\mathrm{O}_{2}$ at the cathode and use highly selective anode electrocatalysts that do not provoke $\mathrm{C}-\mathrm{C}$ bond cleavage when fuelled with an organic molecule. The direct implication is that these energy conversion sources should be intended to power only stationary devices where the risk of pure $\mathrm{O}_{2}$ handling is lower. 
Table 2. Comparative single cell performance of direct C2-C3 alcohol-based fuel cells and electrolysis cells.

\begin{tabular}{|c|c|c|c|c|c|}
\hline Anode catalyst & Cathode catalyst & Separator & Type & Efficiency & Ref. \\
\hline $\begin{array}{c}\text { Pt/Vulcan } \\
\left(1 \mathrm{mg}_{\mathrm{Pt}} \mathrm{cm}^{-2}\right)\end{array}$ & $\begin{array}{l}\text { HYPERMECTM } \\
\text { catalyst (Fe-Cu- } \\
\text { N4/C, Acta) } \\
\left(1 \mathrm{mg} \mathrm{cm}^{-2}\right)\end{array}$ & $\begin{array}{l}\text { Tokuyama } \\
\text { A201 (28 } \\
\mu \mathrm{m}) \text { anion } \\
\text { exchange } \\
\text { membrane }\end{array}$ & Fuel cell & 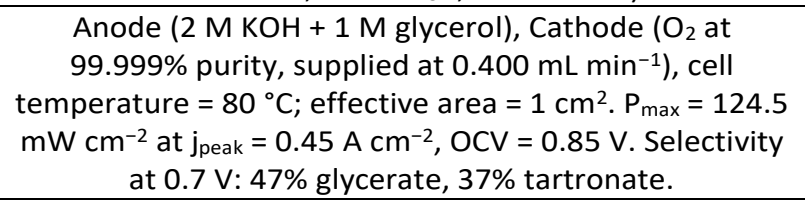 & 24 \\
\hline $\begin{array}{c}\mathrm{PdAg} / \text { carbon } \\
\text { nanotube } \\
\left(0.5 \mathrm{mg}_{\mathrm{Pt}} \mathrm{cm}^{-2} \text { for }\right. \\
\mathrm{Pd}, 1 \mathrm{mg} \mathrm{cm} \mathrm{cm}^{-2} \text { for } \\
\mathrm{Pd}_{1} \mathrm{Ag}_{1} \text {, and } 2 \mathrm{mg} \\
\left.\mathrm{cm}^{-2} \mathrm{PdAg}_{3}\right)\end{array}$ & $\begin{array}{l}\text { Fe-Cu-N4/Carbon } \\
\text { (Acta 4020) } \\
\left(3 \mathrm{mg}_{\text {catalyst }} \mathrm{cm}^{-2}\right)\end{array}$ & $\begin{array}{l}\text { Tokuyama } \\
\text { A901 (10 } \\
\mu \mathrm{m}) \text { anion } \\
\text { exchange } \\
\text { membrane }\end{array}$ & Fuel cell & 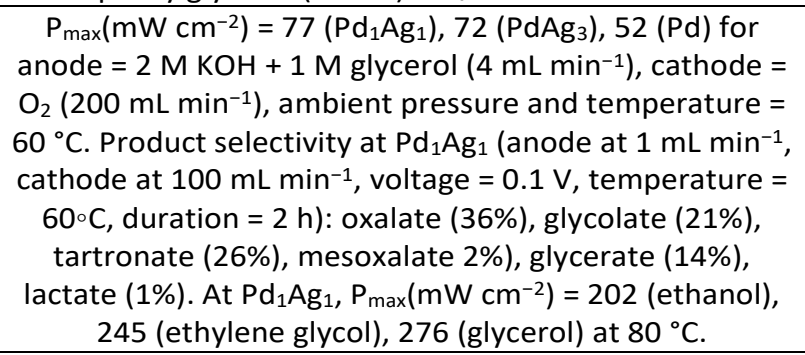 & $\begin{array}{c}177,1 \\
78\end{array}$ \\
\hline $\begin{array}{c}\text { Rh/Vulcan } \\
\left(1 \mathrm{mg}_{\mathrm{Rh}} \mathrm{cm}^{-2}\right)\end{array}$ & $\begin{array}{c}\text { Pt/Vulcan } \\
\left(0.4 \mathrm{mg}_{\text {catalyst }} \mathrm{cm}^{-2}\right)\end{array}$ & $\begin{array}{l}\text { Tokuyama } \\
\text { A-201 } \\
\text { anion } \\
\text { exchange } \\
\text { membrane }\end{array}$ & $\begin{array}{l}\text { Electrolysis } \\
\text { cell }\end{array}$ & $\begin{array}{c}\text { Anode }\left(2 \mathrm{M} \mathrm{KOH}+2 \mathrm{M} \text { alcohol) at } 1 \mathrm{~mL} \mathrm{~min}^{-1} .\right. \\
\text { Temperature }=60{ }^{\circ} \mathrm{C} \text {, effective area }=5 \mathrm{~cm}^{2} . \mathrm{H}_{2} \\
\text { production }\left(\mathrm{Nm}^{3} \mathrm{~m}^{-2}\right)=3 \text { (ethanol), } 2.8(1,2 \text {-propandiol), } \\
5.4(\text { ethylene glycol), } 4.3 \text { (glycerol); energy consumption } \\
\left(\mathrm{kWh} \mathrm{kg}^{-1} \mathrm{H}_{2}\right)=9.6(\text { ethanol), } 14.4(1,2 \text {-propandiol), } 11.0 \\
\text { (ethylene glycol), } 12.6 \text { (glycerol). Glycerol' selectivity at } \\
0.7 \mathrm{~V} \text { : glycerate }(46 \%) \text {, tartronate }(23 \%), \text { carbonate } \\
(18 \%), \text { formate }(8 \%), \text { glycolate }(3 \%), \text { oxalate }(2 \%)\end{array}$ & 261 \\
\hline
\end{tabular}

During the last decade, Li's group reported some pioneering works regarding the use of AEM for DAFC (methanol, ethanol, ethylene glycol and glycerol), especially for cogeneration of electricity and valuable chemicals. $22,24,25,178$ Figs. 9b-e and 9h-I show the electrical performance of DAFC fuelled with the above alcohols $\left(80{ }^{\circ} \mathrm{C}\right.$, Tokuyama A901 AEM) with Fe-based cathode catalyst (Acta 4020 at $3 \mathrm{mg}_{\text {catalyst }} \mathrm{cm}^{-2}, 200 \mathrm{sccm} \mathrm{O}$, ambient pressure) and different anode catalysts $\left(0.5 \mathrm{mg}_{\mathrm{Pd}} \mathrm{cm}^{-2}, 6 \mathrm{M} \mathrm{KOH}\right.$

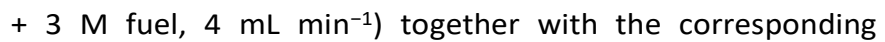
selectivity/stability of a direct glycerol fuel cell at a cell voltage of $0.2 \mathrm{~V}$. For the $\mathrm{PdAg} / \mathrm{CNT}$ anode catalyst that has shown the best activity during the half-cell study by CV, DAFC-AEM fuelled with methanol, ethanol, ethylene glycol and glycerol have $P_{\max }$ =135, 202, 245 and $276 \mathrm{~mW} \mathrm{~cm}^{-2}$ (about 23, 43, 53 and 53\% higher than that of monometallic Pd/CNT, respectively). From Fig. 9i, ([fuel efficiency] $=$ [product selectivity $] \times$ [glycerol conversion]), the quantitative data after $2 \mathrm{~h}$ of electrocatalytic oxidation in a direct glycerol fuel cell at $60{ }^{\circ} \mathrm{C}$ show that the selectivity of $\mathrm{C}_{2}$ oxalate on $\mathrm{Pd} / \mathrm{CNT}, \mathrm{PdAg} / \mathrm{CNT}$ and $\mathrm{PdAg}_{3} / \mathrm{CNT}$ is about 9,23 and $32 \%$, while the corresponding conversion of glycerol is 55, 49 and $47 \%$, respectively; indicating that the addition of $\mathrm{Ag}$ contributes to the $\mathrm{C}-\mathrm{C}$ bond cleavage of $\mathrm{C} 3$ glycerol to $\mathrm{C} 2$ oxalate and lowers glycerol conversion. ${ }^{178}$ Indeed, in the absence of $\mathrm{Ag}$, higher selectivity towards tartronate is reached at $\mathrm{Pd} / \mathrm{CNT}$. So, it comes that the introduction of $\mathrm{Ag}$ atoms to form an nanoalloy phase with $\mathrm{Pd}$ atoms leads to the suppressing of the hydroxyl group deprotonation process and accelerates the aldehyde oxidation process, which are found to 
be more effective on $\mathrm{Pd}$ and $\mathrm{Ag}$, respectively. ${ }^{178}$ In another comparative study of glycerol DAFC-AEM utilizing anode nanocatalysts of $\mathrm{Au} / \mathrm{C}$ (2-6 nm particles size) and Pt/C (1-4 nm), mesoxalate is produced with high selectivity of $46 \%$ from the glycerol electrooxidation on $\mathrm{Au} / \mathrm{C}$ at an operating voltage of 0.3 $\mathrm{V}$, whilst very small amounts of mesoxalate (selectivity $<3 \%$ ) were obtained on a Pt/C anode catalyst. ${ }^{25,262}$ It was also found that the product distribution strongly depends on the anode and $\mathrm{Au}$ promotes the deeper oxidation of glycerol without affecting the $\mathrm{C}-\mathrm{C}$ bonds to afford fully-oxidized $\mathrm{C} 3$ mesoxalate at lower electrode potential of 0.4-0.7 V vs RHE, the normal working range for anode potential in DAFC-AEM. This represents the possibility of harvesting the maximum number of electrons without altering the $\mathrm{C}-\mathrm{C}$ bond (i.e. 8). However, at much higher potentials up to $1.2 \mathrm{~V}$ vs RHE in an electrolysis cell, glycolate is the major product with a selectivity of $65 \%$ and no mesoxalate. ${ }^{25,262}$ The formation of $\mathrm{C} 2$ product of glycolate means that a C1 product is jointly released (carbonate or formate), which is not a positive point in terms of cogeneration. A resume of the performance for the different types of fuel cells is reported in Table 2. These results definitely underpin the relationship between the surface state and the selectivity in electrocatalysis of organic molecules.
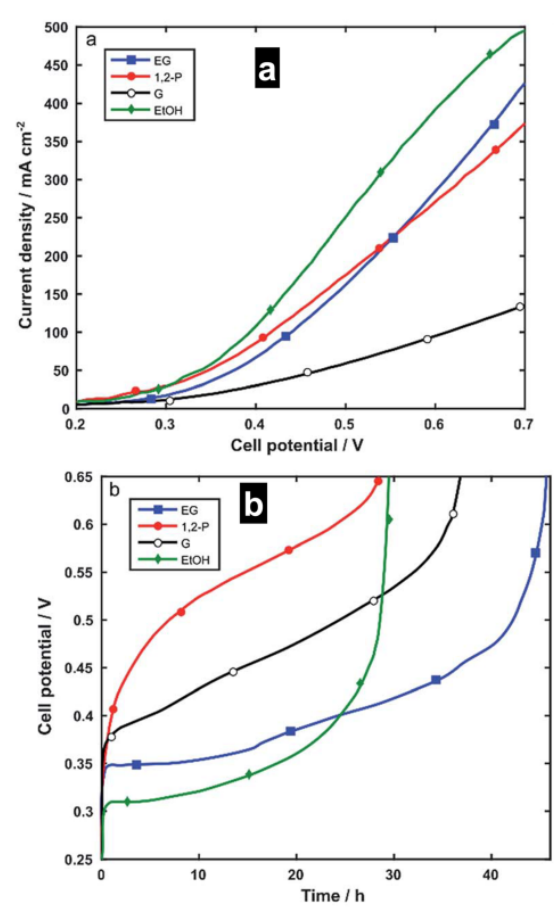
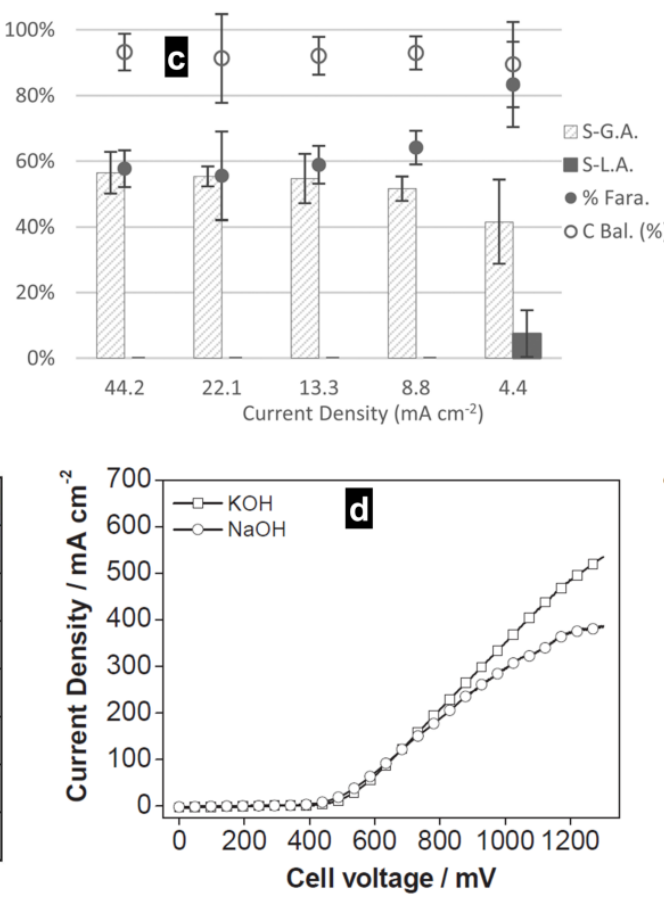
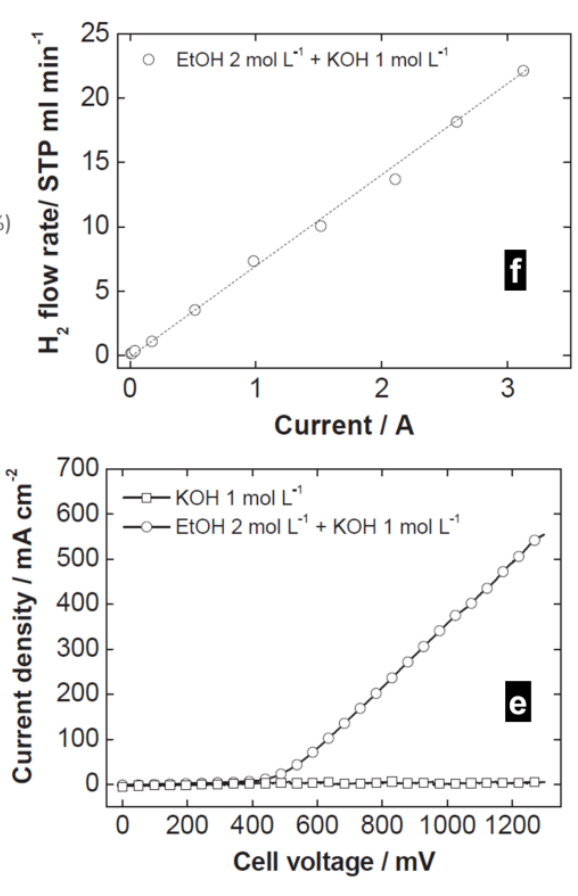

Fig. 10. (a, b) Electrolysis curves in $2 \mathrm{M} \mathrm{KOH}$ fed cathode (Pt/C) and $2 \mathrm{M} \mathrm{KOH}+2 \mathrm{M}$ fed anode $(\mathrm{Rh} / \mathrm{C})$ using Tokuyama A-201 AEM (5 cm²): (a) Linear polarization at $10 \mathrm{mV} \mathrm{s}$-1 and (b) galvanostatic discharge at $125 \mathrm{~mA}$. The flow rate is $30 \mathrm{~mL} \mathrm{~min}^{-1}$ and the cell temperature is $60^{\circ} \mathrm{C}$. (c) Selectivity (\%, histograms) to lactic (S-L.A.) and glyceric acid (S-G.A.), and Faradaic efficiency analysis (\% Fara., filled circles) from glycerol $\left(250 \pm 10 \mathrm{mM}\right.$, dissolved in $0.5 \mathrm{M} \mathrm{NaOH}, 20 \pm 3{ }^{\circ} \mathrm{C}$ ) electrolysis at different current densities: the anode is Co-DPPE (dicobalt octacarbonyl and 1,2-bis(diphenylphosphino)ethane) and cathode is a nickel metal. (d-f) EtOH electrolysis at $80^{\circ} \mathrm{C}$ in $1 \mathrm{M} \mathrm{KOH} \mathrm{(or} \mathrm{NaOH)} \mathrm{fed} \mathrm{cathode} \mathrm{(Pt/C,} 1 \mathrm{~mL} \mathrm{~min}{ }^{-1}$ ) and $1 \mathrm{M} \mathrm{KOH}$ (or $1 \mathrm{M} \mathrm{NaOH})+$ EtOH fed anode (Pd/C, $100 \mathrm{~mL} \mathrm{~min}^{-1}$ ) using Tokuyama A901 AEM (6.25 cm²): (d) $1 \mathrm{M} \mathrm{KOH}$ versus $1 \mathrm{M} \mathrm{NaOH}$ by using $2 \mathrm{M} \mathrm{EtOH;} \mathrm{(e)} \mathrm{Polarization} \mathrm{curves} \mathrm{and} \mathrm{its}$ corresponding $\mathrm{H}_{2}$ production rate (f). (a,b) Reprinted and adapted with permission from Ref. ${ }^{261}$; Copyright 2017, The Royal Society of Chemistry. (c) Reprinted and adapted with permission from Ref. ${ }^{54}$; Copyright 2017, The Royal Society of Chemistry. (d-e) Reprinted and adapted with permission from Ref. ${ }^{263}$; Copyright 2016, Elsevier B.V.

\subsection{C2 and C3 alcohol-fuelled electrolysis cells for clean hydrogen generation and chemicals synthesis}

The previous discussion focused on the utilization of the biomass-derived alcohols in order to produce simultaneously electrical energy and value-added chemicals. For practical realization, even though those organics have moderate gravimetric energy density of 5-9 $\mathrm{kWh} \mathrm{kg}^{-1}$ fuel (compared to $\mathrm{H}_{2}$ that has the highest value of $33 \mathrm{kWh} \mathrm{kg}^{-1}$ fuel), the organic-toelectricity efficiency in low temperature solid alkaline membrane fuel cells remains well below the expectation: $\mathrm{H}_{2}-$ oxidising fuel cells (PEM or AEM) enable achieving $P_{\max }=1-2 \mathrm{~W}$ $\mathrm{cm}^{-2}$, while $P_{\max }=0.2 \mathrm{~W} \mathrm{~cm}^{-2}$ is hardly achieved with a single cell fuel cell fed with organics. ${ }^{12}$ An appealing strategy is their electroreforming in order to combine the production of valuable chemicals with that of high purity $\mathrm{H}_{2}$ at low temperature and atmospheric pressure. $46,52,54-57,261,264$

Figs. 10a-b shows the electrolysis curves in $2 \mathrm{M} \mathrm{KOH}$ fed Pt/C cathode and $2 \mathrm{M} \mathrm{KOH}+2 \mathrm{M}$ fed Rh/C anode (Tokuyama A-201 AEM, cell area of $5 \mathrm{~cm}^{2}$, flow rate of $30 \mathrm{~mL} \mathrm{~min}^{-1}$, temperature of $60{ }^{\circ} \mathrm{C}$ ). The polarization curve shows that ethanol enables achieving the best kinetics. Deeper analysis after galvanostatic discharge at $125 \mathrm{~mA}$ until the cell potential reaches the value of $0.65 \mathrm{~V}$ (Fig. 10b) followed by quantification by HPLC, NMR, and a "Bronkhorst mass specific hydrogen-calibrated flow-meter" show that the $\mathrm{H}_{2}$ production rate is about $3,3,5$ and $4 \mathrm{Nm}^{3} \mathrm{~m}^{-2}$ for ethanol (100\% acetate selectivity), 1,2-propanediol (98\% lactate selectivity), ethylene glycol (76\% Glycolate selectivity) and glycerol (46\% glycerate and $23 \%$ tartronate selectivities) for an energy consumption of $10,14,11$ and $13 \mathrm{kWh} \mathrm{kg}^{-1} \mathrm{H}_{2}$. At the 
cathode, a $100 \%$ faradaic efficiency was obtained, which is obvious since, except the electrode degradation, the only faradaic response is $2 \mathrm{H}_{2} \mathrm{O}_{(\mathrm{l})}+2 \mathrm{e}^{-} \rightarrow \mathrm{H}_{2 \text { (dis/g) }}+2 \mathrm{OH}^{-}$(aq). Conclusively, the utilization of ethanol results in a production of acetate as valuable chemical and $\mathrm{H}_{2}$ fuel at $9.6 \mathrm{kWh} \mathrm{kg}^{-1} \mathrm{H}_{2}$, i.e., an electrical energy saving of $35.4 \mathrm{kWh} \mathrm{kg}^{-1} \mathrm{H}_{2}$ in comparison to the DOE (U.S. Department of Energy) target for PEM water electrolyser stacks, 45 to $43 \mathrm{kWh} \mathrm{kg}^{-1} \mathrm{H}_{2}$ by $2020 .{ }^{265} \mathrm{Fig}$. $10 \mathrm{c}$ shows the performance obtained in glycerol electrolysis, indicating that in addition to glyceric acid (S-G.A.), lactic acid (SL.A.) can be obtained under certain conditions of high current density. ${ }^{54}$
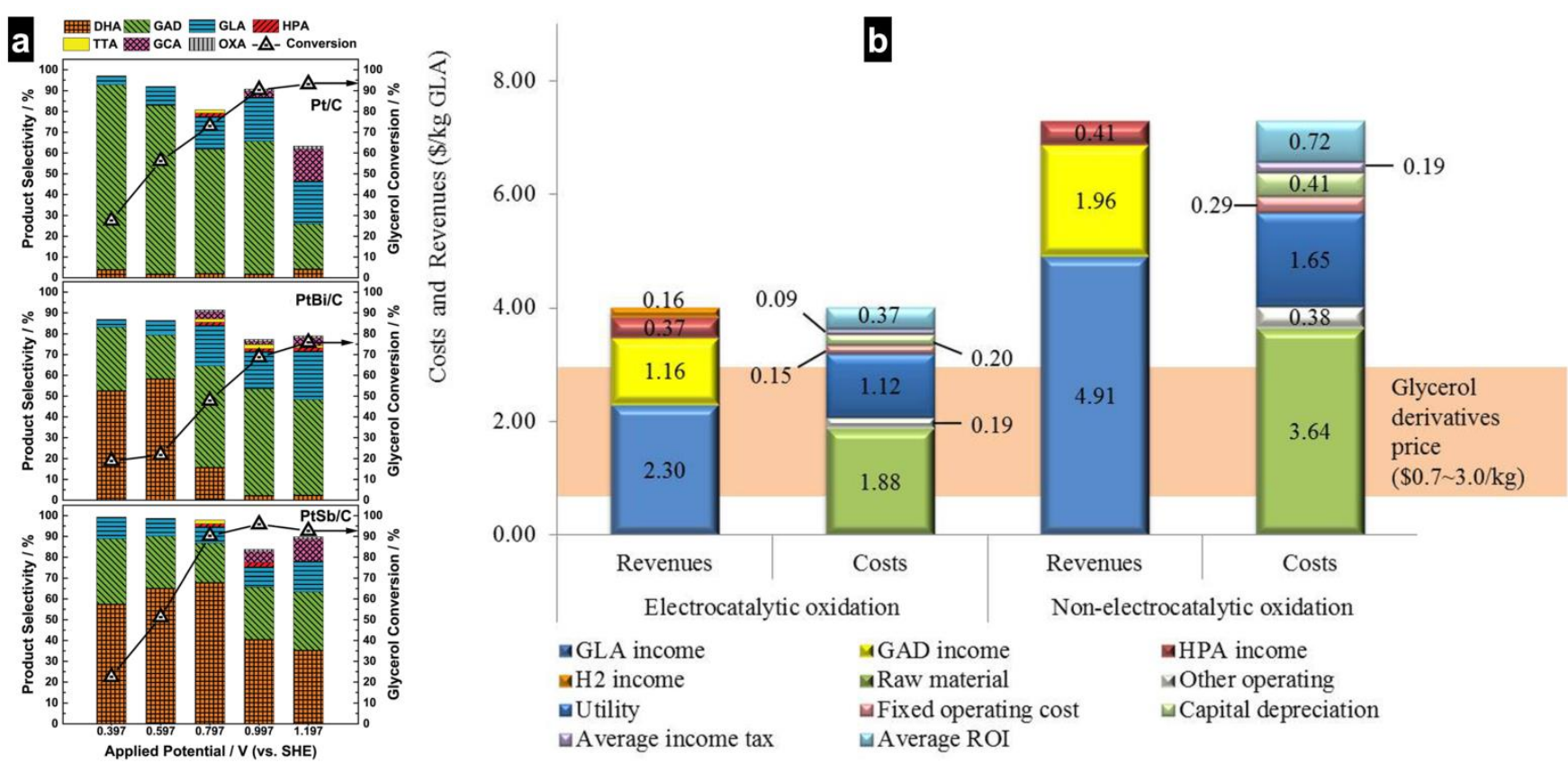

Fig. 11. (a) Product distribution and glycerol conversion with different applied potentials over $\mathrm{Pt} / \mathrm{C}, \mathrm{PtBi} / \mathrm{C}$, and PtSb/C catalysts in $0.5 \mathrm{M} \mathrm{H} \mathrm{SO}_{4}+0.1 \mathrm{M}$ glycerol at $60{ }^{\circ} \mathrm{C}$ for $10 \mathrm{~h}$. (b) Comparison of the costs and revenues of the electrocatalytic and non-electrocatalytic glycerol oxidation strategies. (a) Reprinted and adapted with permission from Ref. 266 ; Copyright 2016, The Royal Society of Chemistry. (b) Reprinted and adapted with permission from Ref. ${ }^{36}$; Copyright 2017, American Chemical Society.

Lucas-Consuegra et al. ${ }^{263}$ investigated the effect of the counter ion on the performance of ethanol electrolysis in AEMbased electrolyser ( $\mathrm{Pt} / \mathrm{C}$ cathode, $\mathrm{Pd} / \mathrm{C}$ anode, Tokuyama A901 AEM). Polarization curves in Fig. 10d evidence that $\mathrm{KOH}$ is a more suitable as an electrolyte than $\mathrm{NaOH}$, especially at high current density (cell voltage $>0.8 \mathrm{~V}$ ) where the fuel demand is much higher. This expected difference in electrocatalysis is ascribed to non-covalent interactions between hydrated cation $\mathrm{OH}_{\mathrm{ad}}-\mathrm{M}^{+}\left(\mathrm{H}_{2} \mathrm{O}\right)_{\mathrm{x}}(\mathrm{M}=\mathrm{Na}, \mathrm{K})$ and $\mathrm{OH}_{\mathrm{ad}}$ on the electrode surface of number of metals. ${ }^{267-271}$ According to this theory, the hydration energy increases when the size of the alkali metal decreases, which means a much higher accumulation of $\mathrm{Na}^{+}\left(\mathrm{H}_{2} \mathrm{O}\right)_{\times}$species on the metallic surface. The consequence is a reduction of the number of available active sites, which is especially decisive at high current densities where fuel demand is very important. Fig. 10f shows that the $\mathrm{H}_{2}$ volume increases linearly with the current density, in line with the Faraday's law. It was also observed that the electrolyser could work continuously over $150 \mathrm{~h}$ producing highly pure $\mathrm{H}_{2}$ (99.999\%) at the cathode and potassium acetate as the main anodic product, which means that no pollutant $\mathrm{CO}$, $\mathrm{CO}_{2}$ or $\mathrm{CO}_{3}{ }^{2-}$ species are produced. Fig. 10e indicates that until a cell voltage of $1.2 \mathrm{~V}$, no production of $\mathrm{H}_{2}$ is feasible from water electrolysis, whereas a current density of $0.5 \mathrm{~A} \mathrm{~cm}^{-2}$ can be achieved in the presence of ethanol. The electricity consumption for the constructed electrolysis cell was evaluated to be 19-30 $\mathrm{kWh} \mathrm{kg}^{-1} \mathrm{H}_{2}$, which is still lower than water electrolysis, but significantly higher, compared to other organics-based electrolysis systems. ${ }^{56,261}$ Table 2 gathers the electrolysis cell performance of C2-C3 alcohols in alkaline environment. Kim et al. ${ }^{36}$ reported experimental and technoeconomic analysis of the coproduction of value-added chemicals and $\mathrm{H}_{2}$ from the electrocatalytic glycerol oxidation to examined whether this is practically achievable or not. Fig. 11a shows the selectivity and conversion at different applied potentials for different anode catalysts of $\mathrm{Pt} / \mathrm{C}, \mathrm{PtBi} / \mathrm{C}$, and $\mathrm{PtSb} / \mathrm{C}$ in $0.5 \mathrm{M} \mathrm{H}_{2} \mathrm{SO}_{4}+0.1 \mathrm{M}$ glycerol $\left(60^{\circ} \mathrm{C}, 10 \mathrm{~h}\right)$. The energy efficiency and economics analysis by considering the costs and revenues of the electrocatalytic and non-electrocatalytic glycerol oxidation strategies are gathered in Fig. 11b, which shows that by adding an income from $\mathrm{H}_{2}$, the electrocatalytic pathway could be an advantageous option. The model for the integrated process of electrocatalytic glycerol oxidation theoretically takes into consideration the separation and recovery (glyceraldehyde, glyceric acid, and hydroxypyruvic acid), heat production, wastewater treatment, storage, etc. The initially introduced $\mathrm{H}_{2} \mathrm{SO}_{4}$ as electrolyte and present in the final liquid mixture is removed by precipitation with $\mathrm{Ca}(\mathrm{OH})_{2}$, distillation columns separate the mixture according to the boiling points of its components [glyceric acid $\left(272{ }^{\circ} \mathrm{C}\right)$, hydroxypyruvic acid $\left(257^{\circ} \mathrm{C}\right)$, glyceraldehyde $\left(208{ }^{\circ} \mathrm{C}\right)$, and 
water $\left.\left(100{ }^{\circ} \mathrm{C}\right)\right]$, which leads to high recovery rates (>95-99\%) with high purities (>99 wt\%). ${ }^{36}$ Based on this script, the minimum selling price (MSP, the price that makes the net present value equal to zero) of glyceric acid for the electrocatalytic process would be $\$ 2.30 / \mathrm{kg}$ compared to $\$ 4.91 / \mathrm{kg}$ for the non-electrocatalytic process. Considering that the model was based on an electrochemical cell without a separating membrane between the anode and cathode compartments, additional costs are to be expected.

\section{Advancements in the valorisation of biomass by co-generative electro-conversion}

\subsection{Oligosaccharides electro-conversion}

5.1.1. Enzymatic and microbial electrocatalysis. The central motivation behind the use of high carbon content biomassderivate such as oligosaccharides is not the complete oxidation to $\mathrm{CO}_{2}$. For example, $24 \mathrm{e}^{-}$could be harnessed within a fuel cell per molecule of glucose by considering total oxidation to $\mathrm{CO}_{2}$. Given the increasing environmental issues and the high cost associated with $\mathrm{CO}_{2}$ transformation, the capital gain seems to be extremely low, if not negative. Then the reliable strategy should be a sequential oxidation without attacking the carbon skeleton. To this end, enzymatic and microbial electrocatalysts (so-called "bioelectrocatalysts") can be seen as the most efficient. The emerged enzymes that oxidized their substrates at the anomeric ( $\mathrm{C} 1$ ) position (2-electron) are glucose oxidase (GOX), flavin adenine dinucleotide-dependent glucose dehydrogenase (FAD-GDH), nicotinamide adenine dinucleotidedependent glucose dehydrogenase (NAD-GDH), pyrroloquinoline quinone-dependent glucose dehydrogenase (PQQ-GDH), cellobiose dehydrogenase $(\mathrm{CDH})$, fructose dehydrogenase (FDH), pyranose oxidase (POx) and pyranose dehydrogenase (PDH). ${ }^{272-281}$ It should be noted that FAD-GDH and $\mathrm{CDH}$ are promising alternatives to $\mathrm{GOx}$ because they do not utilize molecular oxygen as their electron acceptor, thus the efficiency is retained in the presence of $\mathrm{O}_{2}$. Many examples of glucose, fructose, and analogues can be found in the large literature of the biofuel cell science. ${ }^{33,281-286}$ Furthermore, since most oxidase and dehydrogenase enzymes only catalyze twoelectron oxidation of substrates, enzyme cascades appear to be a solution for a deep oxidation and even complete oxidation of fuels, which require advancements in scaffolding for substrate channeling. ${ }^{274,282,287-289}$

The majority of bioelectrocatalysts $(\mathrm{GOx}, \mathrm{GDH}, \mathrm{CDH}, \mathrm{FDH})$ is limited to specific substrates. Minteer's group reported a commercial genetically modified GOx (Amano Enzyme Inc., Japan) with enhanced promiscuity that is capable of oxidizing multiple mono-, di-, and poly-saccharides. ${ }^{274,289}$ This promiscuous GOx with broader substrate specificity is termed bGOx and utilizes a ferrocene-based redox hydrogel (linear polyethyleneimine (LPEI) grafted with dimethylferrocene $\left(\mathrm{FcMe}_{2}\right)$ with a propyl linker, $\mathrm{FcMe}_{2}-\mathrm{C}_{3}$-LPEI) that facilitated mediated electron transfer (MET) between the active site in the enzyme and the carbon electrode. 273,290 Hence, the combination of bGOx and PDH within the same electrode architecture should lead to a bioelectrode that performs multiple oxidations of a range of saccharides, as shown in Figs. $12 \mathrm{a}-\mathrm{h}$. For the bioelectrocatalysts, it is very easy to determine if a measured current signal results from active site or just "a background". This can be done by the denatured enzyme controls typically performed by heating $\left(100{ }^{\circ} \mathrm{C}\right.$ for a tens of minutes), whereby the biocatalytic activity of the enzyme is efficiently suppressed. Fig. 12g shows the different possibilities to use a bi-enzymatic bioelectrode in which dPDH and dbGOx refer to as denatured enzymes. It should be kept in mind that in a cascade reaction, even at the best scaffold, the recorded total current $(\mathrm{I})$ is not always the mathematic addition of the partial currents $\left(I_{p}\right)$ for the simple fact that the number of the active sites solicited for a given elementary step $p$ is not necessary that will be used for the further step $q$, or they will not occur simultaneously. So even though PDH oxidizes saccharide molecules at their $\mathrm{C} 2$ and/or C3 positions (4-electron transfer) whereas bGOx exclusively oxidizes them at the $\mathrm{C} 1$ position (2electron transfer), the current density associated with the bibioelectrocatalyst "PDH+bGOx" that has an overall exchange number of electrons $\left(n_{e x}\right)$ of " $n_{e x}=4+2=6$ " will not be a simple mathematic addition of those of PDH and bGOx. This can be experimentally seen in Figs. 12a-f for CVs and Fig. $12 \mathrm{~h}$ for the experimental exchanged number of electrons per substrate molecule based on the electrolysis $\left(n_{\text {exp }}\right)$. Since $n_{\text {exp }}$ is lower than the theoretical prediction $\mathrm{n}_{\mathrm{ex}}=6$, it was argued that the reaction may lead to a mixture of two reaction products, one from $\mathrm{C} 1+\mathrm{C} 2 / \mathrm{C} 3$ (meaning $2+2=4$ electrons) and another from $\mathrm{C} 1+\mathrm{C} 2+\mathrm{C} 3$ (meaning $2+2+2=6$ electrons), whereby the value of $n_{\exp }$ will be between 4 and 6 , as obtained experimentally. This is very plausible, since $\mathrm{n}_{\exp }$ determined for glucose oxidized at PDH electrode is about 7\% lower than the expected value of 4 .

There is however a number of restrictions regarding the biological electrocatalysts, the limitation in terms of $\mathrm{pH}$ and temperature range and those from the proper orientation of enzymes at the electrodes in order to maximize the number of active sites. The direct consequence is the lower electrical current produced by fuel/electrolysis cells fuelled by those organics, the current density rarely surpasses $1 \mathrm{~mA} \mathrm{~cm}^{-2}$ and the systems cannot operate for hundreds/thousands of hours continuously. In the other side, "abiotic electrocatalysts" can rarely enable reaching comparative selectivity. Then, one logical solution that takes the advantages of both systems is a combination of materials science and bioelectrochemical engineering to design advanced electrodes with switchable surface properties. This could lead to a "hybrid electrode" with much higher current density and prolonged lifetime. Indeed, the efficiency of the biological electrocatalysts depends on the proper electrical contact between the redox protein center and the electrode surface, which hereafter limits the turnover of the electron transfer. For example, one possibility can be an $\mathrm{Au}$ electrode design (Section 5.1.2., Au has excellent selectivity in 
the oligosaccharide electrooxidation by their C1-position) to maximize proteins recognition for better cross-linking. ${ }^{291,292}$ For instance, shape-controlled nanocrystals with different crystallographic facets $\mathrm{Au}(\mathrm{hkl})$ could lead to a kind of hierarchical Au(khl)-biomolecule (enzyme and its cofactors) for an efficient electrochemical oxidation of substrates.
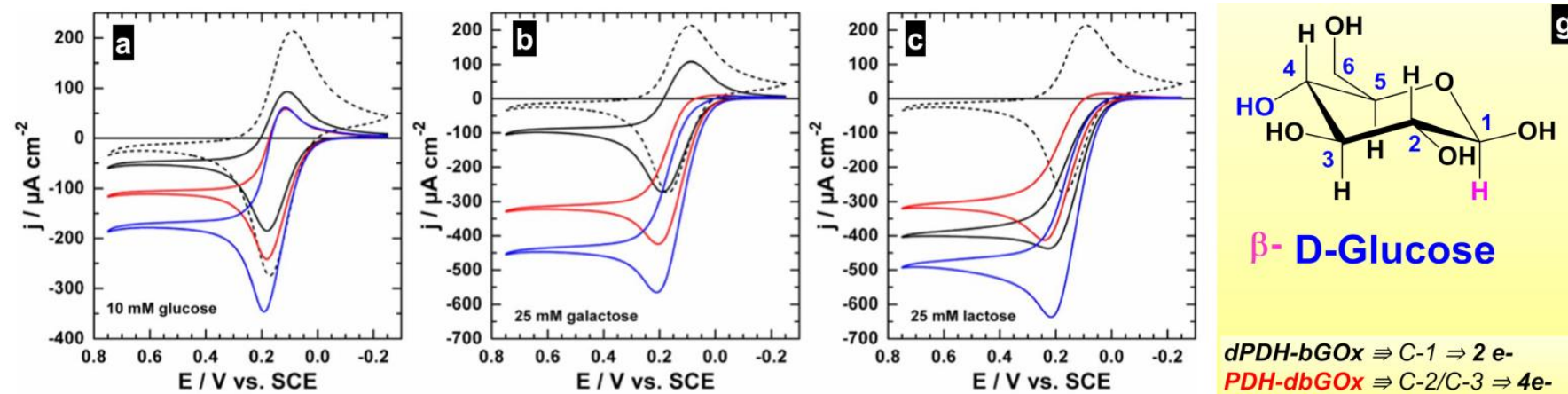

\section{$\beta$ - D-Glucose}
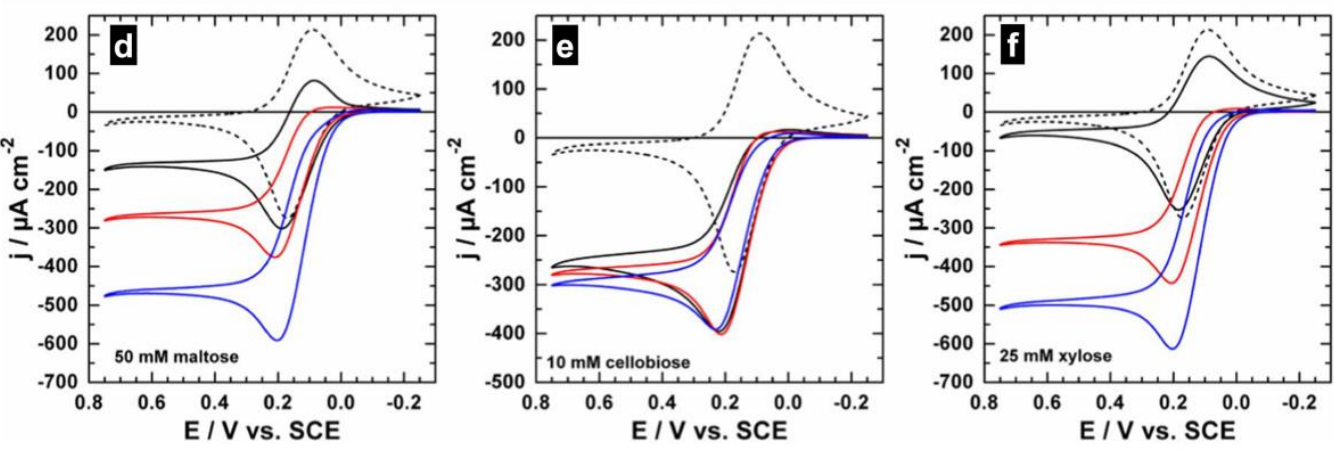

$d P D H-b G O x \Rightarrow C-1 \Rightarrow 2 \mathrm{e}-$

$P D H-d b G O x \Rightarrow C-2 / C-3 \Rightarrow 4 e-$

$P D H-b G O x \Rightarrow C-1 / C-2 / C-3 \Rightarrow 6 e-$

Fig. 12. (a-f) CVs at $10 \mathrm{mV} \mathrm{s}^{-1}$ of the mono- and bi-enzymatic bioelectrodes in citrate/phosphate buffer ( $0.2 \mathrm{M}, \mathrm{pH} 6.5$ ) in the absence (dashed lines) and in the presence (solid lines) of different (oligo)saccharides (solid lines): dPDH-bGOx (black line), PDH-dbGOx (red line) and PDH-bGOx (blue line). (g) Different scenarios of enzymatic glucose electrooxidation. (h) Experimental exchanged number of electrons per substrate molecule based on the electrolysis (Error bars represent one sta ndard deviation, $n \geq 4$ ): the horizontal lines represent the theoretical maximum exchanged number of electrons per molecule of substrate. Reprinted and adapted with permission from Ref. ${ }^{289}$; Copyright 2016, The Electrochemical Society.

5.1.2. Nanostructured electrocatalysts for active and selective oxidation. Despite the fact that Pt is the best electrocatalyst for oligosaccharides, ${ }^{104,293-296} \mathrm{Au}$ is by far the material of choice when it comes to control the oxidation of the carbon chain, i.e. the selectivity. ${ }^{50,51}$ Indeed, monometallic Au exhibits not only remarkable catalytic activity towards aldehydes and hemiacetals, but also high selectivity for carbohydrates by their anomeric position leading to value-added chemicals. For example, gluconic acid is a mild organic acid with tremendous interest in various fields as a raw material or in its derivative forms of $\delta / \gamma$-gluconolactone, sodium and calcium salts (used in food, pharmaceutical, and cosmetic industries). ${ }^{297-301}$ To implement this selectivity trends in electrocatalysis for fuel cells and electrolysis cells, many synthesis methods have been developed to fabricate supported, 50,119,164,302 nanoporous ${ }^{139,189-}$ 191,303-305 and unsupported NPs $163,183,204,306,307$ in order to interrogate the effect of the support, shape and (hkl) facets. The 2011 's report of Wang et al. ${ }^{306}$ appeared to be the first works on the shape-dependent electrocatalytic activity of monodispersed $\mathrm{Au}$ nanocrystals towards glucose oxidation. Authors used a seed-mediated growth method ${ }^{308}$ to fabricate three types of Au polyhedra, rhombic dodecahedra, octahedra and cubes, which have the low-index (110), (111) and (100) facets, respectively. ${ }^{306,308}$ The catalytic tests in $0.1 \mathrm{M} \mathrm{NaOH}+10$ $\mathrm{mM}$ glucose showed that (100)-bonded cubic Au nanocrystals are significantly more active than the (110)-bonded rhombic dodecahedral and (111)-bonded octahedral Au nanocrystals. Hebié and co-workers produced different morphologies of AuNPs and observed that the contribution of the (100) facet on the electrocatalytic activity is much important that other lowindex. ${ }^{165,183,307,309}$ In 2015, it was reported a drastic enhancement of the electrocatalytic reactivity of glucose molecules at the surface of catalysts based on "bare" unprotected gold nanoparticles (AuNPs) synthesized by the laser ablation method in pure deionized water, surpassing the performance of conventional chemically synthesized AuNPs and other metals/alloy-based catalysts. ${ }^{165}$ It should be emphasized that, by comparing the activity of AuNPs obtained in the absence and presence of a capping agent/surfactant, the study also definitely highlighted the importance of the NPs surface cleanliness.

In 2017, Lu et al. ${ }^{310}$ utilized the electrodeposition in a deep eutectic solvent medium (combining the seed and electrode potential mediated synthesis) to produce high-index faceted $\mathrm{Au}$ nanocrystals and probe the effects on the electrocatalytic oxidation of glucose in alkaline media. The approach is resumed 
in Figs. 13a-b. It can be clearly observed that the high-index facets having a high density of atomic steps and kinks (stellated, concave trisoctahedra with high-index (991) facets, and concave hexoctahedra with high-index (421) facets) exhibit higher electrocatalytic activity than that of the bulk Au electrode. This would mean that the steps and kinks serve as the active sites and play an important role in electrocatalysis with AuNPs. ${ }^{204,310}$ Furthermore, an electro-kinetic combined electrochemical study of the glucose electro-oxidation at Au showed that fresh glucose molecules are continuously oxidized over (200) surface, while (111) favoured the oxidation of byproducts. ${ }^{311}$ Hence, the selectivity would therefore be directly related to high-index. The pulse electrodeposition in which lower and upper potential limits in a three-electrode configuration can be used as regulators is recognized to be an elegant method to directly tethered shape-control metal NPs to the surface of carbon substrates with high electrocatalysis activity in oxidation and reduction reactions. ${ }^{312-315}$

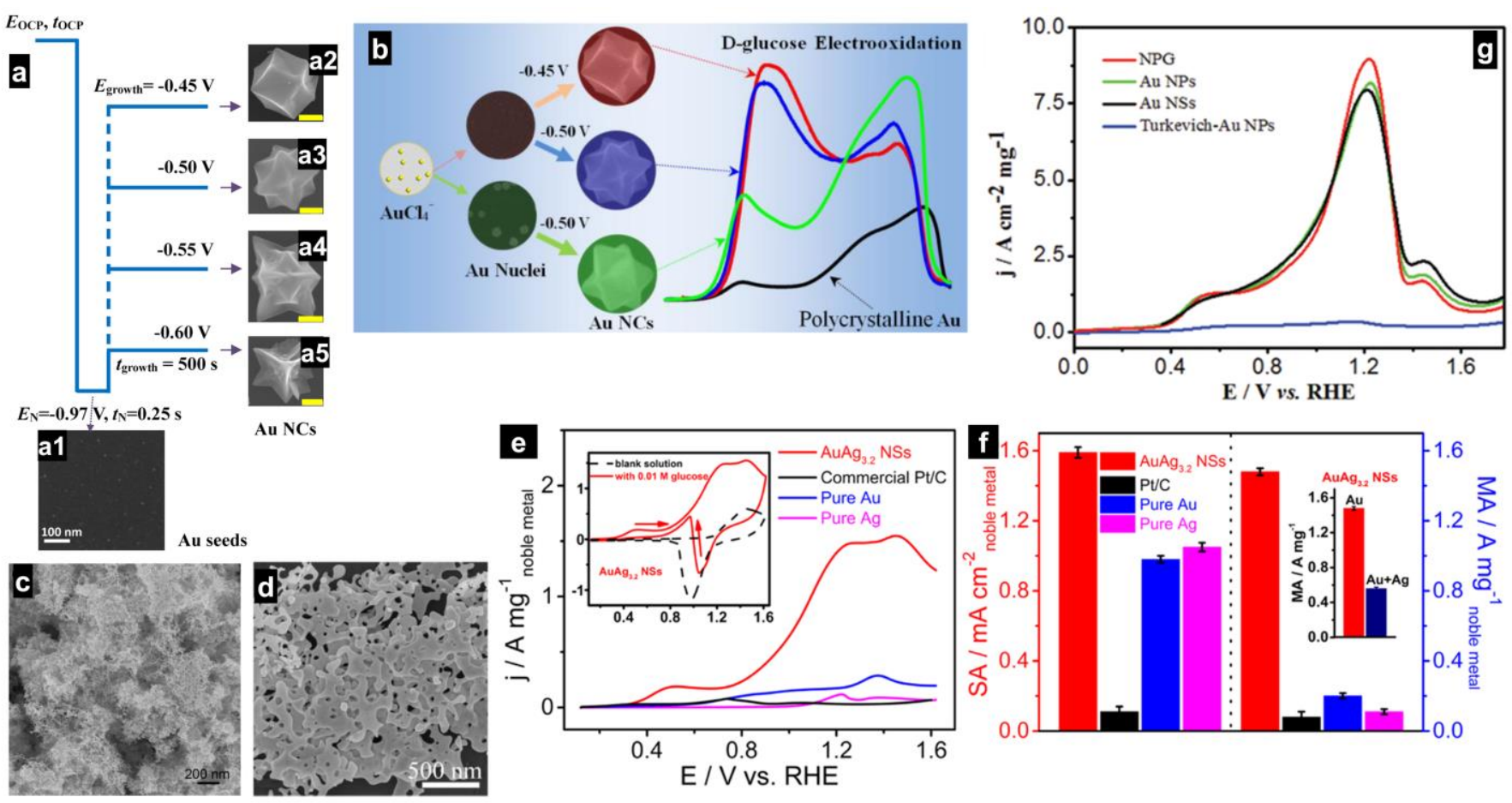

Fig. 13. (a) Procedure and the corresponding SEM images (scale bars: $100 \mathrm{~nm}$ ) of Au NCs deposited at different growth potentials: (a1) Au seeds; (a2-a5) Au NCs deposited at -0.45, $-0.50,-0.55$, and $-0.60 \mathrm{~V}$ vs Pt quasi-reference electrode, respectively. (b) Cartoons of shaped-dependent performance: LSV recorded on stellated, concave trisoctahedra, concave hexoctahedra Au NCs, and polycrystalline Au electrode in $0.1 \mathrm{M} \mathrm{NaOH}+10 \mathrm{mM}$ glucose at scan rate of $50 \mathrm{mV} \mathrm{s}^{-1}$. (c) SEM of AuAg nanoporous sponges (NSs). (d) SEM image of nanoporous gold (NPG). (e) CVs curves at $50 \mathrm{mV} \mathrm{s}^{-1}$ for AuAg NSs, commercial Pt/C, and pure monometallic Au and Ag electrocatalysts for glucose (10 mM) oxidation in $0.1 \mathrm{M} \mathrm{KOH}$ and the corresponding peak current densities (f). (g) CV profiles at $10 \mathrm{mV} \mathrm{s}^{-1}$ for NPG, Au nanoparticles (NPs), and Au nanosheets (NSs) based electrodes in $0.1 \mathrm{M} \mathrm{NaOH}$ in the presence of $10 \mathrm{mM}$ glucose. (a, b) Reprinted and adapted with permission from Ref. ${ }^{310}$; Copyright 2017, American Chemical Society. (c, e, f) Reprinted and adapted with permission from Ref. ${ }^{139}$; Copyright 2018, American Chemical Society. (d, g) Reprinted and adapted with permission from Ref. ${ }^{191}$; Copyright 2017 , The Royal Society of Chemistry.

The self-assembly into 3D of Au nano-architectures with nanoscale and cavity defects in their channels and on their pore walls such as nanoporous, nanosponges, nanocorals, nanothorns, branched belts and flower-like morphologies has emerged as advanced tactics to maximize the electrocatalytic reactivity of glucose by the number of exposed active sites. ${ }^{139,166,316,317}$ Fig. 13c shows a SEM image of Au-Ag nanosponges synthesized by the co-reduction of an aqueous solution of $\mathrm{HAuCl}_{4}$ and $\mathrm{AgNO}_{3}$ by an ice-cold aqueous solution of $\mathrm{NaBH}_{4}{ }^{139}$ It was observed by XPS that for an Au/Ag atomic ratio of $23.87 / 76.13\left(\mathrm{AuAg}_{3.2}\right)$, the $\mathrm{Au} 4 \mathrm{f}$ energy level shifts toward higher binding energies in comparison to that in pure $\mathrm{Au}$, whereas those of $\mathrm{Ag} 3 \mathrm{~d}$ move toward lower binding energies relative to that in pure $\mathrm{Ag}$, indicating an electron transfer from $\mathrm{Au}$ atoms to those of $\mathrm{Ag}$. The voltammetry curves at $50 \mathrm{mV} \mathrm{s}^{-1}$ (Fig. 13e) and corresponding peak current densities
(Fig. 13f) in $0.1 \mathrm{M} \mathrm{KOH}+10 \mathrm{mM}$ glucose demonstrate that the combined nanoporosity (BET surface area of $18.5 \mathrm{~m}^{2} \mathrm{~g}^{-1}$, from $\mathrm{N}_{2}$ adsorption-desorption isotherms) and alloying effects have facilitated the electrocatalysis. Nanoporous gold (NPG) structures are most commonly obtained by methods of dealloying. ${ }^{204,205,207,292,303} \mathrm{Xu}$ et al. ${ }^{191}$ reported in 2017 unusual kinetically controlled synthesis of NPG which possessed abundant high-index facets, kinks, and steps, as effective and high-performance catalysts for the glucose electrooxidation. They utilized a trisodium citrate self-initiated reduction of $\mathrm{Au}(\mathrm{III})$ in the form of an $\mathrm{HAuCl}_{4}$ aqueous solution in a water-ice bath, whereby citrate acts as reducing agent and a $\mathrm{pH}$ mediator, and " $\mathrm{Na}_{2} \mathrm{CO}_{3} \cdot 10 \mathrm{H}_{2} \mathrm{O}$ as another $\mathrm{pH}$ mediator. ${ }^{191}$ Fig. $13 \mathrm{~d}$ shows the SEM micrograph of those NPG wherein the size of $\mathrm{Au}$ ligaments is $50-80 \mathrm{~nm}$ with voids of 50 to $200 \mathrm{~nm}$. The CVs (Fig. $13 \mathrm{~g}$ ) compare the electrocatalytic activity (in $0.1 \mathrm{M} \mathrm{NaOH}+10$ 
mM glucose) of NPG, self-supported AuNPs (similar method by a different maturation time), Au nanosheets (NSs, similar method by a different maturation time), Turkevich-AuNPs obtained by the reputed Turkevich method.318,319 For the later, $95 \mathrm{~mL}$ of $\mathrm{HAuCl}_{4}$ aqueous solution (containing $5 \mathrm{mg}$ of $\mathrm{Au}$ ) was heated to the boiling point and $5 \mathrm{~mL}$ of $1 \%$ sodium citrate solution was added to the boiling solution under good stirring; subsequently, a greyish pink/wine colour appeared before becoming, after $5 \mathrm{~min}$, deep wine/red characteristic of colloid Au particles. ${ }^{191}$ For NPG structures, a current density of $9 \mathrm{~A} \mathrm{~cm}^{-2}$ $\mathrm{mg}^{-1}$ (corresponding to $18 \mathrm{~A} \mathrm{~cm}^{-2}$ or $636 \mathrm{~A} \mathrm{~g}^{-1}$ ) is over 20 times higher than that of AuNPs from the Turkevich method. The authors ascribed the remarkable electrocatalytic activity increase to the large electrochemically active surface area, clean surface, and high-index facets. It should be, however, noted that both self-supported and nanosheets based NPs have similar performance to NPG. The small difference at the peak is due to the much smaller size of the pores in NPG that might facilitate the reactant or products diffusion.

In recent years, Holade and co-workers have screened the ability of Vulcan $50,51,320$ and $\mathrm{rGO}^{164}$ supported Au-based nanomaterials to electro-catalytically oxidize mono- and disaccharides in alkaline and neutral $\mathrm{pHs}$ by integrating electrochemical and analytical techniques. Two different synthesis methods were combined, "Bromide Anion Exchange" and radiolysis. ${ }^{305,321,322}$ Figs. $14 \mathrm{a}$ and $14 \mathrm{~b}$ show the online FTIR spectra collected during chronoamperometry measurements in $\mathrm{NaOH}(0.1 \mathrm{M}, \mathrm{pH} 12.8)$ in the presence of glucose at $0.5 \mathrm{~V}$ vs RHE and those recorded at $30 \mathrm{~min}$ at $0.8 \mathrm{~V}$ vs RHE. The Figs. $14 \mathrm{c}$ and 14d display the spectra from SPAIRS analysis in the presence of glucose and galactose, respectively. The presence of the gluconolactone with its $v_{\mathrm{C}=0}$ specific band at $1742 \mathrm{~cm}^{-1}$ (stretching vibration mode) at $\mathrm{pH} 7.4$ and absence at $\mathrm{pH} 12.3$ show that gluconolactone is an intermediate and its transformation into gluconate is much faster in an alkaline environment. It was reported that, at $\mathrm{pH} 7.4$, the observed corresponding lactone and acid forms detected by their specific vibration bands of 1744 and $1780 \mathrm{~cm}^{-1}$, result from a local $\mathrm{pH}$ decrease within the thin-electrolyte, which has been now accepted as a fait accompli during the organics electrooxidation. $13,51,116,117,119,132,323$ Indeed, the observation of an "acid form" of an electrooxidation product from an organic molecule in strong alkaline media was believed to be highly improbable until 2010. Subsequently, by studying the glycerol electrooxidation reaction on a polycrystalline $A u$ in alkaline media, Jeffery and Camara ${ }^{117}$ observed on SPAIR spectra an intense band at $2343 \mathrm{~cm}^{-1}$ (starting from $0.8 \mathrm{~V}$ vs RHE), which unquestionably belongs to $\mathrm{CO}_{2}$. Based on a relatively simple calculation about the thin layer (thickness ${ }^{117,324-326}$ of 1-10 $\mu \mathrm{m}$ and glycerol consumption ${ }^{117,327}$ of $10 \mathrm{nmol}$ ) they have come up that the $\mathrm{OH}^{-}$consumption during the electrooxidation of glycerol is a consequence of a significant decrease of $\mathrm{pH}$ inside the thin layer. Hence, glycerol or its intermediates have to react with water molecules, thus forming $\mathrm{CO}_{2}$. The band being widely

observed, ${ }^{13,116,118,126,176,328}$ the significant local pH decrease has been definitely endorsed. For the glucose electrocatalysis reported by Holade et al., ${ }^{50,51}$ gluconic acid being a much stronger acid ( $\mathrm{pKa}=3.75$ ), 329 the local decrease of $\mathrm{pH}$ that would result in a rapid protonation of gluconate to gluconic acid is too important from $\mathrm{pH} 12.8$ to $\mathrm{pH}$ around 3.75. However, in a buffered solution of $\mathrm{pH} 7.4$, the decrease is less important and gluconic acid can be observed by FTIRS.

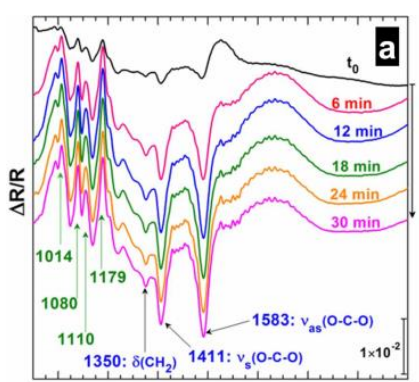

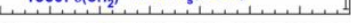

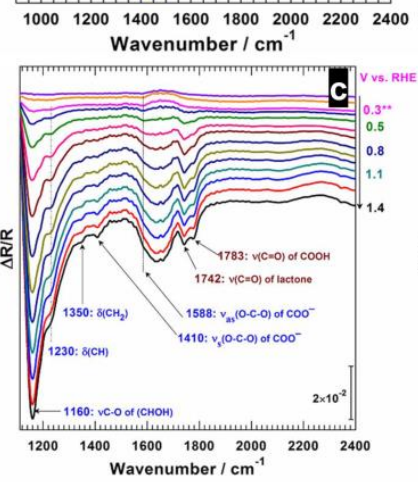

Fig. 14. Spectroelectrochemistry experiments. (a, b) $\mathrm{NaOH}(0.1 \mathrm{M}, \mathrm{pH} 12.8)$ electrolyte in the presence of $50 \mathrm{mM}$ glucose: (a) CA at $0.5 \mathrm{~V}$ vs RHE on $\mathrm{Au}_{60} \mathrm{Pt}_{40} / \mathrm{C}$; (b) CA at $0.8 \mathrm{~V}$ vs RHE on different electrode materials at $t=30 \mathrm{~min}$. (c, d) Phosphate buffer $(0.2 \mathrm{M}, \mathrm{pH}$ 7.4) electrolyte in the presence of $100 \mathrm{mM}$ substrate: SPAIRS at a quasi-steady state scan rate of $1 \mathrm{mV} \mathrm{s}^{-1}$ : (c) $\mathrm{Au}_{80} \mathrm{Pt}_{20} / \mathrm{C}$ electrode material in the presence of glucose; (d) $\mathrm{Au} / \mathrm{C}$ electrode material in the presence of galactose: the inset shows the spectrum recorded at $0.3 \mathrm{~V}$ vs. RHE. Temperature: $22 \pm 2{ }^{\circ} \mathrm{C}$. Reprinted and adapted with permission from Ref. ${ }^{51}$; Copyright 2016, The Electrochemical Society.

Furthermore, the band at $\sim 1350 \mathrm{~cm}^{-1}$ corresponding to the deformation vibration mode of $\delta\left(\mathrm{CH}_{2}\right)^{51}$ supported by the two intense bands at 1584 and $1413 \mathrm{~cm}^{-1}$ - asymmetric stretching vibration $v_{a s}(\mathrm{O}-\mathrm{C}-\mathrm{O})$ and symmetric $\mathrm{v}_{\mathrm{s}}(\mathrm{O}-\mathrm{C}-\mathrm{O})$ of the $\mathrm{COO}^{-}$ function of an oxidized carbohydrate - definitely validate the formation of gluconate as the solely product. Indeed, different products of glucose oxidation could have that $\mathrm{COO}^{-}$function, gluconate (oxidation of the carbon on C1-position, $\mathrm{n}_{\mathrm{ex}}=2$ ), glucuronate (oxidation of the carbon on C6-position, $n_{\mathrm{ex}}=4$ ) and glucarate (both C1-position and C6-position oxidation, $\mathrm{n}_{\mathrm{ex}}=2+$ $4=6$ ). So, since only glucose, gluconolactone and gluconate have the $-\mathrm{CH}_{2}$ - function in $\mathrm{C} 6$-position, it can be used as a distinguishing parameter. The ${ }^{13} \mathrm{C} N M R$ of the electrolyzed glucose and declined in DEPT-135 spectrum (to differentiate $\mathrm{CH}_{3}$ or $\mathrm{CH}$ signals to that of $\mathrm{CH}_{2}$ ) helps to unambiguously solved the assignments and then leads to the identification. ${ }^{50}$ To decipher this definitely, authors employed the LC-MS to distinguish those different acids (after electrolysis, 
neutralization and lyophilisation steps) being based on the mass of their pseudo-molecular ions $[\mathrm{M}-\mathrm{H}]^{-}, \mathrm{m} / \mathrm{z}=209$ (glucaric), 195 (gluconic), and 193 (glucuronic) in negative-ionization mode. ${ }^{50}$

One of the motivations behind the electrochemistry of those derivates of the biomass is the possibility to further design high-performance electrode materials capable of performing the entire cellulose, hemicellulose and lignin electro-conversion efficiently. The next section reviews the few attempts that have been reported in this area over the past ten years, ranging from the bioelectrocatalysts to the molecular or metallic ones.

\subsection{Cellulose, hemicellulose and lignin electro-conversion}

5.2.1. Enzymatic, microbial and molecular electrocatalysis. The previous investigation of the oligosaccharides serves as a starting point for a much wider target, being able to electrocatalytically transformed the whole biomass such as cellulose, hemicellulose and lignin into valuable chemicals. Given the complexity of their structures, enzymatic, microbial or molecular electrocatalysts seems to be the most suitable solutions. One of the widely used catalyst is the 2,2,6,6tetramethyl-1-piperidine N-oxyl (TEMPO, with different appellations of molecular catalyst, catalytic mediator, organic oxidation catalyst) with high electrocatalytic activity and selectivity. This TEMPO can be functionalized for a large scope of electrooxidation reactions. ${ }^{239,288,330-333}$ Parpot et al. ${ }^{330}$ reported seminal works for the oxidation of the primary alcohol groups in carbohydrates in the presence and absence of an aldehyde group. The outcomes in $0.2 \mathrm{M}$ carbonate buffer $(\mathrm{pH}$ 10) show a selective oxidation into sodium uronate with high Faradaic yields when no aldehyde or hemiacetal function is present. Their presence provokes a decrease in selectivities as well as an increase of the amount of by-products. The authors also did the electrolysis of $3 \mathrm{~g} \mathrm{~L}^{-1}$ mercerized microcrystalline cellulose at $0.5 \mathrm{~V}$ vs $\mathrm{Ag} / \mathrm{AgCl}$ and analysed the solution by FTIRS, NMR, and titrations that show a primary alcohol function conversion into carboxylate without affecting the whole structure. It should be noted that cellulose is a polymer of cellobiose, which is a dimer of glucose. Thus, the research of glucose and cellobiose electrooxidation could be translated into cellulose once solubility issue is fixed. For that, many attempts have been imagined in the literature to improve the solubility of those biomass derivates. ${ }^{333-353}$

It was recently observed that the lignin electrolysis at TEMPO-based organic catalysts in $\mathrm{H}_{2} \mathrm{O} / \mathrm{CH}_{3} \mathrm{CN}$ (70/30) solvent with $\mathrm{NaHCO}_{3} / \mathrm{Na}_{2} \mathrm{CO}_{3}$ electrolyte at $\mathrm{pH} 10$ leads to the selective electrocatalytic oxidation of the primary alcohol groups in lignin to carboxylic acids, resulting in the formation of a polyelectrolyte. ${ }^{333}$ The other types of "metal-free" catalysts to electro-convert the lignocellulosic biomass into valuable chemical(s) while producing electricity (fuel cells, microbial fuel cells) or $\mathrm{H}_{2}$ (electrolysis cells) under low temperature conditions (below $100{ }^{\circ} \mathrm{C}$ ) include enzymes, 354,355 bacteria, ${ }^{338,354-356}$ methyl viologen, ${ }^{348,355,357}$ and polyoxometalates (POMs). ${ }^{355,358,359}$ Given the low current density that can be achieved with these types of catalysts, the metal-based systems could be an alternative.

5.2.2. Nanostructured electrocatalysts for active and selective oxidation. Very few studies with metal NPs have been undertaken to interrogate the cellulose, hemicellulose or lignin electrooxidation. ${ }^{340,342,345-347,360,361}$ As aforementioned, the low solubility of those organics in aqueous media associated with the complexity of the carbonaceous chain leads to the perception that the setup needed for a full understanding of the process should be complicated. This is an unfamiliar territory for the electrocatalysis community that used to work with relatively simple molecules. To get significant quantities of "solubilized cellulose", alkaline electrolytes are the most employed. One of the recipes consists of shaking cellulose in concentrated $\mathrm{NaOH}$ (at least $1 \mathrm{M}$ ) for few hours at room temperature (RT), storing the mixture at $-20{ }^{\circ} \mathrm{C}$ until it equilibrate (about one day), and allowing the frozen sample to thaw at RT; a concentration of cellulose of about $5 \mathrm{~g} \mathrm{~L}^{-1}$ can be reached. ${ }^{340,347}$
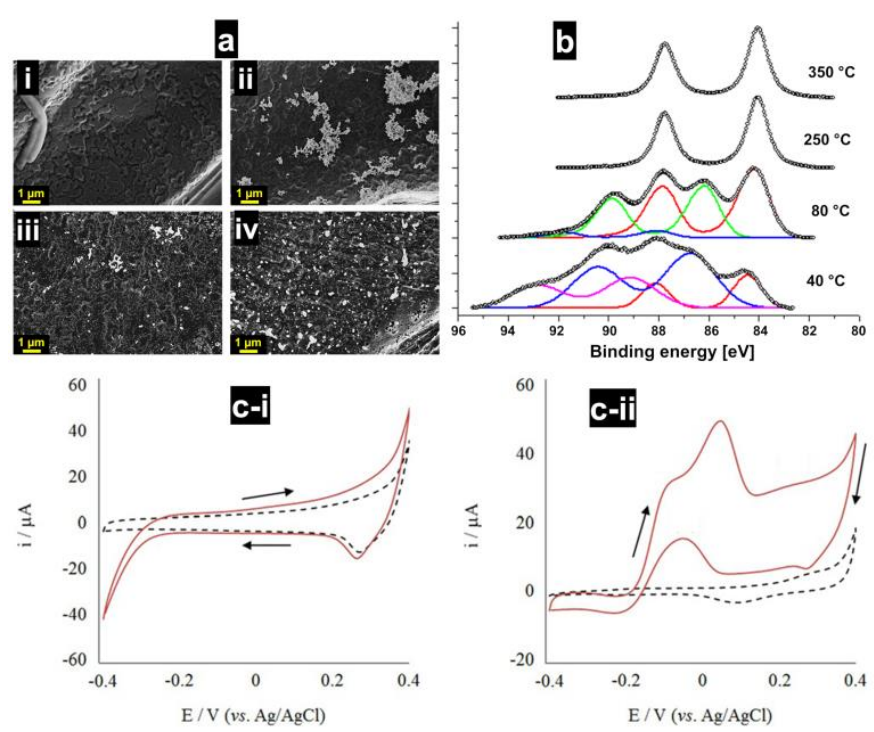

Fig. 15. (a) SEM images of: (i) bare $\mathrm{CP}$, (ii) $\mathrm{CP}$-AuNPs calcined at $40{ }^{\circ} \mathrm{C}$, (iii) $\mathrm{CP}$-AuNPs calcined at $250^{\circ} \mathrm{C}$, (iv) CP-AuNPs calcined at $350^{\circ} \mathrm{C}$. (b) From bottom to up: XPS spectra of Au4f core level of CP-AuNPs after calcination different temperatures of $40^{\circ} \mathrm{C}, 80^{\circ} \mathrm{C}$, $250{ }^{\circ} \mathrm{C}$, and $350{ }^{\circ} \mathrm{C}$. (c) CVs at $10 \mathrm{mV} \mathrm{s}^{-1}$ in $1.3 \mathrm{M} \mathrm{NaOH}$ in the absence (dashed line) and in the presence of $1 \%(\mathrm{w} / \mathrm{v})$ cellulose (solid line) for CP-AuNPs after calcination at: (c-i) $40{ }^{\circ} \mathrm{C}$ and (C-ii) $250{ }^{\circ} \mathrm{C}$. Reprinted and adapted with permission from Ref.; ${ }^{346}$ Copyright 2016, WILEY-VCH Verlag GmbH \& Co. KGaA, Weinheim.

Sugano et al. ${ }^{346}$ used a calcination method to directly incorporate AuNPs into the surface of a carbon paper electrode in order to enhance the electrocatalytic ability towards cellulose electrooxidation. Figs. $15 \mathrm{a}$ and $15 \mathrm{~b}$ show the corresponding SEM and XPS results at different temperatures. A minimum temperature of $250^{\circ} \mathrm{C}$ is necessary to decompose the $\mathrm{Au}(\mathrm{III})$ salt into $\mathrm{Au}(0)$ as shown by XPS. The CVs profiles in Fig. $15 \mathrm{c}(1.3 \mathrm{M}$ $\mathrm{NaOH}$, cellulose at $1 \% \mathrm{w} / \mathrm{v}$ ) show an activity of AuNPs obtained at $250^{\circ} \mathrm{C}$. Except the comparison with a bare polycrystalline $\mathrm{Au}$ electrode that was observed to be higher, no quantitative 
analysis has been fulfilled to determine the nature of the oxidation products. In 2014, it was found that the electrocatalytic oxidation at Au surface led to two types of products; one was a water-soluble material in which some hydroxyl groups of cellulose were oxidized into carboxylic groups and the other was a water-insoluble hybrid material composed of cellulose and AuNPs (about ca. $4 \mathrm{~nm}$ ) generated on the course of the electrolysis, i.e. the support degradation. At carbon aerogel supported AuNPs, Xiao et al. ${ }^{347}$ observed a high conversion of cellulose and selectivity to gluconate wherein AuNPs was the anode and Pt sheet was the cathode (applied current density of $10 \mathrm{~mA} \mathrm{~cm}^{-2}$, no information about $\mathrm{NaOH}$ concentration as well as the role of air that was bubbled into the reaction system at a flow rate of $150 \mathrm{~mL} \mathrm{~min}^{-1}$ ).

\subsection{Theoretical and computational insights}

Although, DFT calculations have been widely and successfully used in the field, it is still very difficult to identify some oxidation reaction pathways as for example for lignin, cellulose, and hemicellulose. This limitation comes from the high complexity of experimental conditions that cannot be fully described by DFT as well as the limited computational capabilities of modern supercomputers. One possible solution is to examine by DFT the stability and the interaction of the corresponding monomers, or even dimers. From this viewpoint, glucose (linear or cyclic forms) is the most facile. Surprisingly, very few studies have been conducted by DFT, at least to examine the interaction between the molecule and the catalyst surface. In 2014, Ishimoto et al. ${ }^{362}$ analysed the surface structure of $A u$ and the glucose oxidation reaction in alkaline solution and came up with the ideas that, in alkaline solution, (i) glucose firstly adsorbs on -OH of Au surface, (ii) then $\mathrm{OH}^{-}$in alkaline solution interacts with - $\mathrm{CHO}$ group of glucose, (iii) $\mathrm{H}_{2} \mathrm{O}$ is formed subsequently by proton transfer from -CHO group of glucose to $\mathrm{OH}^{-}$in solution, (iv) gluconic acid is finally formed by $-\mathrm{OH}$ transfer from $\mathrm{Au}$ surface. Such a mechanistic approach could be not only "unrealistic", but above all, it could not explain a number of experimental observations during electrochemical measurements. Indeed, the first step assumes that at the beginning, the $\mathrm{Au}$ surface must have some adsorbed $\mathrm{OH}$ species. However, in an alkaline media, glucose electrooxidation is observed for electrode potentials for which the surface is not yet covered by these species $(\leq 0.3 \mathrm{~V}$ vs RHE). ${ }^{165,190,191,204,306,363}$ It was furthermore demonstrated that the support (carbon or $\mathrm{ZrO}_{2} / \mathrm{SnO}_{2}$ oxides) of $\mathrm{Au}$ has a notable effect on its catalytic activity; Au-support interaction induces a positive atomic charge of Au catalyst that induces the activity of glucose oxidation reaction to get exalted. ${ }^{364}$

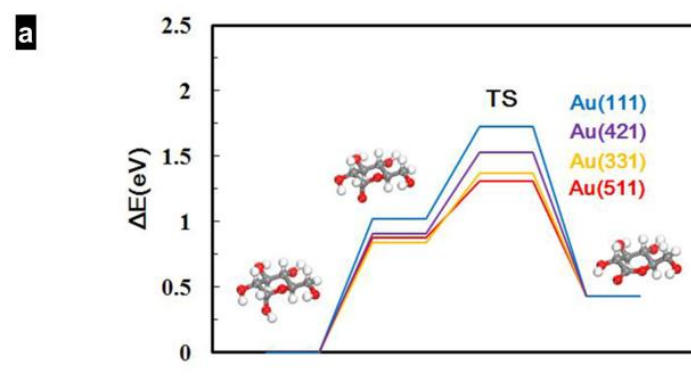

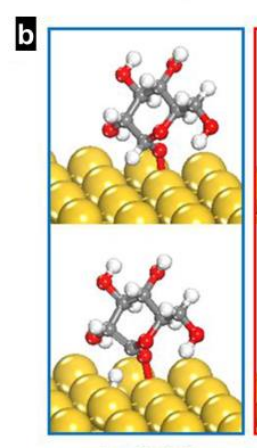

$\mathrm{Au}(111)$

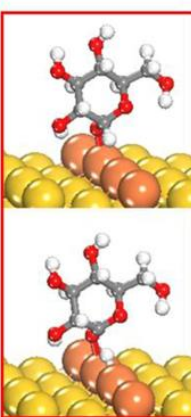

$\mathrm{Au}(511)$

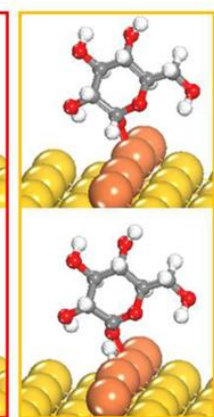

Au(331)

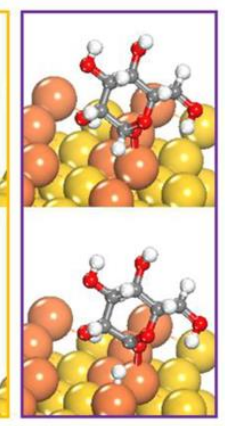

$\mathrm{Au}(421)$
Fig. 16. (a) DFT calculated energy profiles for the anomeric carbon oxidation in glucose on $\mathrm{Au}(111)$ (in blue), $\mathrm{Au}(511)$ (in red), $\mathrm{Au}(331)$ (in yellow), and $\mathrm{Au}(421)$ (in purple) with the molecular structures. (b) Optimized intermediates and transition states for $\mathrm{C}-\mathrm{H}$ bond breaking on different gold surfaces. Reprinted and adapted with permission from Ref. ${ }^{310}$, Copyright 2017, American Chemical Society.

In 2017, Weil et al. ${ }^{310}$ proposed, from DFT calculations, the energy profiles (calculated at an electrode potential of $0 \mathrm{~V}$ vs $\mathrm{SHE}$ ) for the anomeric carbon oxidation in glucose on different surfaces of Au as well as the "optimized" intermediates and transition states for $\mathrm{C}-\mathrm{H}$ bond cleavage (see Figs. 16a-b). According to these authors, the recognized initial glucose oxidation by the dehydrogenation of anomeric carbon forming carbonyl group ( 2 coupled proton-electron transfer) proceeds as follows: (i) firstly, $\mathrm{C}_{6} \mathrm{H}_{11} \mathrm{O}_{6}{ }^{*}$ is formed via the deprotonation of the hydroxyl group of the anomeric carbon, (ii) secondly, the $\mathrm{C}-\mathrm{H}$ bond breaking occurs. This leads to the proposition of the transition states sketched in Fig. 16b, highlighting an adsorbed intermediate by the "O" of the anomeric carbon instead of that carbon itself. One can therefore briefly summarize that, according to authors, the key advance in glucose electrocatalysis at gold is to mastery the "Au-O" bond. However, geometric/spatial considerations and experimental observations contradict this point of view. ${ }^{51,294}$ Indeed, this mechanism suggests that the anomeric form $\alpha$ of glucose would be the most catalytically reactive, which is not the case for either enzymes or metals at which $\beta$-glucose is the best reactive form of glucose. ${ }^{293,294,365 ~ I n ~ a d d i t i o n, ~ t h e ~ s t e r i c ~ c l u t t e r ~ i n ~ b o t h ~}$ forms implies that the easiest approach on a catalytic surface should be logically the one for which " $\mathrm{H}$ " instead of "OH" is oriented towards the surface. Owing to its good spatial arrangement, the adsorption of the anomeric form $\beta$ may lead to an intermediate that is linked to the catalytic surface through the atom of carbon $\mathrm{C} 1$ and not that of oxygen, as proposed in Ref. ${ }^{51}$ Definitely, there is a great need for advanced, sensitive and complementary computational and experimental (mainly 
those based on in-situ measurements) methods development to clearly elucidate mechanism.

\subsection{Biomass-fuelled fuel cells for simultaneous production of electricity and chemicals}

Among the biomass-based compounds, glucose is by far the most studied for fuel cell applications. For electrochemists and bioelectrochemists, the wide term of "fuel cell" can be expanded, depending on the experimental conditions or the purpose that the electricity shall serve. Historically, the glucose electrooxidation has been studied not because of its integration in conventional fuel cells that operate at extreme conditions of acidic or alkaline $\mathrm{pHs}$, but for the great importance of glucose in sensing (diabetes management) as well as the generation of self-sufficient electrical energy through an electrochemical energy converter, the so-called glucose $/ \mathrm{O}_{2}$ "biofuel cell" ( $\mathrm{pH}$ ca. 7.7). Those biofuel cells were intended to power cardiac assisted devices such as "artificial hearts" or pacemakers; or ultimately, supply electrical power to homes or electrical grids by electrooxidizing glucose in wastes or their derivatives. In this case, the cogeneration does not mean that an electrosynthesis will be performed within a "biological body"; rather the oxidation leads to a "guest reaction product" possessing an excellent biocompatibility with the "host body". Figs. 17a-b show the fuel cell performance recorded in buffer $(0.2 \mathrm{M}, \mathrm{pH}$ 6.5; different saccharides at $50 \mathrm{mM}$ ) utilizing a bi-enzymatic anode $\mathrm{PDH}+\mathrm{bGOx}$ and bilirubin oxidase (BOx) biocathode. In this configuration, the glucose fuel has the highest electrical performance $\left(P_{\max }=167 \mu \mathrm{W} \mathrm{cm}{ }^{-2}\right.$, maximum current density of $j_{\mathrm{sc}}=0.7 \mathrm{~mA} \mathrm{~cm}^{-2}$ ). The origin of the enhancement could be the efficiency of the engineered glucose oxidase compared to conventional one as well as the $\mathrm{FCMe}_{2}-\mathrm{C}_{3}$ - $\mathrm{LPEI}$ redox polymer used to facilitate (mediate) electron transfer. ${ }^{51}$ This combination of PDH and bGOx achieves a "deep oxidation, $\mathrm{n}_{\exp }$ $=6$ " of oligosaccharides, whereby each substrate is able to undergo sequential oxidations by PDH and bGOx.
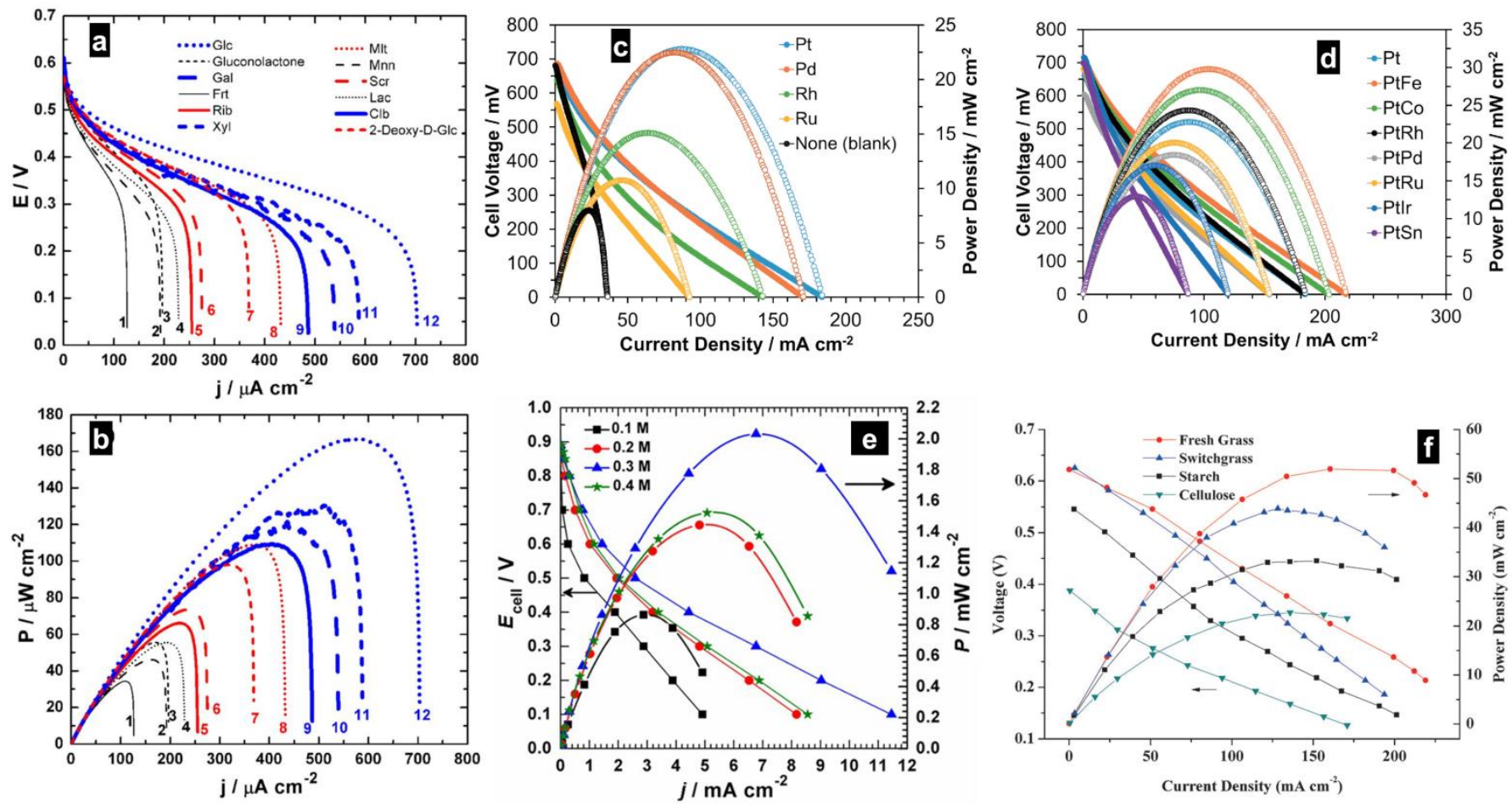

Fig. 17. (a, b) Enzymatic FC polarizations recorded in citrate/phosphate buffer ( $0.2 \mathrm{M}, \mathrm{pH} 6.5)$ containing different saccharides $(50 \mathrm{mM}): 1=\mathrm{Frt}($ fructose), $2=\mathrm{Mnn}$ (mannose), $3=$ gluconolactone, 4 = Lac (lactose), $5=$ Rib (ribose), $6=\mathrm{Scr}$ (sucrose), $7=2$-Deoxy-D-glc (2-deoxy-D-glucose), $8=\mathrm{Mlt}$ (maltose), $9=\mathrm{Clb}$ (cellobiose), $10=\mathrm{Gal}$ (galactose), $11=\mathrm{Xyl}$ (xylose), $12=\mathrm{Glc}$ (glucose). (c, d) Cellulose FC performance at metals and alloys nanomaterials as anode catalysts at $250{ }^{\circ} \mathrm{C}$ : (c) monometallic, and (d) Pt-based bimetallic. (e) FC polarization curves for different concentrations of glucose: $\mathrm{Au} / \mathrm{C}$ anode $\left(0.5 \mathrm{M} \mathrm{KOH}+\right.$ glucose) and Pt/C cathode $\left(0.5 \mathrm{M} \mathrm{KOH}+\mathrm{O}_{2}\right)$, Fumatech AEM. (f) FC polarization curves for different biomasses at $80^{\circ} \mathrm{C}$ using polyoxometalate (POM). (a, b) Reprinted and adapted with permission from Ref. ${ }^{289}$; Copyright 2016, The Electrochemical Society. (c, d) Reprinted and adapted with permission from Ref. ${ }^{361}$; Copyright 2017, The Chemical Society of Japan. (e) Reprinted and adapted with permission from Ref. ${ }^{50}$; Copyright 2016, WILEY-VCH Verlag GmbH \& Co. KGaA, Weinheim. (f) Reprinted and adapted with permission from Ref.; ${ }^{366}$ Copyright 2014, WILEY-VCH Verlag GmbH \& Co. KGaA, Weinheim.

Hibino et al. ${ }^{361}$ have screened the ability of monometallic and Pt-based alloy catalyst anodes for the direct cellulosic biomass fuel cell $\left(\mathrm{H}_{3} \mathrm{PO}_{4}\right.$ electrolyte, $\left.100-250{ }^{\circ} \mathrm{C}\right)$. Fig. $17 \mathrm{c}$ shows the fuel cell polarization at monometallic catalysts, wherein Pt and $\mathrm{Pd}$ are the best promising electrodes. According to the authors, the trend is in agreement with the order for the bond strength of metal and oxygen (M-O) rather than metal and hydrogen $(\mathrm{M}-\mathrm{H})$, which indicates that the $\mathrm{M}-\mathrm{O}$ bond strength should be an important parameter that determines the reaction kinetics. ${ }^{361,367,368}$ From Fig. $17 d$, it can be concluded that the best synergic effect between Pt and a heteroatom is reached for $\mathrm{Fe}$, whereby $\mathrm{Fe}$ has an electronic effect on Pt due to its low electronegativity, which allows electron transfer from Fe to Pt. ${ }^{361,369}$ The fuel cell (Au/C anode, Pt/C cathode, Fumatech 
AEM) polarization curves for different concentrations of glucose of Fig. 17e highlight the importance of the "optimal concentration". In the case of glucose, the value is around 0.3 $1 \mathrm{M}$ whereas for the alkaline electrolyte, the augmentation of the concentration beyond $5 \mathrm{M}$ has negligible impact. ${ }^{50,370-372}$ The main reason is the coverage of the electrode surface by adsorbed reactive molecules and the competition between glucose molecules and hydroxyl ions. This glucose-fuelled fuel cell achieves a $100 \%$ Faradaic yield for the selective oxidation of the anomeric carbon of glucose and its related carbohydrates without any function protection and delivers an output power of $P_{\max }=2 \mathrm{~mW} \mathrm{~cm}^{-2}$, which is of great interest for cogeneration production of electricity (for small stationary applications) and chemicals. ${ }^{50}$ Fig. $17 f$ shows the performance of different types of biomass-fuelled fuel cells where both the fuel and $\mathrm{O}_{2}$ are oxidized and reduced by different POM homogeneous catalysts without any solid metal or metal oxide. ${ }^{366}$ This type of study demonstrates that raw biomass compounds can be used directly to produce electricity without prior purification. The power density of the cellulose-based fuel cells is found to be about three orders of magnitude higher than that of cellulosebased microbial fuel cells. ${ }^{36,373}$ Based on control experiments, the complete oxidation of those organics seems to be the preferential pathway leading to $\mathrm{C} 1$ to $\mathrm{C} 3$ products. Those results thus demonstrate the potentiality of biomass-fuelled fuel cells for electricity production rather than selective electroconversion. The traditional comparison of fuel cell performance is quite tedious and practically impossible for glucose or similar types of organics since the experimental conditions vary from one researcher to another, electrodes size, fuel concentration, electrolyte concentration, operating temperature, testing conditions (batch or continuous flow field, rates), method used to record the polarization curves and in some cases, the unconventional use of a PEM within an alkaline environment. Additionally, care should be taken for the reports of glucose fuel cells that were performed at temperatures higher than $50{ }^{\circ} \mathrm{C}$ since the molecule is not chemically stable above $45-50^{\circ} \mathrm{C} .165,374$
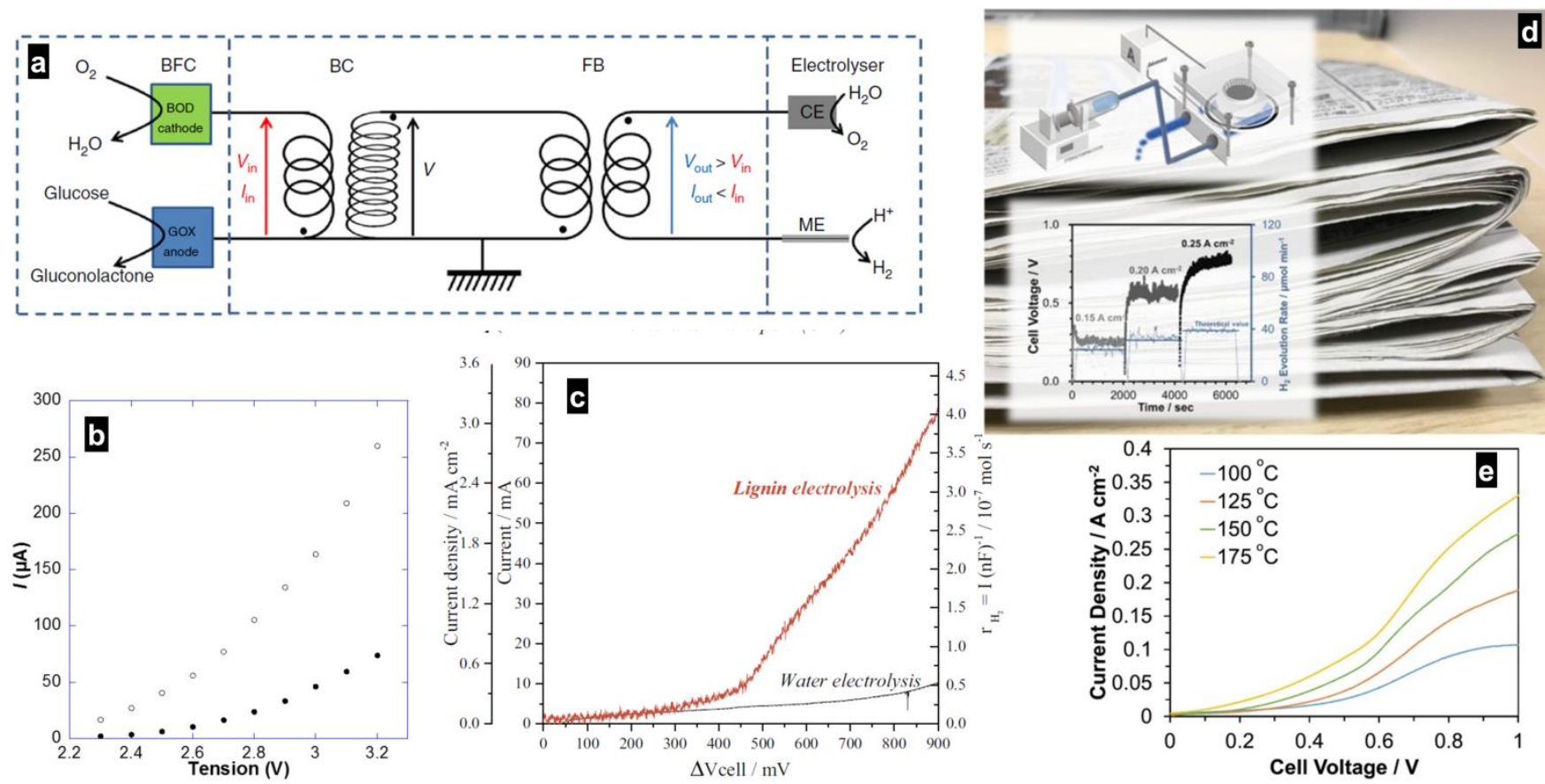

Fig. 18. (a, b) The concept of the uphill reaction: (a) The biofuel cell (left) powers indirectly an electrolyser (right); (b) Electrolysis current for a $100 \mu \mathrm{m}$-diameter (open circles) and a $50 \mu \mathrm{m}$-diameter (full circles) platinum electrode in phosphate buffer $100 \mathrm{mM} \mathrm{pH} 7.2$ at $25^{\circ} \mathrm{C}$. (c) Alkaline lignin electrolysis (AEM: Fumapem FAA-3-50 ${ }^{\circledR}$ of $45-50 \mu \mathrm{m}$ thickness; 80 ${ }^{\circ} \mathrm{C}$ ): LSV from $0 \mathrm{~V}$ to $0.9 \mathrm{~V}$ at $0.5 \mathrm{mV} \mathrm{s}^{-1}$; PtRu/C anode (lignin $10 \mathrm{~g} \mathrm{~L}^{-1}$ in $1 \mathrm{M} \mathrm{NaOH}$, at $2.5 \mathrm{~mL} \mathrm{~min}^{-1}$ (lignin electrolysis) or $\mathrm{NaOH} 1 \mathrm{M}$ at $2.5 \mathrm{~mL} \mathrm{~min}{ }^{-1}$ (water electrolysis)) and Pt/C cathode ( $\mathrm{NaOH} 1 \mathrm{M}$ at $2.5 \mathrm{~mL} \mathrm{~min}-1$ ). (d, e) Working principle of a direct electrolysis of waste newspaper for sustainable hydrogen production: (d) overall scheme; (e) Electrolysis characteristics at Pt/C anode (liquid mixture of $85 \% \mathrm{H}_{3} \mathrm{PO}_{4}$ and newspaper at $0.35 \mathrm{wt}$.\%; flow rate $=0.44 \mathrm{~mL} \mathrm{~min}^{-1}$ ) and Pt/C cathode (electrolyte with argon at a flow rate of $100 \mathrm{~mL}$ $\mathrm{min}^{-1}$ ). (a, b) Reprinted and adapted with permission from Ref. ${ }^{375}$; Copyright 2019, The Authors, Published by Springer Nature Publishing AG. (c) Reprinted and adapted with permission from Ref. ${ }^{52}$; Copyright 2019, The Authors, Published by Elsevier B.V. (d, e) Reprinted and adapted with permission from Ref. ${ }^{360}$; Copyright 2016, 2018 Elsevier B.V.

\subsection{Biomass-fuelled electrolysis cells for simultaneous production of $\mathrm{H}_{2}$ fuel and chemicals}

As discussed in the previous sections, the electrical power density developed by a fuel cell powered by the biomass may not be enough to power a device. Thus, one of the most likely scenarios is to operate as an electrolysis cell where $\mathrm{H}_{2}$ production can be much appealing given the low oxidation potential of those organics. The proof-of-concept of the ability to produce electrochemically $\mathrm{H}_{2}$ from lignin electrooxidation is a relatively old story. It goes back to 1992 (in some case, referred to as "lignin-augmented water electrolysis" 376 ), but the majority of the studies is performed in conventional threeelectrode electrochemical cells. ${ }^{369,376-380}$ So, the demonstration that the systems can work in a real two-electrode electrolysis cell wherein $\mathrm{H}_{2}$ can be easily collected was expected. This research started few years ago and is now gaining strong 
interest in the scientific community. ${ }^{52,360,375,381,382}$ At neutral conditions, biological catalysts can be utilized, but the systems enabling a sustainable and durable production of $\mathrm{H}_{2}$ at a low electrical energy input are those based on abiotic electrocatalysts. The first electrolysis cells fuelled by the lignin was reported in 2017 by Hibino et al. ${ }^{381}$ The study was describing the direct lignin electrolysis at an onset voltage of ca. $0.25 \mathrm{~V}$ (note that water electrolysis cannot start below $1.4 \mathrm{~V}$ ), with high current efficiencies of approximately $100 \%$ for $\mathrm{H}_{2}$ production at the cathode and approximately $85 \%$ for $\mathrm{CO}_{2}$ production at the anode. The anode and cathode were PtFe/C and $\mathrm{Pt} / \mathrm{C}$, respectively. It was estimated that the energy consumption is $1.4 \mathrm{kWh}\left(\mathrm{Nm}^{3}\right)^{-1}$, which is lower than that of ethanol electrolysis of $2 \mathrm{kWh}\left(\mathrm{Nm}^{3}\right)^{-1} .46,381 \mathrm{It}$ is thought that this type of process to produce $\mathrm{H}_{2}$ while releasing significant amount of $\mathrm{CO}_{2}$ apparently, violates the original intention of reducing air pollution and global warming by the employment of the electrochemical methods to produce and use $\mathrm{H}_{2} .{ }^{45}$

Table 3. Single cell performance of oligosaccharides, cellulose, hemicellulose and lignin based fuel cells and electrolysis cells.

\begin{tabular}{|c|c|c|c|c|c|}
\hline Anode catalyst & Cathode catalyst & Separator & Type & Efficiency & Ref. \\
\hline $\begin{array}{l}\text { Au decorated } \\
\text { carbon paper } \\
\left(0.35 \mathrm{mg} \mathrm{cm}^{-2}\right)\end{array}$ & $\begin{array}{c}\text { Pt or } \mathrm{Au} \\
\text { decorated } \\
\text { carbon paper } \\
\left(0.35 \mathrm{mg} \mathrm{cm}^{-2}\right)\end{array}$ & $\begin{array}{l}\text { Fumasep } \\
\text { FAA } \\
\text { (Fumatech) } \\
\text { AEM }\end{array}$ & Fuel cell & $\begin{array}{l}\text { Anode }(0.5 \mathrm{M} \mathrm{KOH}+0.3 \mathrm{M} \text { glucose }) \text {, cathode }(0.5 \mathrm{M} \\
\left.\mathrm{KOH}+\mathrm{O}_{2}\right) \text {, room temperature, effective area }=1 \mathrm{~cm}^{2} \text {. } \\
\text { Au anode: } \mathrm{OCV}=1.02 \mathrm{~V}, \mathrm{P}_{\max }=1.7 \mathrm{~mW} \mathrm{~cm}^{-2} \text { at } 0.40 \mathrm{~V} \text {. } \\
\text { Pt anode: } \mathrm{OCV}=0.99 \mathrm{~V}, \mathrm{P}_{\max }=1.8 \mathrm{~mW} \mathrm{~cm}^{-2} \text { at } 0.73 \mathrm{~V}\end{array}$ & 166 \\
\hline $\begin{array}{l}\text { PtRu nanoparticles } \\
\qquad\left(3 \mathrm{mg} \mathrm{cm}^{-2}\right)\end{array}$ & $\begin{array}{l}\text { Pt nanoparticles } \\
\left(3 \mathrm{mg} \mathrm{cm}^{-2}\right)\end{array}$ & $\begin{array}{c}\text { Tokuyama } \\
\text { AEM }\end{array}$ & Fuel cell & 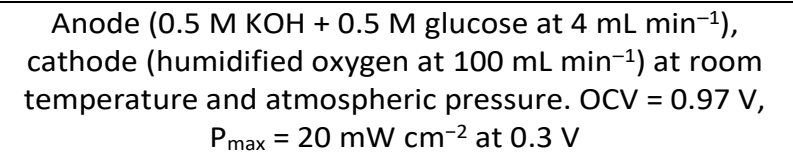 & 383 \\
\hline $\begin{array}{l}\text { Pyranose } \\
\text { dehydrogenase } \\
\text { (PDH) + broad } \\
\text { glucose oxidase } \\
\text { (bGOx) }\end{array}$ & $\begin{array}{l}\text { Bilirubin oxidase } \\
\text { (BOx) }\end{array}$ & $\begin{array}{l}\text { No } \\
\text { membrane }\end{array}$ & Fuel cell & $\begin{array}{c}\text { Anode (buffer ( } 0.2 \mathrm{M}, \mathrm{pH} 6.5)+ \text { different saccharides (50 } \\
\text { mM)), cathode (buffer (0.2 M, pH6.5) at room } \\
\text { temperature and atmospheric pressure. OCV } \approx 0.6 \mathrm{~V} \text {. } \\
\mathrm{P}_{\max }\left(\mathrm{mW} \mathrm{cm}^{-2}\right)=167 \text { (glucose), } 54 \text { (gluconolactone), } \\
118 \text { (galactose), } 34 \text { (fructose), } 66 \text { (ribose), } 130 \text { (xylose), } \\
109 \text { (maltose), } 45 \text { (mannose), } 73 \text { (sucrose), } 55 \text { (lactose), } \\
104 \text { (cellobiose), } 97 \text { (2-Deoxy-D-glucose). Selectivity: } \\
\text { PDH performs single or two sequential oxidations at C2 } \\
\text { and/or C3 yielding up to } 4 \mathrm{e}^{-} \text {, whereas bGOx performs a } \\
\text { single } 2 \mathrm{e}^{-} \text {oxidation at the anomeric (C1) position. } \\
\text { PDH+bGOx }=4 \mathrm{e}^{-} \text {selectivity at C1 }+\mathrm{C} 2+\mathrm{C} 3 \text { positions. }\end{array}$ & 289 \\
\hline $\begin{array}{c}\mathrm{PtFe} / \mathrm{C} \\
\left(1 \mathrm{mg} \mathrm{cm}^{-2}\right)\end{array}$ & $\begin{array}{c}\mathrm{Pt} / \mathrm{C} \\
\left(2 \mathrm{mg} \mathrm{cm}^{-2}\right)\end{array}$ & $\begin{array}{l}\mathrm{Sn}_{0.9} \mathrm{In}_{0.1} \mathrm{P}_{2} \\
\mathrm{O}_{7} \mathrm{PTFE} \\
\text { membrane } \\
(150 \mu \mathrm{m})\end{array}$ & $\begin{array}{l}\text { Electrolysis } \\
\text { cell }\end{array}$ & $\begin{array}{l}\text { Acidic solvents: } 85 \% \mathrm{H}_{3} \mathrm{PO}_{4} \text { and } 96 \% \mathrm{H}_{2} \mathrm{SO}_{4} \text {. Anode: with } \\
\text { lignin powder. Cathode: with argon at a flow rate of } 100 \\
\mathrm{~mL} \mathrm{~min}^{-1} \text {. Onset voltage of electrolysis }=0.25 \mathrm{~V} \text {, current } \\
\text { efficiency }=100 \% \text { for } \mathrm{H}_{2} \text { production at the cathode and } \\
\quad 85 \% \text { for } \mathrm{CO}_{2} \text { production at the anode }\end{array}$ & 381 \\
\hline $\begin{array}{c}\text { PtRu } \\
\left(2 \mathrm{mg} \mathrm{cm}^{-2}\right)\end{array}$ & $\begin{array}{c}\mathrm{Pt} / \mathrm{C} \\
\left(0.2 \mathrm{mg} \mathrm{cm}^{-2}\right)\end{array}$ & $\begin{array}{l}\text { Fumapem } \\
\text { FAA-3-50 } \\
\text { AEM }\end{array}$ & $\begin{array}{l}\text { Electrolysis } \\
\text { cell }\end{array}$ & $\begin{array}{c}\text { Anode }\left(10 \mathrm{~g} \mathrm{~L}^{-1} \text { lignin, } 1 \mathrm{M} \mathrm{NaOH}, 2.5 \mathrm{~mL} \mathrm{~min}^{-1}\right) \\
\text { cathode }\left(1 \mathrm{M} \mathrm{NaOH}, 2.5 \mathrm{~mL} \mathrm{~min}^{-1}\right) \text {, effective area }=25 \\
\mathrm{~cm}^{2} \text {; temperature }=90{ }^{\circ} \mathrm{C} \text {. Onset voltage of electrolysis = } \\
0.45 \mathrm{~V} ; \mathrm{H}_{2} \text { production rate }=0.4 \mu \mathrm{mol} \mathrm{s}^{-1} \text {. }\end{array}$ & 52 \\
\hline
\end{tabular}

Suraniti et al. ${ }^{375}$ have imagined a chemical system that allows the use of the energy from simple reactions to drive subsequent reactions by designing an "uphill reaction". As a result, the $\mathrm{H}_{2}$ production as well as the simultaneous electrosynthesis of gluconate is performed without an external energy source. Figs. 18a-b illustrate the concept of the uphill reaction as follows: (i) The energy from the biofuel cell (GOx and $\mathrm{BOx}$ catalyse glucose oxidation and $\mathrm{O}_{2}$ reduction at the anode, and the cathode respectively) powers an electronic circuit that first raises the voltage in a boost-converter (BC), (ii) A flyback
(FB) electrically isolates the electrolyser ( $\mathrm{Pt}$ reducing $\mathrm{H}^{+}$into $\mathrm{H}_{2}$ and a Pt oxidizing $\mathrm{H}_{2} \mathrm{O}$ into $\mathrm{O}_{2}$ ), (iii) the boosted voltage performs the water electrolysis. The first part of the system is interesting, but the second purpose being the water electrolysis, the overall proposal is not beneficial since a cell voltage of $2.3 \mathrm{~V}$ (meaning a large electrical energy input, Eq. (5)) is required to produce $\mathrm{H}_{2}$. Caravaca et al..$^{52}$ reported a flow AEMbased electrolysis cell that utilizes lignin ( $10 \mathrm{~g} \mathrm{~L}^{-1}$ lignin, PtRu/C anode, $\mathrm{Pt} / \mathrm{C}$ cathode, $1 \mathrm{M} \mathrm{NaOH}$ ). The results are depicted in Fig. 18c, which show that $\mathrm{H}_{2}$ production can start at a relatively low 
cell voltage of $0.45 \mathrm{~V}$. However, no quantitative analysis of the anodic product streams has been done to determine whether the approach would be beneficial in terms of cogeneration of carbon chemicals or not. It should be mentioned that prior to their use, AEM should be activated by soaking them in aqueous solution of typically 0.1-5 $\mathrm{M} \mathrm{NaOH}$ (or $\mathrm{KOH}$ ) for several hours at room temperature (the duration is reduced at high temperatures) to exchange the halide functional groups $\left(\mathrm{Cl}^{-}\right.$, $\mathrm{Br}^{-}$) into $\mathrm{OH}^{-}$groups. ${ }^{38,52,384}$

The chemical composition of the raw biomass is usually complex. Thus, one method to examine whether its direct electrolysis to produce $\mathrm{H}_{2}$ would be possible or not should be the forthrightly use of common biomass materials in the electrolysis cells. Hibino et al. ${ }^{360}$ were recently wondering of the direct electrolysis of "waste newspaper" as a potential sustainable $\mathrm{H}_{2}$ production route, given the high amount of "newspapers" produced per day, Fig. 18d. The goal is to electrooxidize its main organic building blocks of cellulose (69\%) and lignin (12\%). Fig. 18e shows the typical electrolysis cells polarization curves, highlighting a low cell voltage compared to the direct water electrolysis. It was observed that the carbon black functionalized with carbonyl groups showed better characteristics than a Pt/C catalyst as anode, which could be attributed to the poisoning of $\mathrm{Pt}$ active sites by strongly adsorbed reaction intermediates or products such as $\mathrm{CO}$ species. It was estimated that $\mathrm{H}_{2}$ yield is ca. $0.2 \mathrm{~g}$ per $1 \mathrm{~g}$ of newspaper in a batch cell and the energy consumed for the electrolysis at a current density of $0.15 \mathrm{~A} \mathrm{~cm}^{-2}$ is $1.27 \mathrm{kWh}$ $\left(\mathrm{Nm}_{3}\right)^{-1}$. However, the main product from the anodic compartment is $\mathrm{CO}_{2}$, which is not the "best news when using newspapers as fuel" regarding the destiny of $\mathrm{CO}_{2}$.

\section{New alternative scenarios of co-generative electrosynthesis: Coupling $\mathrm{CO}_{2}$ and $\mathrm{N}_{2}$ reduction with organics oxidation}

This section briefly outlines some new paradigms in designing an efficient and low-energy consumption electrolysis cells. Electrolysis is always about "oxidizing something at the positive electrode (anode) and reducing something else at the negative electrode (cathode)". There is no exception to the rule; the trick is to choose the best combination. As explained in the previous sections and sketched in Fig. 19a, the low oxidation potential of organic molecules compared to $\mathrm{H}_{2} \mathrm{O}$ is expected to lower the total energy input as well as additional benefits (Figs. 19b-c). Typically, instead of coupling either $\mathrm{CO}_{2}$ reduction (into platform molecules of $\mathrm{CO}, \mathrm{CH}_{4}$, ethanol, etc.) or $\mathrm{N}_{2}$ reduction (into $\mathrm{NH}_{3}$ as the historical Haber-Bosch process) at the cathode to the classical OER at the anode, one can imagine oxidizing an organic molecule. Indeed a significant portion of the energy required to electrochemically reduce $\mathrm{CO}_{2}$ or $\mathrm{N}_{2}$ to fuels and chemicals is typically consumed by the accompanying OER. ${ }^{385-}$ 388

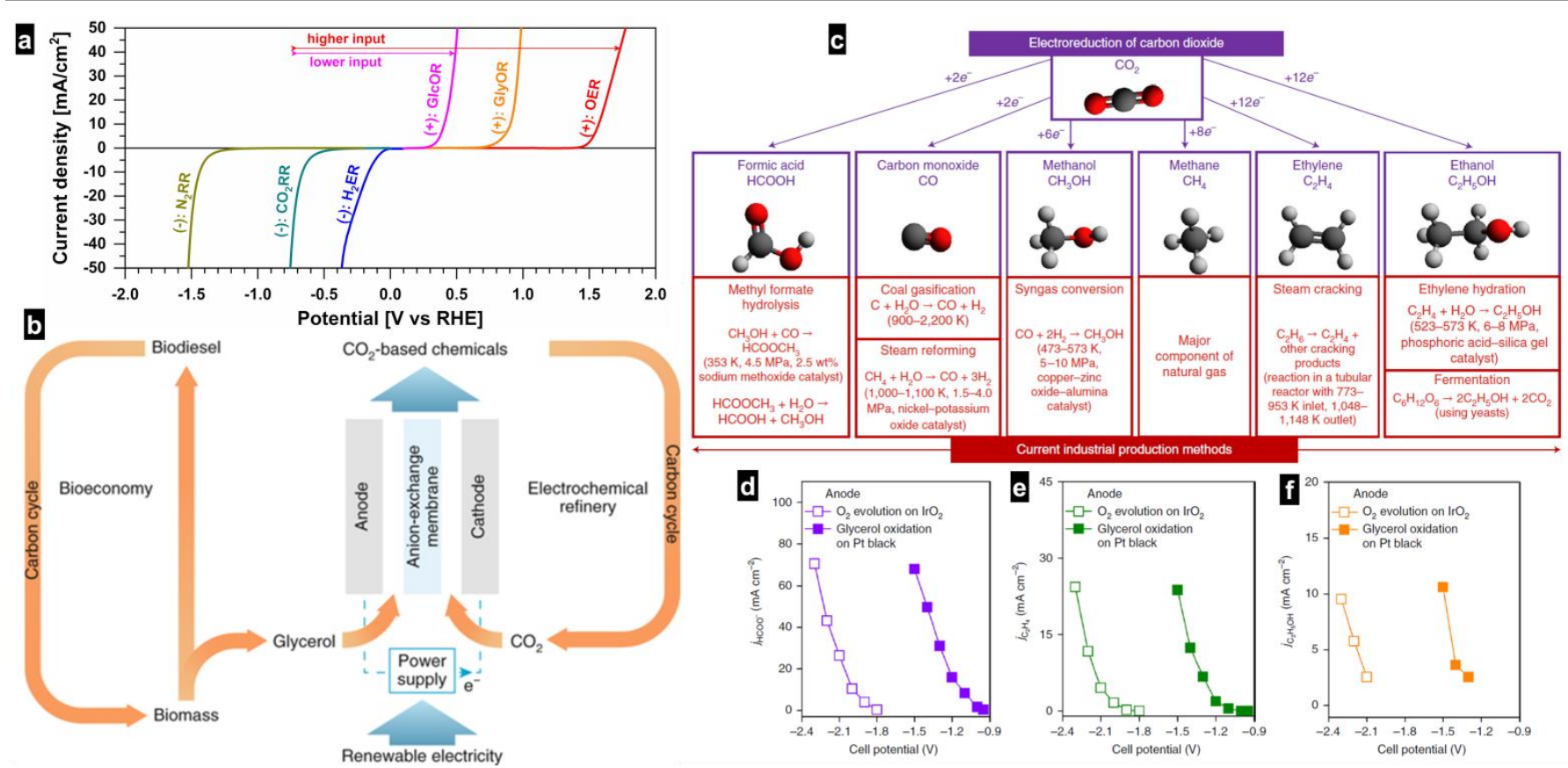

Fig. 19 (a) Typical half-cell polarization curves illustrating the working principle of different scenarios of co-generative electrosynthesis that couple a process at negative electrode (cathode) to one of positive electrode (anode). (b) Use of glycerol for coupling electrochemical $\mathrm{CO}_{2}$ conversion to the bioeconomy producing biodiesel. (c) Overview of selected $\mathrm{CO}_{2} \mathrm{RR}$ products, along with the current industrial methods to manufacture these products. (d-f) Partial current densities of $\mathrm{CO}_{2} \mathrm{RR}$ to: $(\mathrm{d}) \mathrm{HCOO}^{-}$on tin, (e) $\mathrm{C}_{2} \mathrm{H}_{4}$ on copper, $(\mathrm{f}) \mathrm{C}_{2} \mathrm{H}_{5} \mathrm{OH}$ on copper, coupled to OER or GlyOR at the anode (catholyte $=2 \mathrm{M} \mathrm{KOH}$; anolyte $=2 \mathrm{M} \mathrm{KOH}$ for OER, and $2 \mathrm{M} \mathrm{KOH}+2 \mathrm{M}$ glycerol for GlyOR). (b-f) Reprinted and adapted with permission from Ref. ${ }^{386}$ and from Ref. ${ }^{387}$; Copyright 2019, Springer Nature Publishing AG.

Glycerol is one possible organic molecule that enables to achieve not only a low cell voltage, but also a high current density (Fig. 19d-f). Verma and co-workers recently reported alternative oxidative reactions using biodiesel-waste to improve the economics and emission profiles of this process. ${ }^{386,387}$ As illustrated in Fig. 19b, the concept of "two wastes into one 
value" utilizes glycerol as the first waste that is oxidized at the anode into $\mathrm{CO}_{2}$ (second waste) which in turn will feed the cathode to be electro-reduced in a 12-electron product of ethanol or ethylene. ${ }^{387}$ For the $\mathrm{CO}_{2}$ electrocatalysis, significant advances have been made in recent years to discover new electrocatalysts and develop a fundamental understanding of the electrochemical $\mathrm{CO}_{2}$ reduction processes. ${ }^{389}$ The next technological gap and/or paradigm to be overcome are to translate this fundamental knowledge towards the development of practical $\mathrm{CO}_{2}$ electrolysers that requires gasdiffusion electrodes to address the low solubility of $\mathrm{CO}_{2}$ in aqueous electrolytes. For $\mathrm{N}_{2}$ electroreduction by enzymatic/abiotic catalysts, ${ }^{113,114,388}$ a lot of work still needs to be done. Indeed, the current density achieved by these kinds of electrolysers is on the order of micro or milliamps per square centimeter. This is not technically enough to enable the production of large quantities of $\mathrm{NH}_{3}$. Overall, it should become an alternative to the historical Haber-Bosch process which operates under drastic conditions of temperatures and pressures leading to high energy consumption.

\section{Conclusions and outlook}

Foreseeing advanced and innovative strategies is a key approach and constitutes a cornerstone for accessing clean, affordable and reliable energy and platform molecules to satisfy not only the world's increasing prosperity and economic growth, but also to face up the environmental issues. To these ends, electrocatalysis with the aim of converting electrical energy from sustainable sources into electricity in fuel cells or synthetic fuels/chemicals in electrolysis cells (so-called electrolysers) has become a growing field of research during the last decade. The practical realization of this elegant opportunity of great importance is, however, facing several challenges, among which, the efficient design of electrode materials exhibiting improved intrinsic performance (technically worded as activity, durability and selectivity) and the scale-up of the proof-of-concept prototypes for the large-scale deployment. In this contribution, we critically reviewed the recent advances in the use of organic molecules in those electrochemical reactors of fuel cells or electrolysis cells for the energy, chemicals and $\mathrm{H}_{2}$ production. After an in-depth analysis of the literature over the last ten years, it appears that, biomass-based organics such as ethanol, glycerol or oligosaccharides would better be used as a fuel in Power-to- $X$ ( $X=$ fuel, chemical) scenarios than a fuel for $\mathrm{X}$-to-Power systems since the typical electrical current density achieved with a single fuel cell testing is too low compared to the traditional $\mathrm{H}_{2}$-fuelled fuel cells. Indeed, given their low oxidation potential compared to the oxygen evolution reaction (OER) at the anode, their selective oxidation instead of water molecules greatly lowers the input energy relative to conventional water electrolysis by at least two times. This represents considerable energy savings. This anodic oxidation is desired to be coupled with the emerged world-class reactions of hydrogen evolution reaction ( $\mathrm{HER}), \mathrm{CO}_{2}$ reduction $\left(\mathrm{CO}_{2} \mathrm{RR}\right)$, $\mathrm{N}_{2}$ reduction $\left(\mathrm{N}_{2} \mathrm{RR}\right)$ in order to electro-synthesize high valueadded chemicals. It should be noted that the organic electrosynthesis that is on the verge of a renaissance has historically been a powerful tool to produce molecules, while minimizing hazardous reagents and avoiding large quantities of stoichiometric oxidizers and reductive reagents, which means that the waste originating from the used reagents is almost negligible.

The majority of the electrocatalytic oxidation reactions of organic molecules in aqueous media is confronted to twin processes that involve multi-electrons and multi-protons transfer couplings, and induces many reaction intermediates/barriers, which results in larger overpotentials, and many reaction products. It was pointed out that the synergistic collaboration between theoretical and experimental chemists provides a better understanding of the thermodynamic and kinetic aspects of those electrochemical reactions occurring at the surface of catalysts. However, a deep screening of the literature shows important contradictions for the description of the key and elementary steps ("surface-C" or "surface-O" binding) of the adsorption of organic molecule at an electrocatalytic surface. Hence, for those anode reactions, several challenges still need to be addressed: (i) designing efficient electrocatalytic materials to exhibit not only improved activity, but also high selectivity to avoid the production of multitude of by-products that complicate the further steps of separation and purification, (ii) understanding the dynamics of atomic rearrangement within nanocatalysts during the longterm electrooxidation, (iii) implementing a thorough fundamental understanding approach of the functional operation of an electrocatalyst (mostly those with multicomponents) by combining theoretical, computational and experimental screenings to find out the relevant descriptors, (iv) considering the actual electrocatalysis operating conditions in half or single cells testing to scale up the system for practical applications.

It was experimentally observed that, the addition of a cocatalyst from the list $\mathrm{Bi}-\mathrm{Sb}-\mathrm{Pb}-\mathrm{Sn}-\mathrm{In}-\mathrm{Ag}-\mathrm{Cu}$ to base elements of Au-Pt-Pd allows not only a distinguished increase of the electrocatalytic activity with a meaningful diminution of the overpotential, but also a modulation of the $\mathrm{C}-\mathrm{C}$ bond cleavage to yield tuneable selectivities. Obviously, it can be summed up that the electrocatalytic oxidation whereby the selectivity is not for $\mathrm{CO}_{2}$ but unbroken $\mathrm{C}-\mathrm{C}$ products having a value-added and for which the separation/purification steps do not contribute to additional cost and/or a layer of complexity should now be prioritized.

\section{Conflicts of interest}

There are no conflicts to declare

\section{Acknowledgements}

This work has been partially funded by the CNRS Energy unit (Cellule Energie) through the project "PEPS19-ELECTROFUEL", the French National Agency (ANR) through the LabEx CheMISyst (ANR-10-LABX-05-01), and the European Institute of 
Membranes of Montpellier through the Exploratory Project COGENFC (PAT-Axis-Energy-2018). We thank Dr. Ross D. Milton (University of Geneva, Switzerland) for his help in proofreading the manuscript.

\section{Notes and references}

Footnotes

¥ Let us consider a crystallographic system $f c c$, the number of atoms $\mathbf{p}_{(\mathrm{hkl})}$, the monolayer charges $\mathbf{q}_{(\mathrm{hkl})}$ and the occupancy rates $\tau_{(\mathrm{hkl})}$ of the crystallographic planes (hkl) are explicated below: "a" being the lattice parameter and " $e$ " the elementary charge of an electron. For (100), an area equivalent to a square of side a contains " $1+4 \times 1 / 4$ " atoms, i.e. 2 atoms for an area $a^{2}: p_{(100)}=$ $2 / \mathrm{a}^{2}, \mathrm{q}_{(100)}=2 \mathrm{e} / \mathrm{a}^{2}$ and $\tau_{(100)}=\boldsymbol{\pi} / \mathbf{4}=\mathbf{0 . 7 8 5}$. For $(110)$, an area equivalent to a rectangle of sides $\mathbf{a}$ and $\mathbf{a} \times 2^{1 / 2}$ contains " $2 \times 1 / 2+$ $4 \times 1 / 4^{\prime \prime}$ atoms, i.e. 2 atoms for an area $a^{2} \times 2^{1 / 2}: p_{(110)}=2^{1 / 2} / a^{2}, q_{(110)}$ $=2^{1 / 2} \times \mathrm{e} / \mathrm{a}^{2}$ and $\tau_{(110)}=\boldsymbol{\pi} \times \mathbf{2}^{1 / 2} / \mathbf{2}=\mathbf{0 . 5 5 5}$. For (111), an area equivalent to an equal side triangle of side $a \times 2^{1 / 2}$ contains " $3 \times 1 / 6$ $+3 \times 1 / 2^{\prime \prime}$ atoms, i.e. 2 atoms for an area $\left(a^{2} \times 3^{1 / 2}\right) / 2: p_{(111)}=2^{1 / 2} / a^{2}$, $\mathrm{q}_{(111)}=\left(4 \times 3^{1 / 2}\right) \times \mathrm{e} /\left(3 \mathrm{a}^{2}\right)$ and $\tau_{(111)}=\pi \times 3^{1 / 2} / 6=0.907$. For Pt $(\mathrm{a}=$ $3.924 \AA): p_{(100)}=1.30 \times 10^{15}$ at. $\mathrm{cm}^{-2}, \mathrm{p}_{(110)}=0.92 \times 10^{15}$ at. $\mathrm{cm}^{-2}$, $\mathrm{p}_{(111)}=1.50 \times 10^{15}$ at. $\mathrm{cm}^{-2}$ while $\mathrm{q}_{(100)}=208 \mu \mathrm{C} \mathrm{cm}^{-2}, \mathrm{q}_{(110)}=147$ $\mu \mathrm{C} \mathrm{cm}^{-2}$ and $\mathrm{q}_{(111)}=240 \mu \mathrm{C} \mathrm{cm}^{-2}$.

References

1. N. S. Lewis, Energy Environ. Sci., 2016, 9, 2172-2176.

2. N. S. Lewis and D. G. Nocera, Proc. Natl. Acad. Sci., 2006, 103, 15729-15735.

3. B. Burrows, J. Chem. Educ., 1971, 48, 732-736.

4. J. M. Tarascon and M. Armand, Nature, 2001, 414, 359-367.

5. M. S. Whittingham, Science, 1976, 192, 1126-1127.

6. F. T. Bacon, Nature, 1960, 186, 589-592.

7. U. Eberle, B. Muller and R. von Helmolt, Energy Environ. Sci., 2012, 5, 8780-8798.

8. M. K. Debe, Nature, 2012, 486, 43-51.

9. H. Corti and E. R. Gonzalez, Direct Alcohol Fuel Cells, Springer Netherlands, Dordrecht, Netherlands, 2014.

10. L. A. Soares, C. Morais, T. W. Napporn, K. B. Kokoh and P. Olivi, J. Power Sources, 2016, 315, 47-55.

11. Y. S. Li, T. S. Zhao and Z. X. Liang, J. Power Sources, 2009, 187, 387-392.

12. Y. Holade, K. Servat, S. Tingry, T. W. Napporn, H. Remita, D. Cornu and K. B. Kokoh, ChemPhysChem, 2017, 18, 2573-2605.

13. Y. Holade, C. Morais, K. Servat, T. W. Napporn and K. B. Kokoh, ACS Catal., 2013, 3, 2403-2411.

14. Y. Holade, C. Morais, S. Arrii-Clacens, K. Servat, T. W. Napporn and K. B. Kokoh, Electrocatalysis, 2013, 4, 167-178.

15. H. Xu, J. Wang, B. Yan, K. Zhang, S. Li, C. Wang, Y. Shiraishi, Y. Du and P. Yang, Nanoscale, 2017, 9, 12996-13003.

16. L. M. Palma, T. S. Almeida, C. Morais, T. W. Napporn, K. B. Kokoh and A. R. de Andrade, ChemElectroChem, 2017, 4, 39-45.

17. R. G. Da Silva, S. Aquino Neto, K. B. Kokoh and A. R. De Andrade, J. Power Sources, 2017, 351, 174-182.

18. S. Li, J. Lai, R. Luque and G. Xu, Energy Environ. Sci., 2016, 9, 3097 3102.

19. A. C. Garcia, J. Caliman, E. B. Ferreira, G. Tremiliosi-Filho and J. J. Linares, ChemElectroChem, 2015, 2, 1036-1041.

20. A. Zalineeva, A. Serov, M. Padilla, U. Martinez, K. Artyushkova, S. Baranton, C. Coutanceau and P. B. Atanassov, J. Am. Chem. Soc., 2014, 136, 3937-3945.
21. M. Simões, S. Baranton and C. Coutanceau, ChemSusChem, 2012, 5, 2106-2124.

22. Z. Zhang, L. Xin, J. Qi, D. J. Chadderdon and W. Li, Appl. Catal. B: Env., 2013, 136-137, 29-39.

23. A. Marchionni, M. Bevilacqua, C. Bianchini, Y.-X. Chen, J. Filippi, P. Fornasiero, A. Lavacchi, H. Miller, L. Wang and F. Vizza, ChemSusChem, 2013, 6, 518-528.

24. Z. Zhang, L. Xin and W. Li, Appl. Catal. B: Env., 2012, 119-120, 4048.

25. L. Xin, Z. Zhang, Z. Wang and W. Li, ChemCatChem, 2012, 4, 11051114.

26. C. Bianchini and P. K. Shen, Chem. Rev., 2009, 109, 4183-4206.

27. R. L. Arechederra, B. L. Treu and S. D. Minteer, J. Power Sources, 2007, 173, 156-161.

28. Y. Hong, H. J. Kim, H. J. Lee, J. Kim and S.-I. Choi, Front. Chem., 2019, 7.

29. L. An, T. S. Zhao, R. Chen and Q. X. Wu, J. Power Sources, 2011, 196, 6219-6222.

30. M. Gamella, A. Koushanpour and E. Katz, Bioelectrochemistry, 2018, 119, 33-42.

31. E. Katz, Bioelectron. Med., 2015, 2, 1-12.

32. Y. Holade, K. MacVittie, T. Conlon, N. Guz, K. Servat, T. W. Napporn, K. B. Kokoh and E. Katz, Electroanalysis, 2014, 26, 24452457.

33. E. Katz and K. MacVittie, Energy Environ. Sci., 2013, 6, 2791-2803.

34. L. Du, Y. Shao, J. Sun, G. Yin, C. Du and Y. Wang, Catal. Sci. Technol., 2018, 8, 3216-3232.

35. M. S. E. Houache, K. Hughes and E. A. Baranova, Sustainable Energy Fuels, 2019, 3, 1892-1915.

36. H. J. Kim, Y. Kim, D. Lee, J.-R. Kim, H.-J. Chae, S.-Y. Jeong, B.-S. Kim, J. Lee, G. W. Huber, J. Byun, S. Kim and J. Han, ACS Sustainable Chem. Eng., 2017, 5, 6626-6634.

37. L. Wang, M. Bellini, H. A. Miller and J. R. Varcoe, J. Mater. Chem. A, 2018, 6, 15404-15412.

38. T. J. Omasta, X. Peng, H. A. Miller, F. Vizza, L. Wang, J. R. Varcoe, D. R. Dekel and W. E. Mustain, J. Electrochem. Soc., 2018, 165, J3039-J3044.

39. D. R. Dekel, J. Power Sources, 2018, 375, 158-169.

40. L. Wang, J. J. Brink and J. R. Varcoe, Chem. Commun., 2017, 53, 11771-11773.

41. H. A. Miller, F. Vizza, M. Marelli, A. Zadick, L. Dubau, M. Chatenet, S. Geiger, S. Cherevko, H. Doan, R. K. Pavlicek, S. Mukerjee and D. R. Dekel, Nano Energy, 2017, 33, 293-305.

42. T. J. Omasta, L. Wang, X. Peng, C. A. Lewis, J. R. Varcoe and W. E. Mustain, J. Power Sources, 2018, 375, 205-213.

43. H. Cho, S. Moon Kim, Y. Sik Kang, J. Kim, S. Jang, M. Kim, H. Park, J. Won Bang, S. Seo, K.-Y. Suh, Y.-E. Sung and M. Choi, Nat. Commun., 2015, 6, Article number: 8484.

44. V. Hacker and S. Mitsushima, Fuel Cells and Hydrogen: From Fundamentals to Applied Research, Elsevier, 2018.

45. X. Zou and Y. Zhang, Chem. Soc. Rev., 2015, 44, 5148-5180.

46. C. Lamy, T. Jaubert, S. Baranton and C. Coutanceau, J. Power Sources, 2014, 245, 927-936.

47. J. Tollefson, Nature, 2010, DOI: 10.1038/4641262a, 1262-1264.

48. B. R. Rosen, E. W. Werner, A. G. O'Brien and P. S. Baran, J. Am. Chem. Soc., 2014, 136, 5571-5574.

49. E. J. Horn, B. R. Rosen, Y. Chen, J. Tang, K. Chen, M. D. Eastgate and P. S. Baran, Nature, 2016, 533, 77-81.

50. Y. Holade, K. Servat, T. W. Napporn, C. Morais, J.-M. Berjeaud and K. B. Kokoh, ChemSusChem, 2016, 9, 252-263. 
51. Y. Holade, A. B. Engel, K. Servat, T. W. Napporn, C. Morais, S. Tingry, D. Cornu and K. B. Kokoh, J. Electrochem. Soc., 2018, 165, H425-H436.

52. A. Caravaca, W. E. Garcia-Lorefice, S. Gil, A. de Lucas-Consuegra and P. Vernoux, Electrochem. Commun., 2019, 100, 43-47.

53. L. Chen and J. Shi, J. Mater. Chem. A, 2018, 6, 13538-13548.

54. C. H. Lam, A. J. Bloomfield and P. T. Anastas, Green Chem., 2017, 19, 1958-1968.

55. H. A. Miller, M. Bellini, F. Vizza, C. Hasenohrl and R. D. Tilley, Catal. Sci. Technol., 2016, 6, 6870-6878.

56. J. González-Cobos, S. Baranton and C. Coutanceau, ChemElectroChem, 2016, 3, 1694-1704.

57. A. Caravaca, A. de Lucas-Consuegra, A. B. Calcerrada, J. Lobato, J. L. Valverde and F. Dorado, Appl. Catal. B: Env., 2013, 134-135, 302-309.

58. E. J. Horn, B. R. Rosen and P. S. Baran, ACS Central Science, 2016, 2, 302-308.

59. M. Yan, Y. Kawamata and P. S. Baran, Angew. Chem. Int. Ed., 2018, 57, 4149-4155.

60. R. D. Little and K. D. Moeller, Chem. Rev., 2018, 118, 4483-4484.

61. B. A. Frontana-Uribe, R. D. Little, J. G. Ibanez, A. Palma and R. Vasquez-Medrano, Green Chem., 2010, 12, 2099-2119.

62. M. Yan, Y. Kawamata and P. S. Baran, Chem. Rev., 2017, 117, 13230-13319.

63. S. Möhle, M. Zirbes, E. Rodrigo, T. Gieshoff, A. Wiebe and S. R. Waldvogel, Angew. Chem. Int. Ed., 2018, 57, 6018-6041.

64. A. Wiebe, T. Gieshoff, S. Möhle, E. Rodrigo, M. Zirbes and S. R. Waldvogel, Angew. Chem. Int. Ed., 2018, 57, 5594-5619.

65. R. Francke and R. D. Little, Chem. Soc. Rev., 2014, 43, 2492-2521.

66. M. Atobe, H. Tateno and Y. Matsumura, Chem. Rev., 2018, 118, 4541-4572.

67. D. Pletcher, R. A. Green and R. C. D. Brown, Chem. Rev., 2017, $118,4573-4591$.

68. K. Mitsudo, Y. Kurimoto, K. Yoshioka and S. Suga, Curr. Opin. Electrochim, 2018, 8, 8-13.

69. C. Coutanceau and S. Baranton, Wiley Interdiscip. Rev.: Energy Environ., 2016, 5, 388-400.

70. J. G. Ibanez, B. A. Frontana-Uribe and R. Vasquez-Medrano, J. Mex. Chem. Soc., 2016, 60, 247-260.

71. M. Tian, C. Cousins, D. Beauchemin, Y. Furuya, A. Ohma and G. Jerkiewicz, ACS Catal., 2016, 6, 5108-5116.

72. A. J. Bard, J. Am. Chem. Soc., 2010, 132, 7559-7567.

73. C. L. Bentley, M. Kang and P. R. Unwin, J. Am. Chem. Soc., 2019, 141, 2179-2193.

74. A. J. Bard and L. R. Faulkner, Electrochemical Methods: Fundamentals and Applications, John Wiley \& Sons, Inc., USA, 2nd edn., 2001.

75. Y. Shao and N. M. Markovic, Nano Energy, 2016, 29, 1-3.

76. N. M. Markovic, Nat. Mater., 2013, 12, 101-102.

77. V. R. Stamenkovic, D. Strmcnik, P. P. Lopes and N. M. Markovic, Nat. Mater., 2017, 16, 57-69.

78. EUROSTAT, https://ec.europa.eu/eurostat/statisticsexplained/index.php?title=Electricity price statistics, (Data extracted in May 2019; Accessed 06 August 2019).

79. J. P. N. Ross, V. Radmilovic and N. M. Markovic, in Catalysis and Electrocatalysis at Nanoparticle Surfaces, eds. A. Wieckowski, E. R. Savinova and C. G. Vayenas, CRC Press, New York, USA, 2003, DOI: 10.1201/9780203912713.ch9, pp. 311-342.

80. A. A. Folgueiras-Amador and T. Wirth, J. Flow Chem., 2017, 7, $94-$ 95.

81. T. Noël, Y. Cao and G. Laudadio, Acc. Chem. Res., 2019, 52, 28582869.
82. A. Glüsen, F. Dionigi, P. Paciok, M. Heggen, M. Müller, L. Gan, P. Strasser, R. E. Dunin-Borkowski and D. Stolten, ACS Catal., 2019, 9, 3764-3772.

83. T. Fuchigami, M. Atobe and S. Inagi, Fundamentals and Applications of Organic Electrochemistry: Synthesis, Materials, Devices, John Wiley \& Sons Ltd, Chichester, UK, 2014.

84. V. S. Bagotsky, Fundamentals of Electrochemistry, Second Edition, John Wiley \& Sons, Inc., 2006.

85. O. Hammerich and B. Speiser, Organic Electrochemistry, CRC Press, 2006.

86. C. Stang and F. Harnisch, ChemSusChem, 2016, 9, 50-60.

87. J. Grimshaw, Electrochemical Reactions and Mechanisms in Organic Chemistry, Elsevier Science B.V., Amsterdam, 2000.

88. S. C. S. Lai, S. E. F. Kleijn, F. T. Z. Öztürk, V. C. van Rees Vellinga, J. Koning, P. Rodriguez and M. T. M. Koper, Catal. Today, 2010, 154, 92-104.

89. M. T. M. Koper, Chem. Sci., 2013, 4, 2710-2723.

90. N. Y. Suzuki, P. V. B. Santiago, T. S. Galhardo, W. A. Carvalho, J. Souza-Garcia and C. A. Angelucci, J. Electroanal. Chem., 2016, 780, 391-395.

91. J. Joo, T. Uchida, A. Cuesta, M. T. M. Koper and M. Osawa, J. Am. Chem. Soc., 2013, 135, 9991-9994.

92. Y. Kwon, S. C. S. Lai, P. Rodriguez and M. T. M. Koper, J. Am. Chem. Soc., 2011, 133, 6914-6917.

93. P. Rodriguez and M. T. M. Koper, Phys. Chem. Chem. Phys., 2014, 16, 13583-13594.

94. B. N. Zope, D. D. Hibbitts, M. Neurock and R. J. Davis, Science, 2010, 330, 74-78.

95. W. C. Ketchie, M. Murayama and R. J. Davis, Top. Catal., 2007, 44, 307-317.

96. N. E. de Souza, J. F. Gomes and G. Tremiliosi-Filho, J. Electroanal. Chem., 2017, 800, 106-113.

97. K. Mayrhofer, S. J. Ashton, J. Kreuzer and M. Arenz, Int. J. Electrochem. Sci., 2009, 4, 1-8.

98. E. M. Belgsir, E. Bouhier, H. Essis Yei, K. B. Kokoh, B. Beden, H. Huser, J. M. Leger and C. Lamy, Electrochim. Acta, 1991, 36, 11571164.

99. J. G. Chen, C. W. Jones, S. Linic and V. R. Stamenkovic, ACS Catal., 2017, 7, 6392-6393.

100. G. Dong, M. Fang, H. Wang, S. Yip, H.-Y. Cheung, F. Wang, C.Y. Wong, S. T. Chu and J. C. Ho, J. Mater. Chem. A, 2015, 3, 1308013086.

101. T. W. Napporn, Y. Holade, B. Kokoh, S. Mitsushima, K. Mayer, B. Eichberger and V. Hacker, in Fuel Cells and Hydrogen: From Fundamentals to Applied Research, eds. V. Hacker and S. Mitsushima, Elsevier, 2018, DOI: 10.1016/B978-0-12-8114599.00009-8, pp. 175-214.

102. A. Tiwari, T. Maagaard, I. Chorkendorff and S. Horch, ACS Energy Lett., 2019, DOI: 10.1021/acsenergylett.9b01064, 16451649.

103. S. Barnartt, J. Electrochem. Soc., 1961, 108, 102-104.

104. K. B. Kokoh, P. Parpot, E. M. Belgsir, J. M. Léger, B. Beden and C. Lamy, Electrochim. Acta, 1993, 38, 1359-1365.

105. N. Elgrishi, K. J. Rountree, B. D. McCarthy, E. S. Rountree, T. T. Eisenhart and J. L. Dempsey, J. Chem. Educ., 2017, 95, 197-206.

106. A. L. Eckermann, D. J. Feld, J. A. Shaw and T. J. Meade, Coord. Chem. Rev., 2010, 254, 1769-1802.

107. O. W., B. F. and G. U., Mater. Corros., 2006, 57, 455-466.

108. M. E. Orazem and B. Tribollet, Electrochemical Impedance Spectroscopy, John Wiley \& Sons, Inc. , Hoboken, New Jersey, USA, 2 edn., 2017. 
109. A. Lasia, Electrochemical Impedance Spectroscopy and its Applications, Springer-Verlag, New York, NY, USA, 2014.

110. J. C. K. Ho, G. T. Filho, R. Simpraga and B. E. Conway, J. Electroanal. Chem., 1994, 366, 147-162.

111. Y. Lai, Y. Li, L. Jiang, W. Xu, X. Lv, J. Li and Y. Liu, J. Electroanal. Chem., 2012, 671, 16-23.

112. T. Audichon, T. W. Napporn, C. Canaff, C. Morais, C. Comminges and K. B. Kokoh, J. Phys. Chem. C, 2016, 120, 25622573.

113. L. F. Greenlee, J. N. Renner and S. L. Foster, ACS Catal., 2018, DOI: 10.1021/acscatal.8b02120, 7820-7827.

114. L. Li, C. Tang, B. Xia, H. Jin, Y. Zheng and S.-Z. Qiao, ACS Catal., 2019, 9, 2902-2908.

115. B. Eneau-Innocent, D. Pasquier, F. Ropital, J. M. Léger and K. B. Kokoh, Appl. Catal. B: Env., 2010, 98, 65-71.

116. J. Gomes and G. Tremiliosi-Filho, Electrocatalysis, 2011, 2, 96105.

117. D. Z. Jeffery and G. A. Camara, Electrochem. Commun., 2010, 12, $1129-1132$

118. Y. Kwon, Y. Birdja, I. Spanos, P. Rodriguez and M. T. M. Koper, ACS Catal., 2012, 2, 759-764.

119. P. Tonda-Mikiela, T. W. Napporn, C. Morais, K. Servat, A. Chen and K. B. Kokoh, J. Electrochem. Soc., 2012, 159, H828-H833.

120. A. H. Wonders, T. H. M. Housmans, V. Rosca and M. T. M. Koper, J. Appl. Electrochem., 2006, 36, 1215-1221.

121. Y. Kwon, K. J. P. Schouten and M. T. M. Koper, ChemCatChem, 2011, 3, 1176-1185.

122. M. Weber, P. Collot, H. El Gaddari, S. Tingry, M. Bechelany and Y. Holade, ChemElectroChem, 2018, 5, 743-747.

123. F. Scholz, Electroanalytical Methods: Guide to Experiments and Applications, Springer-Verlag Berlin Heidelberg, 2010.

124. Y. Kwon and M. T. M. Koper, Anal. Chem., 2010, 82, 54205424.

125. V. L. Oliveira, C. Morais, K. Servat, T. W. Napporn, G. Tremiliosi-Filho and K. B. Kokoh, Electrochim. Acta, 2014, 117, 255-262.

126. V. L. Oliveira, C. Morais, K. Servat, T. W. Napporn, G. Tremiliosi-Filho and K. B. Kokoh, J. Electroanal. Chem., 2013, 703, 56-62.

127. M. S. E. Houache, E. Cossar, S. Ntais and E. A. Baranova, J. Power Sources, 2018, 375, 310-319.

128. B. Habibi and N. Delnavaz, RSC Adv., 2016, 6, 31797-31806.

129. R. Rizo and B. Roldan Cuenya, ACS Energy Lett., 2019, 4, 14841495

130. H. Guesmi, Gold Bull., 2013, 46, 213-219.

131. M. F. Juárez, G. Soldano, H. Guesmi, F. Tielens and E. Santos, Surf. Sci., 2015, 631, 235-247.

132. R. S. Ferreira Jr, M. Janete Giz and G. A. Camara, J. Electroanal. Chem., 2013, 697, 15-20.

133. S. Y. Shen, T. S. Zhao, J. B. Xu and Y. S. Li, J. Power Sources, 2010, 195, 1001-1006.

134. S. T. Nguyen, H. M. Law, H. T. Nguyen, N. Kristian, S. Wang, S. H. Chan and X. Wang, Appl. Catal. B: Env., 2009, 91, 507-515.

135. Y. Wang, Z. M. Sheng, H. Yang, S. P. Jiang and C. M. Li, Int. J. Hydrogen Energy, 2010, 35, 10087-10093.

136. W. Hong, C. Shang, J. Wang and E. Wang, Energy Environ. Sci., 2015, 8, 2910-2915.

137. J. F. Gomes, A. C. Garcia, C. Pires, E. B. Ferreira, R. Q Albuquerque, G. Tremiliosi-Filho and L. H. S. Gasparotto, J. Phys. Chem. C, 2014, 118, 28868-28875.

138. C. Roth, N. Benker, R. Theissmann, R. J. Nichols and D. J. Schiffrin, Langmuir, 2008, 24, 2191-2199.
139. J. Wang, F. Chen, Y. Jin and Y. Lei, ACS Appl. Mater. Interfaces., 2018, 10, 6276-6287.

140. N. Pittayaporn, A. Therdthianwong and S. Therdthianwong, J. Appl. Electrochem., 2018, DOI: 10.1007/s10800-018-1155-9.

141. K. Bhunia, S. Khilari and D. Pradhan, ACS Sustainable Chem. Eng., 2018, 6, 7769-7778.

142. M. Boutonnet, J. Kizling, P. Stenius and G. Maire, Colloids Surf., 1982, 5, 209-225.

143. S. Eriksson, U. Nylén, S. Rojas and M. Boutonnet, Appl. Catal. A: Gen., 2004, 265, 207-219.

144. I. Capek, Adv. Colloid Int. Sci., 2004, 110, 49-74.

145. C. Bock, H. Halvorsen and B. MacDougall, in PEM Fuel Cell Electrocatalysts and Catalyst Layers, ed. J. Zhang, Springer-Verlag London, London, UK, 2008, DOI: 10.1007/978-1-84800-936-3_9, ch. 9, pp. 447-485.

146. H. H. Ingelsten, R. Bagwe, A. Palmqvist, M. Skoglundh, C. Svanberg, K. Holmberg and D. O. Shah, J. Colloid Int. Sci., 2001, 241, 104-111.

147. A. Habrioux, Thèse de Doctorat, Université de Poitiers, 2009.

148. M. Simões, Thèse de Doctorat, Université de Poitiers, 2011.

149. M. Simões, S. Baranton and C. Coutanceau, J. Phys. Chem. C, 2009, 113, 13369-13376.

150. A. Habrioux, D. Diabaté, J. Rousseau, T. Napporn, K. Servat, L. Guétaz, A. Trokourey and K. B. Kokoh, Electrocatalysis, 2010, 1, 51-59.

151. A. Habrioux, E. Sibert, K. Servat, W. Vogel, K. B. Kokoh and N. Alonso-Vante, J. Phys. Chem. B, 2007, 111, 10329-10333.

152. A. Habrioux, W. Vogel, M. Guinel, L. Guetaz, K. Servat, B. Kokoh and N. Alonso-Vante, Phys. Chem. Chem. Phys., 2009, 11, 3573-3579.

153. M.-L. Wu, D.-H. Chen and T.-C. Huang, Chem. Mater., 2001, 13, 599-606.

154. D. Diabaté, T. W. Napporn, K. Servat, A. Habrioux, S. ArriiClacens, A. Trokourey and K. B. Kokoh, J. Electrochem. Soc., 2013, 160, $\mathrm{H} 302-\mathrm{H} 308$

155. F. Fievet, J. P. Lagier, B. Blin, B. Beaudoin and M. Figlarz, Solid State lonics, 1989, 32-33, Part 1, 198-205.

156. F. Bonet, C. Guéry, D. Guyomard, R. Herrera Urbina, K. Tekaia-Elhsissen and J. M. Tarascon, Int. J. Inorg. Mater., 1999, 1, 47-51.

157. C. Bock, C. Paquet, M. Couillard, G. A. Botton and B. R. MacDougall, J. Am. Chem. Soc., 2004, 126, 8028-8037.

158. M. S. Nashner, A. I. Frenkel, D. Somerville, C. W. Hills, J. R. Shapley and R. G. Nuzzo, J. Am. Chem. Soc., 1998, 120, 8093-8101.

159. Y. Takasu, T. Fujiwara, Y. Murakami, K. Sasaki, M. Oguri, T. Asaki and W. Sugimoto, J. Electrochem. Soc., 2000, 147, 44214427.

160. M. Rahsepar, M. Pakshir, Y. Piao and H. Kim, Fuel Cells, 2012, 12, 827-834.

161. T. Lv, Y. Wang, S.-I. Choi, M. Chi, J. Tao, L. Pan, C. Z. Huang, Y. Zhu and Y. Xia, ChemSusChem, 2013, 6, 1923-1930.

162. F. Ksar, L. Ramos, B. Keita, L. Nadjo, P. Beaunier and H. Remita, Chem. Mater., 2009, 21, 3677-3683.

163. Y. Holade, A. Lehoux, H. Remita, K. B. Kokoh and T. W. Napporn, J. Phys. Chem. C, 2015, 119, 27529-27539.

164. S. Ghosh, Y. Holade, H. Remita, K. Servat, P. Beaunier, A. Hagège, K. B. Kokoh and T. W. Napporn, Electrochim. Acta, 2016, 212, 864-875.

165. S. Hebié, Y. Holade, K. Maximova, M. Sentis, P. Delaporte, K. B. Kokoh, T. W. Napporn and A. V. Kabashin, ACS Catal., 2015, 5, 6489-6496. 
166. Y. Holade, D. P. Hickey and S. D. Minteer, J. Mater. Chem. A, 2016, 4, 17154-17162.

167. M. Weber, N. Tuleushova, J. Zgheib, C. Lamboux, I. latsunskyi, E. Coy, V. Flaud, S. Tingry, D. Cornu, P. Miele, M. Bechelany and Y. Holade, Appl. Catal. B: Env., 2019, 257, 117917.

168. L. Assaud, N. Brazeau, M. K. S. Barr, M. Hanbucken, S. Ntais, E. A. Baranova and L. Santinacci, ACS Appl. Mater. Interfaces., 2015, 7, 24533-24542.

169. M. K. S. Barr, L. Assaud, N. Brazeau, M. Hanbücken, S. Ntais, L. Santinacci and E. A. Baranova, J. Phys. Chem. C, 2017, 121, 17727-17736.

170. Y. Hajar, V. Di Palma, V. Kyriakou, M. A. Verheijen, E. A. Baranova, P. Vernoux, W. M. M. Kessels, M. Creatore, M. C. M. van de Sanden and M. N. Tsampas, Electrochem. Commun., 2017, 84, 40-44.

171. D. Xu, Y. Liu, S. Zhao, Y. Lu, M. Han and J. Bao, Chem. Commun., 2017, 53, 1642-1645.

172. Cabot, Vulcan ${ }^{\circledR} \quad$ XC 72R, http://www.cabotcorp.com/Downloads/DL201402171145AM963/, 2013.

173. Cabot, Vulcan $^{\circledR} \quad$ XC 72, http://www.cabotcorp.com/Downloads/DL201402171144AM698/, 2013.

174. Y. Holade, C. Morais, K. Servat, T. W. Napporn and K. B. Kokoh, Phys. Chem. Chem. Phys., 2014, 16, 25609-25620.

175. T. S. Almeida, L. M. Palma, P. H. Leonello, C. Morais, K. B. Kokoh and A. R. De Andrade, J. Power Sources, 2012, 215, 53-62.

176. A. C. Garcia, M. J. Kolb, C. van Nierop y Sanchez, J. Vos, Y. Y. Birdja, Y. Kwon, G. Tremiliosi-Filho and M. T. M. Koper, ACS Catal., 2016, 6, 4491-4500.

177. N. Benipal, J. Qi, Q. Liu and W. Li, Appl. Catal. B: Env., 2017, 210, 121-130.

178. J. Qi, N. Benipal, C. Liang and W. Li, Appl. Catal. B: Env., 2016, 199, 494-503.

179. C. Zhu, S. Guo and S. Dong, Adv. Mater., 2012, 24, 2326-2331.

180. R. M. Arán-Ais, F. J. Vidal-Iglesias, J. Solla-Gullón, E. Herrero and J. M. Feliu, Electroanalysis, 2015, 27, 945-956.

181. M. A. Montiel, F. J. Vidal-Iglesias, V. Montiel and J. SollaGullón, Curr. Opin. Electrochim, 2017, 1, 34-39.

182. H. Yang, Y. Tang and S. Zou, Electrochem. Commun., 2014, 38, 134-137.

183. S. Hebié, L. Cornu, T. W. Napporn, J. Rousseau and B. K. Kokoh, J. Phys. Chem. C, 2013, 117, 9872-9880.

184. J. Chen, J. Mao, J. Zhao, M. Ren and M. Wei, RSC Adv., 2014, 4, 28832-28835.

185. G. Chen, Y. Tan, B. Wu, G. Fu and N. Zheng, Chem. Commun., 2012, 48, 2758-2760.

186. Y. Holade, C. Morais, T. W. Napporn, K. Servat and K. B. Kokoh, ECS Trans., 2014, 58, 25-35.

187. Y. Holade, K. Servat, T. W. Napporn and K. B. Kokoh, Electrochim. Acta, 2015, 162, 205-214.

188. G. G. Li, Y. Lin and H. Wang, Nano Lett., 2016, 16, 7248-7253.

189. X. Li, H. J. Qiu, J. Q. Wang and Y. Wang, Corros. Sci., 2016, 106, $55-60$.

190. A. Zhang, Z. Yang, Y. Chen, L. Yin, P. Schützendübe, Y. Huang, Y. Liu and Z. Wang, J. Electrochem. Soc., 2019, 166, H650-H655.

191. M. Xu, Y. Sui, G. Xiao, X. Yang, Y. Wei and B. Zou, Nanoscale, 2017, 9, 2514-2520.

192. B. Jiang, H. Ataee-Esfahani, C. Li, S. M. Alshehri, T. Ahamad, J. Henzie and Y. Yamauchi, Chem. Eur. J., 2016, 22, 7174-7178.

193. C. Xu, Q. Hao and H. Duan, J. Mater. Chem. A, 2014, 2, 88758880.

194. H. M. Song, D. H. Anjum, R. Sougrat, M. N. Hedhili and N. M. Khashab, J. Mater. Chem., 2012, 22, 25003-25010.
195. S. M. Alia, Y. S. Yan and B. S. Pivovar, Catal. Sci. Technol., 2014, 4, 3589-3600.

196. A. G. M. da Silva, T. S. Rodrigues, S. J. Haigh and P. H. C. Camargo, Chem. Commun., 2017, 53, 7135-7148.

197. Y. Zhou, Y. Shen, J. Xi and X. Luo, ACS Appl. Mater. Interfaces., 2019, 11, 28953-28959.

198. Y. Sun and Y. Xia, J. Am. Chem. Soc., 2004, 126, 3892-3901.

199. Y. Sun, B. T. Mayers and Y. Xia, Nano Lett., 2002, 2, 481-485.

200. M. S. Yavuz, Y. Cheng, J. Chen, C. M. Cobley, Q. Zhang, M. Rycenga, J. Xie, C. Kim, K. H. Song, A. G. Schwartz, L. V. Wang and Y. Xia, Nat. Mater., 2009, 8, 935-939.

201. S. E. Skrabalak, L. Au, X. Li and Y. Xia, Nat. Protocols, 2007, 2, 2182-2190.

202. X. Yang, M. Yang, B. Pang, M. Vara and Y. Xia, Chem. Rev., 2015, 115, 10410-10488.

203. A. Ruditskiy and Y. Xia, ACS Nano, 2017, 11, 23-27.

204. Z. Wang, P. Liu, J. Han, C. Cheng, S. Ning, A. Hirata, T. Fujita and M. Chen, Nat. Commun., 2017, 8, 1066.

205. X. Zhang and Y. Ding, Catal. Sci. Technol., 2013, 3, 2862-2868.

206. J. Snyder, T. Fujita, M. W. Chen and J. Erlebacher, Nat. Mater., 2010, 9, 904-907.

207. T. Fujita, P. Guan, K. McKenna, X. Lang, A. Hirata, L. Zhang, T. Tokunaga, S. Arai, Y. Yamamoto, N. Tanaka, Y. Ishikawa, N. Asao, Y. Yamamoto, J. Erlebacher and M. Chen, Nat. Mater., 2012, 11, 775-780.

208. J. Erlebacher, M. J. Aziz, A. Karma, N. Dimitrov and K. Sieradzki, Nature, 2001, 410, 450-453.

209. M.-J. Kim, H.-J. Na, K. C. Lee, E. A. Yoo and M. Lee, J. Mater. Chem., 2003, 13, 1789-1792.

210. Y. Zhou, Y. Shen and J. Piao, ChemElectroChem, 2018, 5, 1636-1643.

211. Y. Zhou and Y. Shen, Electrochem. Commun., 2018, 90, 106110.

212. Y. Zhou, Y. Shen and J. Xi, Appl. Catal. B: Env., 2019, 245, 604612.

213. Z. Chen, C. Liu, X. Zhao, H. Yan, J. Li, P. Lyu, Y. Du, S. Xi, K. Chi, X. Chi, H. Xu, X. Li, W. Fu, K. Leng, S. J. Pennycook, S. Wang and K. P. Loh, Adv. Mater., 2019, 31, 1804763.

214. D. M. Whitfield, S. Stojkovski and B. Sarkar, Coord. Chem. Rev., 1993, 122, 171-225.

215. S. J. Angyal, Chem. Soc. Rev., 1980, 9, 415-428.

216. A. Abbadi and H. van Bekkum, Appl. Catal. A: Gen., 1995, 124, 409-417.

217. M. Wenkin, P. Ruiz, B. Delmon and M. Devillers, J. Mol. Catal. A: Chem., 2002, 180, 141-159.

218. Z. W. Seh, J. Kibsgaard, C. F. Dickens, I. Chorkendorff, J. K. Nørskov and T. F. Jaramillo, Science, 2017, 355, eaad4998.

219. E. D. Wang, J. B. Xu and T. S. Zhao, J. Phys. Chem. C, 2010, 114, 10489-10497.

220. S. Sakong and A. Groß, J. Catal., 2005, 231, 420-429.

221. B. Miao, Z.-P. Wu, H. Xu, M. Zhang, Y. Chen and L. Wang, J. Comp. Mater. Sci., 2019, 156, 175-186.

222. Y. Choi and P. Liu, Catal. Today, 2011, 165, 64-70.

223. X.-K. Gu, B. Liu and J. Greeley, ACS Catal., 2015, 5, 2623-2631.

224. Y. Chen, M. Salciccioli and D. G. Vlachos, J. Phys. Chem. C, 2011, 115, 18707-18720.

225. A. Ilie, M. Simoes, S. Baranton, C. Coutanceau and S. Martemianov, J. Power Sources, 2011, 196, 4965-4971.

226. B. Liu and J. Greeley, J. Phys. Chem. C, 2011, 115, 1970219709.

227. P. Tereshchuk, A. S. Chaves and J. L. F. Da Silva, J. Phys. Chem. C, 2014, 118, 15251-15259. 
228. B. Liu, M. Zhou, M. K. Y. Chan and J. P. Greeley, ACS Catal., 2015, 5, 4942-4950.

229. R. C. Amaral, P. Tereshchuk, Y. Seminovski and J. L. F. Da Silva, J. Phys. Chem. C, 2017, 121, 3445-3454.

230. N. Shan and B. Liu, Langmuir, 2018, DOI: 10.1021/acs.langmuir.8b02385.

231. M. Valter, M. Busch, B. Wickman, H. Grönbeck, J. Baltrusaitis and A. Hellman, J. Phys. Chem. C, 2018, 122, 10489-10494.

232. J. E. B. Randles, Trans. Faraday Soc., 1956, 52, 1573-1581.

233. S. Trasatti, J. Electroanal. Chem. Interf. Electrochem., 1974, 52, 313-329.

234. J. R. Farrell and P. McTigue, J. Electroanal. Chem. Interf. Electrochem., 1982, 139, 37-56.

235. S. Trasatti, J. Electroanal. Chem. Interf. Electrochem., 1982, 139, 1-13.

236. H. Gerischer and W. Ekardt, Appl. Phys. Lett., 1983, 43, 393395.

237. F. Forstmann, AIP Conference Proceedings, 2008, 979, 181 194.

238. V. Tripkovic, M. E. Björketun, E. Skúlason and J. Rossmeisl, Phys. Rev. B, 2011, 84, 115452 .

239. D. P. Hickey, D. A. Schiedler, I. Matanovic, P. V. Doan, P. Atanassov, S. D. Minteer and M. S. Sigman, J. Am. Chem. Soc., 2015, 137, 16179-16186.

240. Z. Wu, M. Zhang, H. Jiang, C.-J. Zhong, Y. Chen and L. Wang, Phys. Chem. Chem. Phys., 2017, 19, 15444-15453.

241. B. Miao, Z. Wu, H. Xu, M. Zhang, Y. Chen and L. Wang, Chem. Phys. Lett., 2017, 688, 92-97.

242. A. Wieckowski, E. R. Savinova and C. G. Vayenas, Catalysis and Electrocatalysis at Nanoparticle Surfaces, Marcel Dekker, Inc., New York, USA, 2003.

243. C. R. Henry, Prog. Surf. Sci., 2005, 80, 92-116.

244. J.-H. Choi, K.-W. Park, B.-K. Kwon and Y.-E. Sung, J. Electrochem. Soc., 2003, 150, A973-A978.

245. T. V. Reshetenko, H.-T. Kim, H. Lee, M. Jang and H.-J. Kweon, J. Power Sources, 2006, 160, 925-932.

246. J. Zhang, G. Yin, Z. Wang and Y. Shao, J. Power Sources, 2006, 160, 1035-1040.

247. K. Kang, S. Park, S. O. Cho, K. Choi and H. Ju, Fuel Cells, 2014, 14, 694-700.

248. N. Kimiaie, K. Wedlich, M. Hehemann, R. Lambertz, M. Muller, C. Korte and D. Stolten, Energy Environ. Sci., 2014, 7, 30133025.

249. E. A. Monyoncho, T. K. Woo and E. A. Baranova, in Electrochemistry: Volume 15, The Royal Society of Chemistry, 2019, vol. 15, pp. 1-57.

250. N. Fujiwara, Z. Siroma, S.-i. Yamazaki, T. Ioroi, H. Senoh and K. Yasuda, J. Power Sources, 2008, 185, 621-626.

251. L. M. Palma, T. S. Almeida, P. H. Leonello and A. R. D. Andrade, J. Electrochem. Soc., 2014, 161, F473-F479.

252. C. Bianchini, V. Bambagioni, J. Filippi, A. Marchionni, F. Vizza, P. Bert and A. Tampucci, Electrochem. Commun., 2009, 11, 10771080.

253. Y. S. Li, T. S. Zhao and Z. X. Liang, J. Power Sources, 2009, 190, 223-229.

254. T. S. Almeida, L. M. Palma, C. Morais, K. B. Kokoh and A. R. De Andrade, J. Electrochem. Soc., 2013, 160, F965-F971.

255. J. B. Xu, T. S. Zhao, Y. S. Li and W. W. Yang, Int. J. Hydrogen Energy, 2010, 35, 9693-9700.

256. O. I. Deavin, S. Murphy, A. L. Ong, S. D. Poynton, R. Zeng, H. Herman and J. R. Varcoe, Energy Environ. Sci., 2012, 5, 8584-8597.
257. J. R. Varcoe, P. Atanassov, D. R. Dekel, A. M. Herring, M. A. Hickner, P. A. Kohl, A. R. Kucernak, W. E. Mustain, K. Nijmeijer, K. Scott, T. Xu and L. Zhuang, Energy Environ. Sci., 2014, 7, 3135 3191.

258. B. P. Setzler, Z. Zhuang, J. A. Wittkopf and Y. Yan, Nat. Nanotechnol., 2016, 11, 1020

259. Y. Chen, M. Bellini, M. Bevilacqua, P. Fornasiero, A. Lavacchi, H. A. Miller, L. Wang and F. Vizza, ChemSusChem, 2015, 8, 524 533.

260. J. Qi, L. Xin, Z. Zhang, K. Sun, H. He, F. Wang, D. Chadderdon, Y. Qiu, C. Liang and W. Li, Green Chem., 2013, 15, 1133-1137.

261. M. V. Pagliaro, M. Bellini, M. Bevilacqua, J. Filippi, M. G. Folliero, A. Marchionni, H. A. Miller, W. Oberhauser, S. Caporali, M. Innocenti and F. Vizza, RSC Adv., 2017, 7, 13971-13978.

262. L. Xin, Z. Zhang, Z. Wang and W. Li, ChemCatChem, 2013, 5, 2749-2749.

263. A. de Lucas-Consuegra, A. R. de la Osa, A. B. Calcerrada, J. J. Linares and D. Horwat, J. Power Sources, 2016, 321, 248-256.

264. A. Caravaca, F. M. Sapountzi, A. de Lucas-Consuegra, C. Molina-Mora, F. Dorado and J. L. Valverde, Int. J. Hydrogen Energy, 2012, 37, 9504-9513.

265. , Fuel Cell Technologies Office: Fuel Cell Technologies Office Multi-Year Research, Development, and Demonstration Plan, Updated June 2015 (Accessed 15 september 2019).

266. S. Lee, H. J. Kim, E. J. Lim, Y. Kim, Y. Noh, G. W. Huber and W. B. Kim, Green Chem., 2016, 18, 2877-2887.

267. StrmcnikD, KodamaK, D. van der Vliet, GreeleyJ, V. R. Stamenkovic and N. M. Marković, Nat. Chem., 2009, 1, 466-472.

268. J. Durst, M. Chatenet and F. Maillard, Phys. Chem. Chem. Phys., 2012, 14, 13000-13009.

269. D. Strmcnik, D. F. van der Vliet, K. C. Chang, V. Komanicky, K. Kodama, H. You, V. R. Stamenkovic and N. M. Marković, J. Phys. Chem. Lett., 2011, 2, 2733-2736.

270. C. A. Angelucci, H. Varela, G. Tremiliosi-Filho and J. F. Gomes, Electrochem. Commun., 2013, 33, 10-13.

271. E. Sitta, B. C. Batista and H. Varela, Chem. Commun., 2011, 47, 3775-3777.

272. R. D. Milton, D. P. Hickey, S. Abdellaoui, K. Lim, F. Wu, B. Tan and S. D. Minteer, Chem. Sci., 2015, 6, 4867-4875.

273. R. D. Milton, K. Lim, D. P. Hickey and S. D. Minteer, Bioelectrochemistry, 2015, 106, Part A, 56-63.

274. R. D. Milton, F. Wu, K. Lim, S. Abdellaoui, D. P. Hickey and S. D. Minteer, ACS Catal., 2015, 5, 7218-7225.

275. M. N. Zafar, F. Tasca, S. Boland, M. Kujawa, I. Patel, C. K. Peterbauer, D. Leech and L. Gorton, Bioelectrochemistry, 2010, 80, 38-42.

276. P. Ó Conghaile, M. Falk, D. MacAodha, M. E. Yakovleva, C. Gonaus, C. K. Peterbauer, L. Gorton, S. Shleev and D. Leech, Anal. Chem., 2016, 88, 2156-2163.

277. M. E. Yakovleva, C. Gonaus, K. Schropp, P. Oconghaile, D. Leech, C. K. Peterbauer and L. Gorton, Phys. Chem. Chem. Phys., 2015, 17, 9074-9081.

278. F. C. Macazo, D. P. Hickey, S. Abdellaoui, M. S. Sigman and S. D. Minteer, Chem. Commun., 2017, 53, 10310-10313.

279. S. Tsujimura, K. Murata and W. Akatsuka, J. Am. Chem. Soc., 2014, 136, 14432-14437.

280. I. Willner, V. Heleg-Shabtai, R. Blonder, E. Katz, G. Tao, A. F. Bückmann and A. Heller, J. Am. Chem. Soc., 1996, 118, 10321 10322.

281. H. Sakai, T. Nakagawa, Y. Tokita, T. Hatazawa, T. Ikeda, S. Tsujimura and K. Kano, Energy Environ. Sci., 2009, 2, 133-138. 
282. F. C. Macazo and S. D. Minteer, Curr. Opin. Electrochim, 2017, 5, 114-120.

283. D. P. Hickey, R. D. Milton, M. Rasmussen, S. Abdellaoui, K. Nguyen and S. D. Minteer, in Electrochemistry: Volume 13, The Royal Society of Chemistry, 2016, vol. 13, pp. 97-132.

284. M. Rasmussen, S. Abdellaoui and S. D. Minteer, Biosens. Bioelectron., 2015, 76, 91-102.

285. A. de Poulpiquet, A. Ciaccafava and E. Lojou, Electrochim. Acta, 2014, 126, 104-114.

286. S. Cosnier, A. J. Gross, A. Le Goff and M. Holzinger, J. Power Sources, 2016, 325, 252-263.

287. D. P. Hickey, F. Giroud, D. W. Schmidtke, D. T. Glatzhofer and S. D. Minteer, ACS Catal., 2013, 3, 2729-2737.

288. D. P. Hickey, M. S. McCammant, F. Giroud, M. S. Sigman and S. D. Minteer, J. Am. Chem. Soc., 2014, 136, 15917-15920.

289. Y. Holade, M. Yuan, R. D. Milton, D. P. Hickey, A. Sugawara, C. K. Peterbauer, D. Haltrich and S. D. Minteer, J. Electrochem. Soc., 2017, 164, H3073-H3082.

290. M. T. Meredith, D.-Y. Kao, D. Hickey, D. W. Schmidtke and D. T. Glatzhofer, J. Electrochem. Soc., 2011, 158, B166-B174.

291. C. Gutiérrez-Sánchez, M. Pita, C. Vaz-Domínguez, S. Shleev and A. L. De Lacey, J. Am. Chem. Soc., 2012, 134, 17212-17220.

292. X. Wang, X. Liu, X. Yan, P. Zhao, Y. Ding and P. Xu, PLoS ONE, 2011, 6, e24207.

293. B. Beden, F. Largeaud, K. B. Kokoh and C. Lamy, Electrochim. Acta, 1996, 41, 701-709.

294. F. Largeaud, K. B. Kokoh, B. Beden and C. Lamy, J. Electroanal. Chem., 1995, 397, 261-269.

295. H. Druliolle, K. B. Kokoh and B. Beden, Electrochim. Acta, 1994, 39, 2577-2584.

296. K. Bamba, K. B. Kokoh, K. Servat and J. M. Léger, J. Appl. Electrochem., 2006, 36, 233-238.

297. R. D. Armstrong, J. Hirayama, D. W. Knight and G. J. Hutchings, ACS Catal., 2019, 9, 325-335.

298. Z. Zhang, P. Gibson, S. Clark, G. Tian, P. Zanonato and L. Rao, J. Solution Chem., 2007, 36, 1187-1200.

299. J.-C. Portais, P. Tavernier, I. Besson, J. Courtois, B. Courtois and J.-N. Barbotin, FEBS Lett., 1997, 412, 485-489.

300. S. A. Parke, G. G. Birch, D. B. MacDougall and D. A. Stevens, Chem. Senses, 1997, 22, 53-65.

301. M. Besson, G. Flèche, P. Fuertes, P. Gallezot and F. Lahmer, Recl. Trav. Chim. Pays-Bas, 1996, 115, 217-221.

302. A. Both Engel, Y. Holade, S. Tingry, A. Cherifi, D. Cornu, K. Servat, T. W. Napporn and K. B. Kokoh, J. Phys. Chem. C, 2015, 119, 16724-16733.

303. Q. Li, S. Cui and X. Yan, J. Solid State Electrochem., 2012, 16, 1099-1104.

304. H. Jeong and J. Kim, Electrochim. Acta, 2012, 80, 383-389.

305. Y. Holade, A. Lehoux, H. Remita, K. B. Kokoh and T. W. Napporn, in Electrocatalysts for Low Temperature Fuel Cells: Fundamentals and Recent Trends, eds. T. Maiyalagan and V. S. Saji, Wiley-VCH Verlag GmbH \& Co. KGaA, 2017, DOI: https://doi.org/10.1002/9783527803873.ch18, ch. 18, pp. 511531.

306. J. Wang, J. Gong, Y. Xiong, J. Yang, Y. Gao, Y. Liu, X. Lu and Z. Tang, Chem. Commun., 2011, 47, 6894-6896.

307. S. Hebié, K. B. Kokoh, K. Servat and T. Napporn, Gold Bull. 2013, 46, 311-318.

308. W. Niu, S. Zheng, D. Wang, X. Liu, H. Li, S. Han, J. Chen, Z. Tang and G. Xu, J. Am. Chem. Soc., 2009, 131, 697-703.

309. S. Hebié, T. W. Napporn, C. Morais and K. B. Kokoh, ChemPhysChem, 2016, 17, 1454-1462.
310. L. Wei, T. Sheng, J.-Y. Ye, B.-A. Lu, N. Tian, Z.-Y. Zhou, X.-S. Zhao and S.-G. Sun, Langmuir, 2017, 33, 6991-6998.

311. N. Arjona, G. Trejo, J. Ledesma-Garcia, L. G. Arriaga and M. Guerra-Balcazar, RSC Adv., 2016, 6, 15630-15638.

312. N.-F. Yu, N. Tian, Z.-Y. Zhou, T. Sheng, W.-F. Lin, J.-Y. Ye, S. Liu, H.-B. Ma and S.-G. Sun, ACS Catal., 2019, 9, 3144-3152.

313. N. Tian, Z.-Y. Zhou, N.-F. Yu, L.-Y. Wang and S.-G. Sun, J. Am. Chem. Soc., 2010, 132, 7580-7581.

314. L. Wei, Y.-J. Mao, Y.-S. Wei, J.-W. Li, X.-M. Nie, X.-S. Zhao, Y.J. Fan and S.-G. Sun, Cryst. Growth Des., 2019, 19, 1532-1539.

315. Y. Li, Y. Jiang, M. Chen, H. Liao, R. Huang, Z. Zhou, N. Tian, S. Chen and S. Sun, Chem. Commun., 2012, 48, 9531-9533.

316. T.-M. Cheng, T.-K. Huang, H.-K. Lin, S.-P. Tung, Y.-L. Chen, C.Y. Lee and H.-T. Chiu, ACS Appl. Mater. Interfaces., 2010, 2, 27732780.

317. S.-P. Tung, T.-K. Huang, C.-Y. Lee and H.-T. Chiu, RSC Adv., 2012, 2, 1068-1073.

318. J. Turkevich, P. C. Stevenson and J. Hillier, Discuss. Faraday Soc., 1951, 11, 55-75.

319. J. Turkevich and G. Kim, Science, 1970, 169, 873-879.

320. Y. Holade, K. Servat, T. W. Napporn and K. B. Kokoh, ECS Trans., 2017, 77, 1547-1557.

321. Y. Holade, T. W. Napporn and B. K. Kokoh, in Advanced Electrode Materials, eds. A. Tiwari, F. Kuralay and L. Uzun, John Wiley \& Sons, Inc., 2016, DOI: https://doi.org/10.1002/9781119242659.ch4, ch. 4, pp. 103-146.

322. H. Remita and S. Remita, in Recent Trends in Radiation Chemistry, eds. J. F. Wishart and B. S. M. Rao, World Scientific Publishing Co Pte Ltd, 2010, DOI: doi:10.1142/9789814282093_0013, pp. 347-383.

323. P. S. Fernández, C. A. Martins, M. E. Martins and G. A. Camara, Electrochim. Acta, 2013, 112, 686-691.

324. T. Iwasita and F. C. Nart, Prog. Surf. Sci., 1997, 55, 271-340.

325. A. Bewick and K. Kunimatsu, Surf. Sci., 1980, 101, 131-138.

326. A. Bewick, K. Kunimatsu and B. Stanley Pons, Electrochim. Acta, 1980, 25, 465-468.

327. G. A. Camara and T. Iwasita, J. Electroanal. Chem., 2005, 578 315-321.

328. L. M. Palma, T. S. Almeida, V. L. Oliveira, G. Tremiliosi-Filho, E. R. Gonzalez, A. R. de Andrade, K. Servat, C. Morais, T. W. Napporn and K. B. Kokoh, RSC Adv., 2014, 4, 64476-64483.

329. P. M. Collins, Dictionary of Carbohydrates, Chapman \& Hall/CRC, 2 edn., 2006.

330. P. Parpot, K. Servat, A. P. Bettencourt, H. Huser and K. B. Kokoh, Cellulose, 2010, 17, 815-824.

331. J. E. Nutting, M. Rafiee and S. S. Stahl, Chem. Rev., 2018, 118 , 4834-4885.

332. T. Breton, G. Bashiardes, J.-M. Léger and K. B. Kokoh, European Journal of Organic Chemistry, 2007, 2007, 1567-1570.

333. M. Rafiee, M. Alherech, S. D. Karlen and S. S. Stahl, J. Am. Chem. Soc., 2019, DOI: 10.1021/jacs.9b07243.

334. L. E. Wise, Trans. Electrochem. Soc., 1938, 73, 79-94.

335. J. O. M. Bockris, B. J. Piersma and E. Gileadi, Electrochim. Acta, 1964, 9, 1329-1332.

336. K. Kamida, K. Okajima, T. Matsui and K. Kowsaka, Polym. J., 1984, 16, 857.

337. J. Zhou, L. Zhang and J. Cai, J. Polym. Sci. B Polym. Phys., 2004, 42, 347-353.

338. Z. Ren, T. E. Ward and J. M. Regan, Environ. Sci. Technol., 2007, 41, 4781-4786.

339. M. Mascal and E. B. Nikitin, Angew. Chem. Int. Ed., 2008, 47, 7924-7926. 
340. Y. Sugano, M. d. Vestergaard, H. Yoshikawa, M. Saito and E. Tamiya, Electroanalysis, 2010, 22, 1688-1694.

341. Z.-X. Wang, G. Li, F. Yang, Y.-L. Chen and P. Gao, Carbohydrate Polymers, 2011, 86, 1807-1813.

342. Y. Sugano, R.-M. Latonen, M. Akieh-Pirkanniemi, J. Bobacka and A. Ivaska, ChemSusChem, 2014, 7, 2240-2247.

343. F. Yang, Q. Zhang, H.-X. Fan, Y. Li and G. Li, J. Ind. Eng. Chem. (Amsterdam, Neth.), 2014, 20, 3487-3492.

344. K. Dussan, B. Girisuta, M. Lopes, J. J. Leahy and M. H. B. Hayes, ChemSusChem, 2015, 8, 1411-1428.

345. Y. Sugano, T. Saloranta, J. Bobacka and A. Ivaska, Phys. Chem. Chem. Phys., 2015, 17, 11609-11614.

346. Y. Sugano, N. Kumar, M. Peurla, J. Roine, A. Aho, J. Bobacka and J.-P. Mikkola, ChemCatChem, 2016, 8, 2401-2405.

347. H. Xiao, M. Wu and G. Zhao, Catalysts, 2016, 6, Article number: 5 .

348. S. Li and X. Song, J. Electroanal. Chem., 2018, 810, 55-61.

349. L. Yan and X. Qi, ACS Sustainable Chem. Eng., 2014, 2, 897901.

350. C. Li, Q. Wang and Z. K. Zhao, Green Chem., 2008, 10, 177182.

351. S. Zhu, Y. Wu, Q. Chen, Z. Yu, C. Wang, S. Jin, Y. Ding and G. Wu, Green Chem., 2006, 8, 325-327.

352. L. Zhang, Y. Mao, J. Zhou and J. Cai, Ind. Eng. Chem. Res., 2005, 44, 522-529.

353. J. Zhou and L. Zhang, Polym. J., 2000, 32, 866-870.

354. F. Rezaei, T. L. Richard and B. E. Logan, Biotechnol. Bioeng., 2008, 101, 1163-1169.

355. X. Zhao, W. Liu, Y. Deng and J. Y. Zhu, Renew. Sustain. Energy Rev., 2017, 71, 268-282.

356. F. Rezaei, T. L. Richard, R. A. Brennan and B. E. Logan, Environ. Sci. Technol., 2007, 41, 4053-4058.

357. M. Hao, X. Liu, M. Feng, P. Zhang and G. Wang, J. Power Sources, 2014, 251, 222-228.

358. Z. Zhang, C. Liu, W. Liu, Y. Cui, X. Du, D. Xu, H. Guo and Y. Deng, Appl.Energy, 2017, 200, 226-236.

359. Z. Zhang, C. Liu, W. Liu, X. Du, Y. Cui, J. Gong, H. Guo and Y. Deng, Energy, 2017, 141, 1019-1026.

360. T. Hibino, K. Kobayashi, M. Ito, M. Nagao, M. Fukui and S. Teranishi, Appl. Catal. B: Env., 2018, 231, 191-199.

361. T. Hibino, K. Kobayashi, P. Lv, M. Nagao and S. Teranishi, Bull. Chem. Soc. Jpn., 2017, 90, 1017-1026.

362. T. Ishimoto, H. Kazuno, T. Kishida and M. Koyama, Solid State Ionics, 2014, 262, 328-331.

363. S. B. Aoun, Z. Dursun, T. Koga, G. S. Bang, T. Sotomura and I. Taniguchi, J. Electroanal. Chem., 2004, 567, 175-183.

364. T. Ishimoto, Y. Hamatake, H. Kazuno, T. Kishida and M. Koyama, Appl. Surf. Sci., 2015, 324, 76-81.

365. Y. Degani and A. Heller, J. Phys. Chem., 1987, 91, 1285-1289.

366. W. Liu, W. Mu and Y. Deng, Angew. Chem. Int. Ed., 2014, 126, 13776-13780.

367. S. Trasatti, Surf. Sci., 1995, 335, 1-9.

368. K. L. Ley, R. Liu, C. Pu, Q. Fan, N. Leyarovska, C. Segre and E. S. Smotkin, J. Electrochem. Soc., 1997, 144, 1543-1548.

369. D.-S. Yang, M.-S. Kim, M. Y. Song and J.-S. Yu, Int. J. Hydrogen Energy, 2012, 37, 13681-13688.

370. J. Chen, H. Zheng, J. Kang, F. Yang, Y. Cao and M. Xiang, RSC Adv., 2017, 7, 3035-3042.

371. Y.-L. Yang, X.-H. Liu, M.-Q. Hao and P.-P. Zhang, Int. J. Hydrogen Energy, 2015, 40, 10979-10984.

372. D. Basu and S. Basu, Int. J. Hydrogen Energy, 2012, 37, 46784684.
373. K. P. Gregoire and J. G. Becker, Bioresour. Technol., 2012, 119, 208-215.

374. L. H. E. Yei, B. Beden and C. Lamy, J. Electroanal. Chem. Interf. Electrochem., 1988, 246, 349-362.

375. E. Suraniti, P. Merzeau, J. Roche, S. Gounel, A. G. Mark, P. Fischer, N. Mano and A. Kuhn, Nat. Commun., 2018, 9, Article number: 3229.

376. S. B. Lalvani and P. Rajagopal, J. Electrochem. Soc., 1992, 139, L1-L2.

377. S. B. Lalvani and P. Rajagopal, Holzforschung, 1993, 47, 283286.

378. H. R. Ghatak, S. Kumar and P. P. Kundu, Int. J. Hydrogen Energy, 2008, 33, 2904-2911.

379. O. Movil, M. Garlock and J. A. Staser, Int. J. Hydrogen Energy, 2015, 40, 4519-4530.

380. H. Roy Ghatak, Int. J. Hydrogen Energy, 2006, 31, 934-938.

381. T. Hibino, K. Kobayashi, M. Nagao and S. Teranishi, ChemElectroChem, 2017, 4, 3032-3036.

382. T. Hibino, K. Kobayashi, M. Ito, Q. Ma, M. Nagao, M. Fukui and S. Teranishi, ACS Sustainable Chem. Eng., 2018, 6, 9360-9368.

383. N. Fujiwara, S.-i. Yamazaki, Z. Siroma, T. Ioroi, H. Senoh and K. Yasuda, Electrochem. Commun., 2009, 11, 390-392.

384. S. Kabir, A. Serov and P. Atanassov, J. Power Sources, 2017, 375, 255-264.

385. A. Tatin, C. Comminges, B. Kokoh, C. Costentin, M. Robert and J.-M. Savéant, Proc. Natl. Acad. Sci., 2016, 113, 5526-5529.

386. A. Bardow and M. Wessling, Nat. Energy, 2019, 4, 440-441.

387. S. Verma, S. Lu and P. J. A. Kenis, Nat. Energy, 2019, 4, 466474.

388. R. D. Milton, S. Abdellaoui, N. Khadka, D. R. Dean, D. Leech, L. C. Seefeldt and S. D. Minteer, Energy Environ. Sci., 2016, 9, 2550-2554.

389. D. Higgins, C. Hahn, C. Xiang, T. F. Jaramillo and A. Z. Weber, ACS Energy Lett., 2018, 4, 317-324. 